\title{
Periconceptional treatment with growth hormone alters fetal growth and development in sheep
}

\author{
Jill Marie Koch \\ West Virginia University
}

Follow this and additional works at: https://researchrepository.wvu.edu/etd

\section{Recommended Citation}

Koch, Jill Marie, "Periconceptional treatment with growth hormone alters fetal growth and development in sheep" (2008). Graduate Theses, Dissertations, and Problem Reports. 2707.

https://researchrepository.wvu.edu/etd/2707

This Dissertation is protected by copyright and/or related rights. It has been brought to you by the The Research Repository @ WVU with permission from the rights-holder(s). You are free to use this Dissertation in any way that is permitted by the copyright and related rights legislation that applies to your use. For other uses you must obtain permission from the rights-holder(s) directly, unless additional rights are indicated by a Creative Commons license in the record and/ or on the work itself. This Dissertation has been accepted for inclusion in WVU Graduate Theses, Dissertations, and Problem Reports collection by an authorized administrator of The Research Repository @ WVU.

For more information, please contact researchrepository@mail.wvu.edu. 
Periconceptional Treatment with Growth Hormone Alters Fetal Growth and Development in Sheep

By

Jill Marie Koch

Dissertation submitted to the Davis College of Agriculture Forestry and Consumer Sciences at West Virginia University in partial fulfillment of the requirements for the degree of

\author{
Doctor of Philosophy \\ in \\ Reproductive Physiology
}

\author{
Approved by \\ Matthew E. Wilson, Committee Chairperson \\ Kenneth P. Blemings \\ Paul E. Lewis \\ Janet Tou \\ Michael W. Vernon
}

Division of Animal and Nutritional Sciences

Morgantown, WV

2008

Key Words: Growth Hormone, Fetal Growth and Development 


\begin{abstract}
Periconceptional Treatment with Growth Hormone Alters Fetal Growth and Development in Sheep
\end{abstract}

Jill Marie Koch

\begin{abstract}
Altering the fetal environment can modify the composition or growth rate of the fetus, a concept known as fetal programming. A majority of the research in this area has focused on intrauterine growth restriction (IUGR), which has been linked to adult diseases. A few studies have attempted to ameliorate the negative effects of IUGR, by applying growth promoters late in gestation, and have only observed transient effects. Our laboratory has previously shown that growth hormone $(\mathrm{GH})$ treatment around the time of breeding alters the uterine environment early in gestation and results in larger lambs at birth. Therefore there were three main objectives investigated in the current work, each encompassing a different period of gestation. The first objective was to examine how a periconceptional injection of $\mathrm{GH}$ alters the uterine environment at the time of early embryonic development and if the trophectoderm to inner cell mass ratio is altered by treatment. The second objective was to determine how $\mathrm{GH}$ treatment may program nutrient transport in the placenta late in gestation. The third objective was to examine how a periconceptional injection of $\mathrm{GH}$ alters fetal growth and development at birth and how the $\mathrm{GH}$ axis may be altered in lambs born to ewes treated with $\mathrm{GH}$. Periconceptional $\mathrm{GH}$ treatment altered the concentration of growth factors in uterine luminal fluid including TGF-ß1, insulin like growth factor-I and urea, but did not alter the ratio of trophectoderm to inner cell mass cells or the total number of blastomeres. Treatment with $\mathrm{GH}$ appeared to alter the placental expression of some nutrient transporters during gestation. Periconceptional treatment with growth hormone appears to alter the uterine environment during embryonic development, programming the cells of the embryo to exhibit an altered physiology. Periconceptional GH treatment increased lamb weight and abdominal girth. Lambs born to ewes treated with $\mathrm{GH}$ also had an altered $\mathrm{GH}$ axis as determined by a reduced hepatic expression of both insulin like growth factor-I and growth hormone receptor at birth and an altered response to $\mathrm{GH}$ releasing hormone challenge at 100 days of age.

Periconceptional GH appears to program embryonic cells which develop into a more efficient placenta allowing for an increase in nutrient availability, ultimately leading to larger lambs at birth with an altered composition and an altered growth hormone axis.
\end{abstract}




\section{Acknowledgments}

"No matter how much I've accomplished, or how much outside praise has come my way, or where I go from here, there's one clear fact that will never, ever be lost to me. I didn't do this alone." The basis of this quote comes from Power $\mathrm{Bar}^{\mathrm{TM}}$ and I hope that it makes everyone realize that they each contributed to my educational success in their own way and to each I am indebted.

I would like to thank Dr. Matt Wilson for never giving up on the girl who took out the microphone and almost the podium in one of her first scientific presentations. The number of things passed along to me from Dr. Wilson are inconceivable but most of all I would like to thank him for passing on his enthusiasm for science and education. I look forward to all the times in the future when our paths will cross and we can enjoy a nice cold class of milk and some cookies.

I would like to thank all of my family from the bottom of my heart. I consider myself lucky because I have a family that provided a support system that allowed me to continue my education. Without the endless care packages, cards and just moments of relaxation and good conversation, I probably would have experienced multiple mental meltdowns. I would like to especially thank my mom for showing tough love when I really need it and constantly reminding me that "I am made of the tough stuff."

The number of "thanks" that I owe my officemates, graduate colleagues and friends, Caleb Lemley and Tiffany Wilmoth, can't be counted. I would particularly like to thank them for how much they loved waking up early for surgery, working sheep and just sharing laughs. 


\section{Table of Contents}

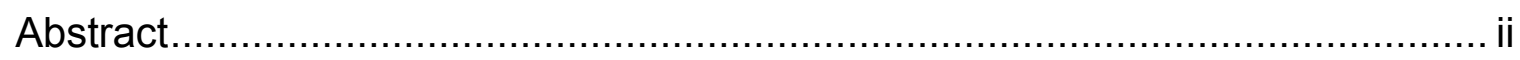

Acknowledgments .................................................................................. ii

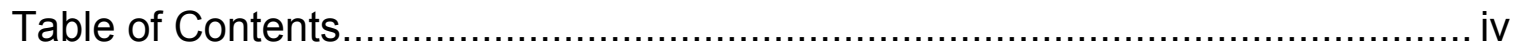

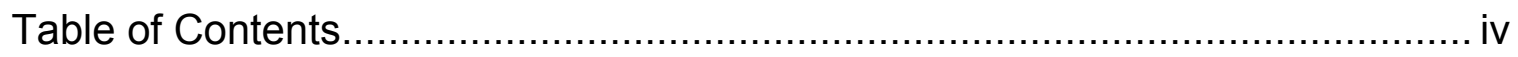

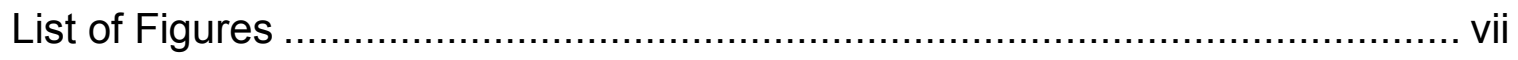

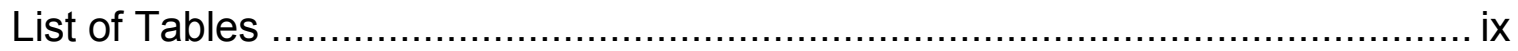

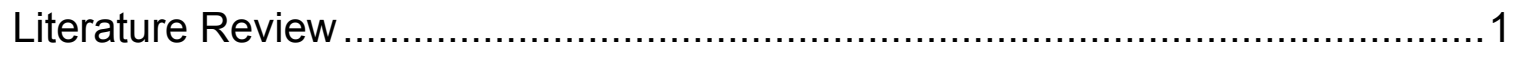

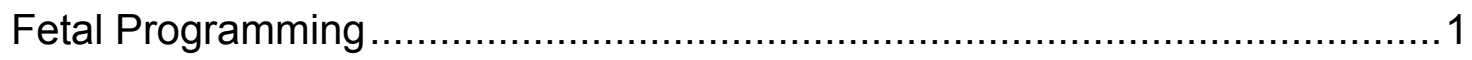

Embryonic and Early Fetal Development ...............................................

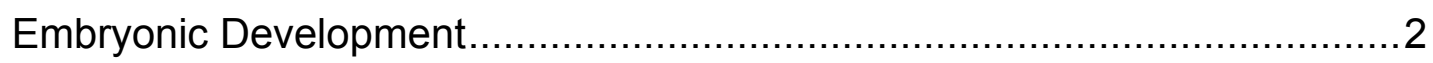

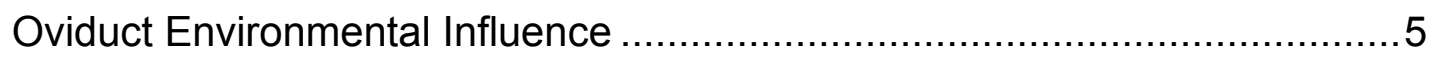

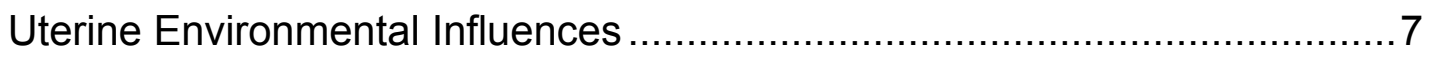

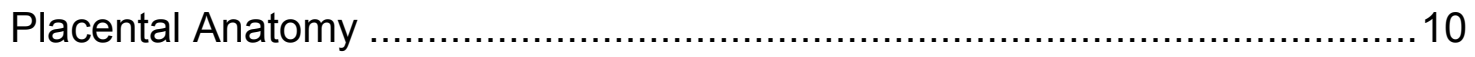

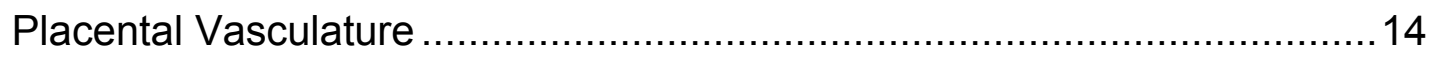

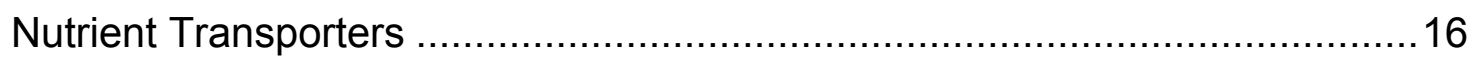

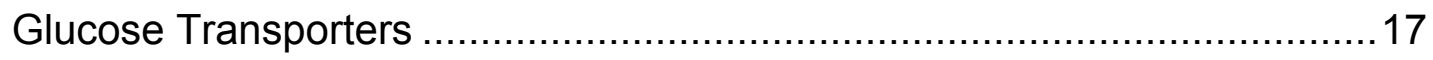

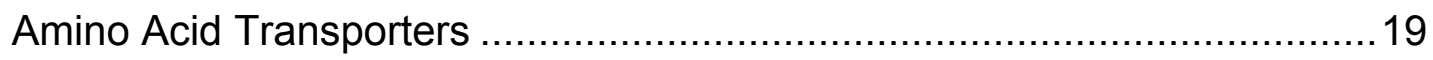

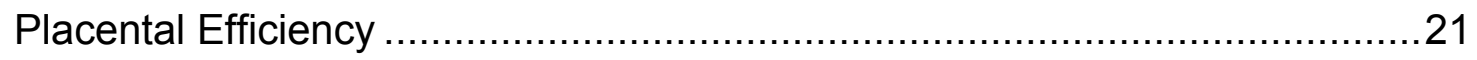

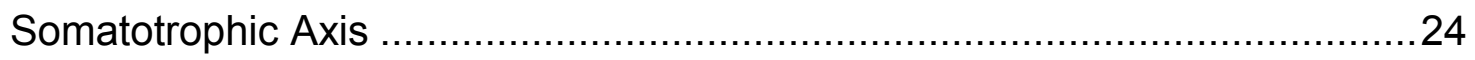

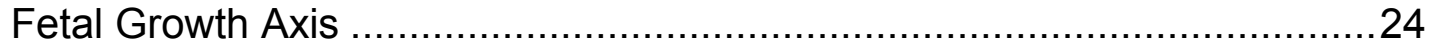

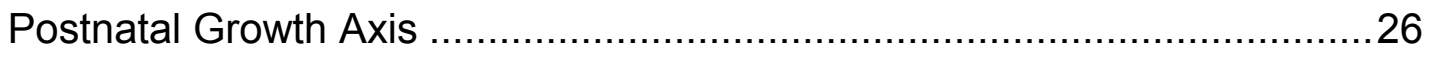

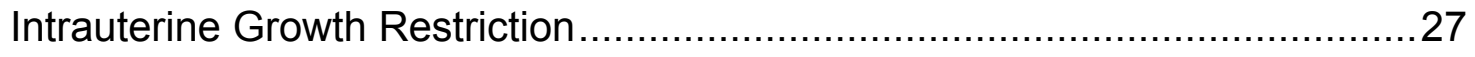

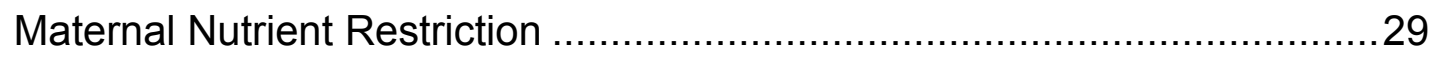

Overnourished Adolescent Ewe Model...................................................31 


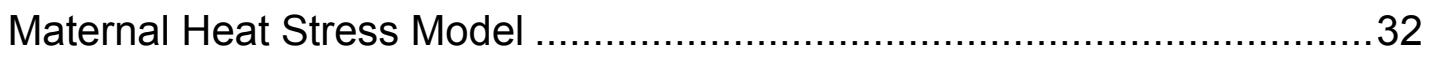

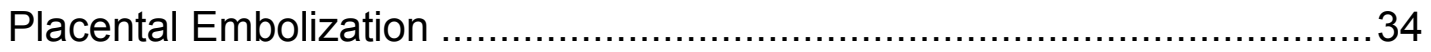

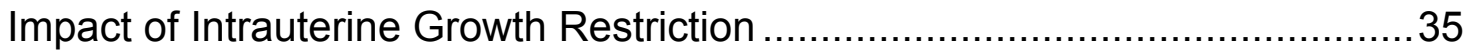

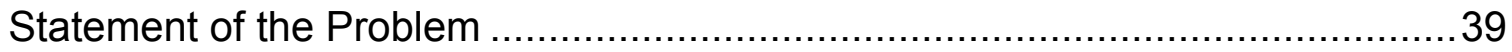

Peri-Conceptional Growth Hormone Treatment Alters Early Uterine Environment

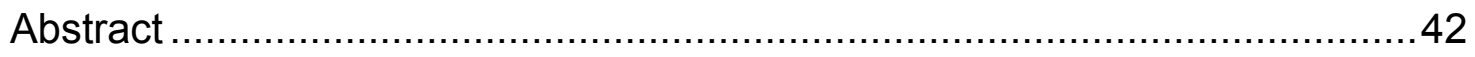

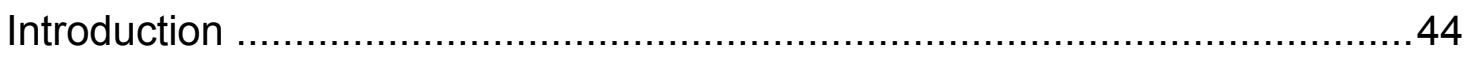

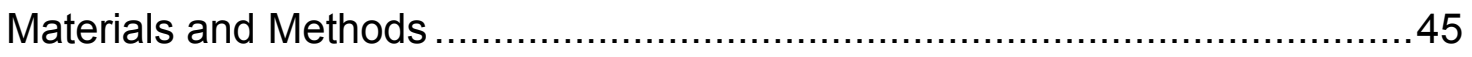

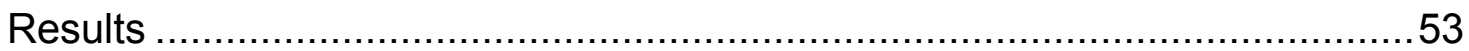

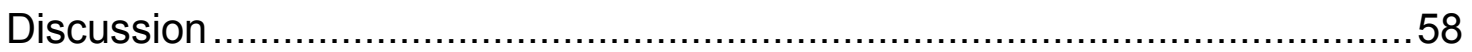

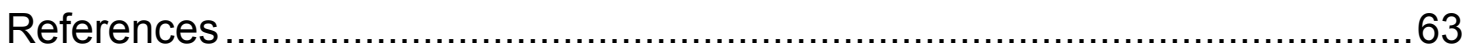

Periconceptional Growth Hormone Treatment Alters the Expression of Nutrient

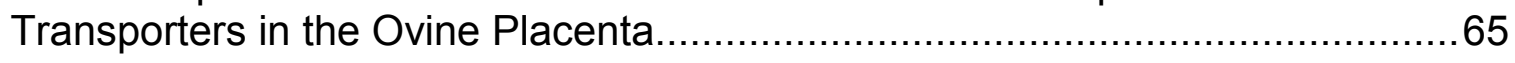

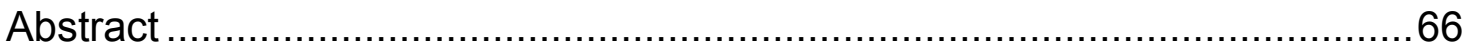

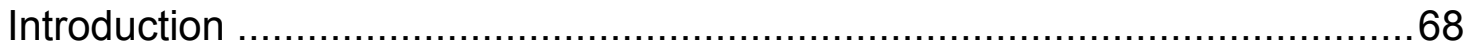

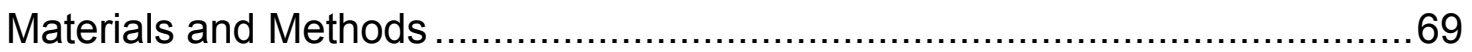

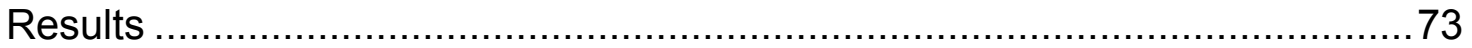

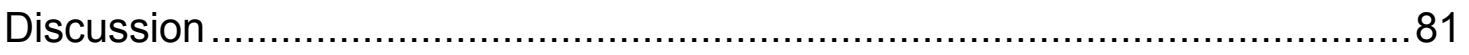

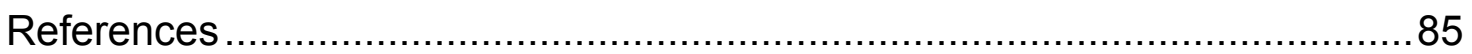

Peri-Conceptional Growth Hormone Treatment Alters Fetal Growth and

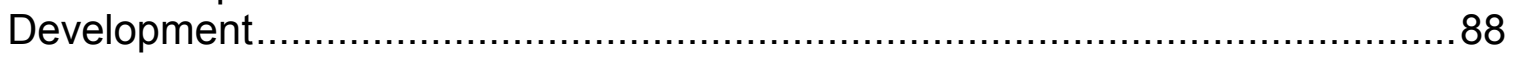

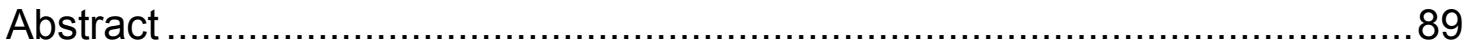

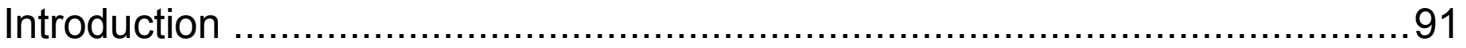

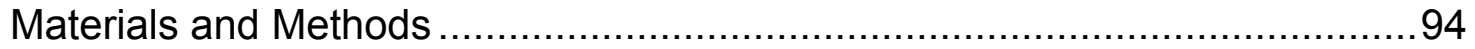

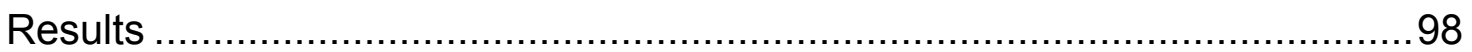




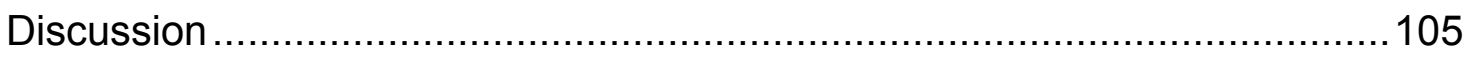

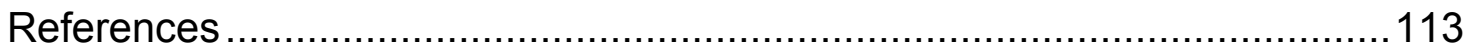

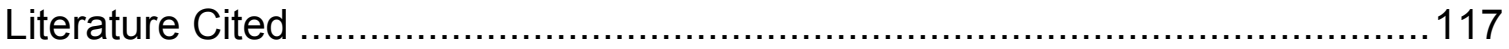




\section{List of Figures}

FIGURE 1. Schematic demonstrating early embryonic cell division and growth from fertilization up to day 16 of pregnancy as well as the progesterone and estrogen profile during this period.

FIGURE 2. Schematic of the sheep placentome including caruncular and cotyledonary tissue layers.

FIGURE 3. Differential staining of a blastocyst collected on day 6.5 by immunosurgical lysis. The inner cell mass cells are stained blue while the trophectoderm is stained pink

FIGURE 4. Maternal progesterone concentration on day 6.5 of gestation in control ewes and those treated with a periconceptional GH injection.

FIGURE 5. Maternal insulin concentration on day 6.5 of gestation in control ewes and those treated with a periconceptional $\mathrm{GH}$ injection.

FIGURE 6. Uterine luminal urea content on day 6.5 of gestation in control ewes and those treated with a periconceptional $\mathrm{GH}$ injection.

FIGURE 7. Uterine luminal TGFß-1 content on day 6.5 of gestation in control ewes and those treated with a periconceptional $\mathrm{GH}$ injection.

FIGURE 8. The expression of GLUT-3 in cotyledonary tissue collected on day 80 and 140 of gestation

Figure 9. Expression of EAAT-1 in cotyledonary tissue collected on day 80 and 140 of gestation from conceptuses gestated by control ewes or ewes treated with sustained release growth hormone at breeding

Figure 10. Expression of EAAT-3 in cotyledonary tissue collected on day 80 and 140 of gestation from conceptuses gestated by control ewes or ewes treated with sustained release growth hormone at breeding

Figure 11. The expression of CAT-1 in cotyledonary tissue collected on day 80 and 140 of gestation

Figure 12. The expression of SNAT-2 in cotyledonary tissue collected on day 80 and 140 of gestation

Figure 13. The expression of LAT-2 in cotyledonary tissue collected on day 80 and 140 of gestation

FIGURE 14. Birth data of lambs born to control ewes and ewes treated with sustained release growth hormone at breeding a) birth weight b) abdominal girth c) crown-rump length 
FIGURE 15. Ventricular wall thicknesses of fetal hearts in ram lambs born to control ewes and ewes treated with sustained release growth hormone at breeding.

FIGURE 16. Neonatal hepatic mRNA expression of IGF-I and growth hormone receptor from ram lambs born to control ewes and ewes treated with sustained release growth hormone at breeding. 102

FIGURE 17. Weight of ewe lambs at postnatal day 100 that were either born to control ewes or ewes treated with growth hormone.

FIGURE 18. Pattern of secretion of IGF-I following growth hormone releasing hormone challenge on postnatal day 100 by ewe lambs born to control ewes and ewes treated with sustained release growth hormone at breeding. 104 


\section{List of Tables}

TABLE 1. Maternal (caruncular) and fetal (cotyledonary) angiogenic changes that occur between day 50 and 140 of gestation. All measures increase except for area per capillary in cotyledonary tissue.

TABLE 2. Amino acid transporter systems, gene name, amino acids transported, the location of transported in fetal trophoblast cells in the human and the type of

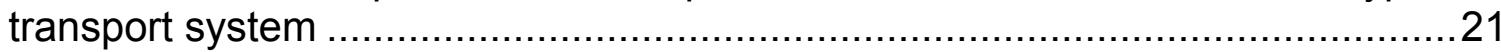

TABLE 3. Impact of nutrient restriction models on fetal components and organ weights

TABLE 4. Nutrient transporter primer sequences and the efficiency for each primer set. 


\section{Literature Review}

\section{Fetal Programming}

Fetal programming is described as any environmental insult or stimulus that occurs during the development of key organs or tissues and results in long lasting or permanent physiological alterations of the offspring (Godfrey and Barker, 2000; Armitage et al., 2004). The amount of data collected on fetal programming is vast and includes both retrospective studies in humans and prospective studies in animals. The concept of fetal programming stems from the "Barker Hypothesis" which developed from the medical records of adults who were gestated during the Dutch famine. During this period, daily caloric intake dropped as low as 580 calories (Ravelli et al., 1976). The epidemiological data collected from these humans gestated during the Dutch famine linked low birth weight with several adult onset diseases. More specifically, low caloric intake during early gestation was linked to hypertension, but limited caloric intake during late gestation has been linked to adult obesity and glucose intolerance (i.e., metabolic disorders; Barker, 1995; Ravelli et al., 1999; Ameritage et al., 2004).

Exposure to an insult or a stimulus that result in long lasting and permanent physiological alterations is a phenomenon known as programming (Godfrey \& Barker, 2000). The impact of the uterine environment on fetal growth and development is more specifically known as fetal programming. The "fetal origins" hypothesis suggests fetal programming results in permanent alterations in the structure, physiology and metabolism of the offspring, which predisposes 
them to adult onset diseases (Barker 1995; Godfrey \& Barker 2000). In fact, the use of animal models has allowed researchers to link a deleterious uterine environment during specific stages of fetal development to altered development and function (i.e., program) of the cardiovascular, respiratory, endocrine, reproductive, skeletal, immune and central nervous systems as well as the function of the kidneys and liver (Godfrey and Barker, 2000; Wu et al., 2004).

The influence of the uterine environment from ovulation through birth permanently impacts the development of the offspring, ultimately influencing the health of the adult. It has been suggested that the offspring's genotype contributes only $15 \%$ to the variation in birth weight, while maternal environment (i.e., nutrition available to the fetus) has double the influence at $30 \%$. The remaining $55 \%$ is influenced by other stimuli (i.e., maternal size and uterine environment; Nathanielsz, 2000). Animal models can be utilized to assess the impact of an altered uterine environment both in vivo and ex vivo. The use of animals allows critical assessment of the effect of uterine environment (i.e. secretion, timing and space) on embryonic development, fetal growth and ultimately postnatal life.

\section{Embryonic and Early Fetal Development}

\section{Embryonic Development}

In sheep, the oviduct is the sight of fertilization and as such it is responsible for providing the proper environmental conditions in which early embryonic development occurs. For fertilization to occur, the gametes must first 
be transported to the site of fertilization at the ampullary-isthmic junction. Sperm travel from the site of deposition in the most exterior portion of the cervix to the ampullary-isthmic junction. The cilia in the upper portion of the oviduct always beat toward the site of fertilization (toward the uterus) and move oocyte to the ampullary-isthmic junction. However, the other parts of female reproductive tract are sensitive to the estrogen to progesterone ratio. A high estrogen to progesterone ratio results in contraction of the female reproductive tract toward the site of fertilization while a low ratio stimulates oviductal contractions which move the zygote (i.e., fertilized oocyte) toward the uterus (Crisman et al., 1980).

The fertilized ovum starts as a single cell surrounded by a glycoprotein layer called the zona pelucida (Figure 1). The first divisions of the embryo are synchronous and called cleavage divisions. Cleavage divisions take place until the embryo becomes a morula. In the sheep, the embryo enters the uterus in the morula stage on day four following mating (Figure 1; Spencer and Bazer, 2004; Spencer et al., 2004). The cells of the morula will become one of two embryonic cell types in the blastocyst, either the inner cell mass or the trophectoderm. The trophectoderm is a single layer of cells connected by gap junctions. These cells form a barrier around the inner cell mass and allow for the formation of a fluid filled cavity called the blastocoele. The trophectoderm develops into the chorion portion of the placenta. The inner cell mass is a ball of cells located inside the trophectoderm. The inner cell mass will develop later into the embryo proper and eventually the fetus and portions of the placenta. Transition from a morula to a blastocyst takes place in the uterus and only requires about 48 hours (day six of 
pregnancy). The morula transforms into a compact morula with trophectoderm cells forming on the outside and inner cell mass cells on the inside. As the blastocyst continues to develop a blastocoelic cavity forms. Further development between days six and eight leads to the blastocyst hatching out of the zona pelucida (Spencer et al., 2004). It is not until around day eleven that the embryo starts to elongate going from a round sphere to a more filamentous shape. Growth continues to increase dramatically as the size of the embryo goes from about $30 \mathrm{~mm}$ on day 12 to about $190 \mathrm{~mm}$ by day 16 (Spencer et al., 2004). Around day 12, the embryo starts to produce vast quantities of interferon $\tau$. Interferon $\tau$ is considered to be one of the molecules secreted by the embryo that signals maternal recognition of pregnancy and is thought to be stimulated by proper histotrophic nutrition (Gray et al., 2000; Gray et al., 2002; Spenser and Bazer, 2004). Prior to day 16 , the trophectoderm of the embryo has only been loosely associated with the endometrium; however, around day 16 the embryo starts to adhere to the endometrium (Spencer and Bazer, 2004; Spencer et al., 2004). The lack of any permanent attachments until day 16 limits the nutrients available to the embryo to just those found in the lumen of the oviduct and the uterus (i.e., histotrophic nutrition). 

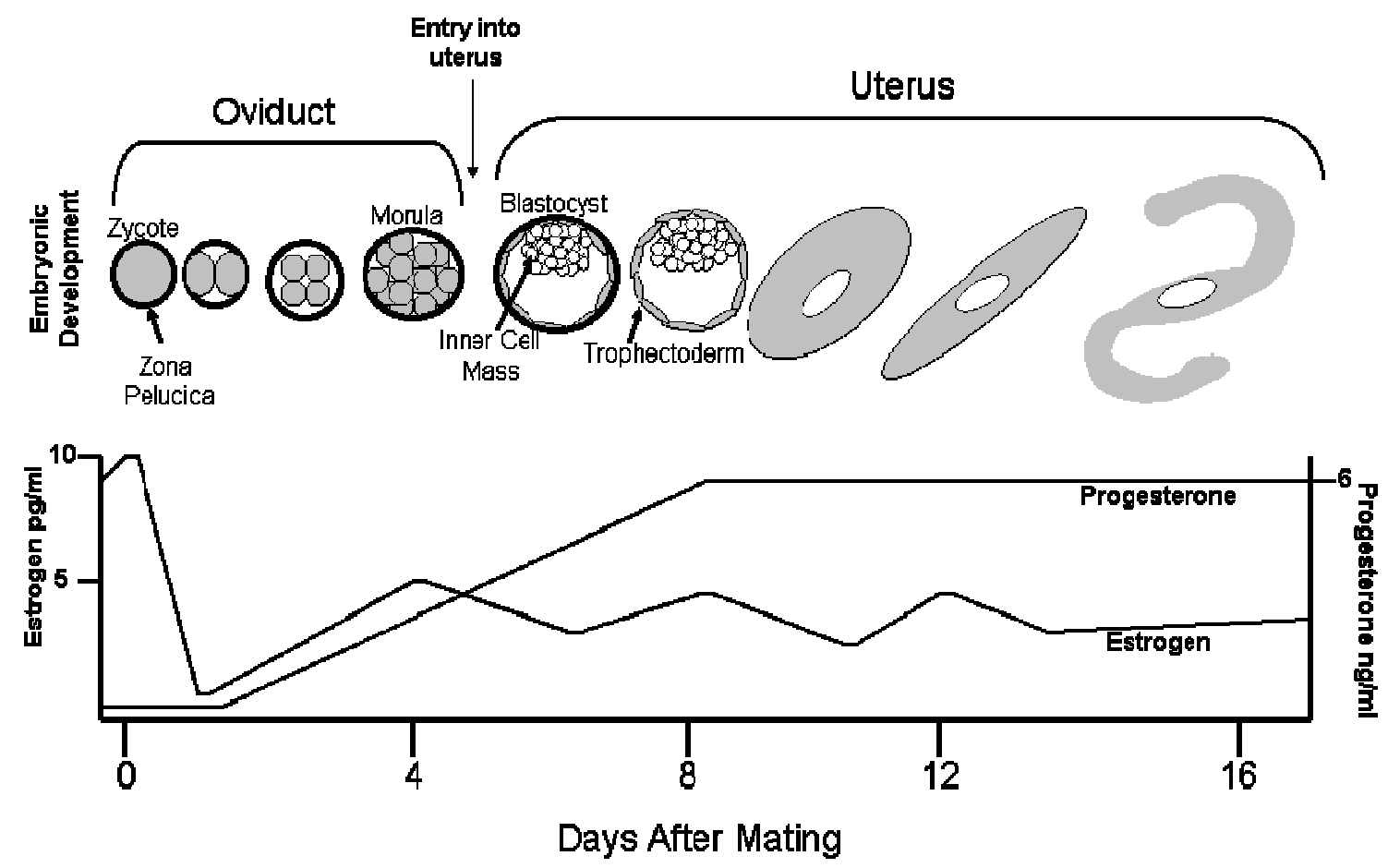

FIGURE 1. Schematic demonstrating early embryonic cell division and growth from fertilization up to day 16 of pregnancy as well as the progesterone and estrogen profile during this period. Redrawn from Spencer et al., 2004. Reproduction. 128:657-668.

\section{Oviduct Environmental Influence}

The oviductal fluid contains vitamins, amino acids, carbohydrates (glucose, pyruvate and lactate) growth factors, enzymes and proteins (Gandolfi et al., 1989; Nancarrow and Hill, 1995; Buhi et al., 2000; Killian, 2004; Aguilar and Reyley, 2005). The components of the oviductal fluid are similar to plasma with the exception of a few proteins secreted only by the oviduct. For example, the concentration of some amino acids (methionine, leucine, phenylalanine, lysine, aspartic acid, glycine, alanine, taurine, tyrosine) are actually only $25 \%$ of that which is observed in plasma, while others (threonine, serine, ornithine) are 
actually higher in oviductal fluid (Aguilar and Reyley, 2005). Compared to other species, only a small list of growth factors have been detected in sheep oviductal fluid and include basic fibroblast growth factor, insulin-like growth factor binding proteins 3 and 4 , insulin like growth factor-I and II, transforming growth factor $\alpha$ and $B$ and prostaglandins $E_{2}$ and $F_{2} \alpha$ (Aguilar and Reyley, 2005).

Oviductal fluid only contains one tenth the protein found in plasma and it comes from two sources. The primary source is plasma which provides proteins like albumin, immunoglobulins and high density lipoproteins which are present in the oviduct at a constant concentration and make up approximately $95 \%$ of the total protein found in oviductal fluid (Gandolfi et al., 1989; Killian, 2004; Aguilar and Reyley, 2005). The secondary source of protein are those produced and secreted by the epithelium that lines the oviduct. In sheep, and most other mammals, a group of oviduct specific glycoproteins or "oviductins" are only synthesized by oviductal epithelium. These glycoproteins contribute to the extracellular matrix of the embryo, the oviduct micro environment and interact with the zona pelucida (Gandolfi et al., 1989; Murray, 1993; Buhi et al., 2000). Estrogen stimulates the oviductal epithelial cells to synthesize and secrete oviductins such that they are high at estrus. Not surprising, these proteins are secreted, coincident with the time in which an embryo would be present, from day two to four and dropping to undetectable levels on day four shortly after the embryo should enter the uterus (Sutton et al., 1986; Murray, 1993).

The importance of oviductal proteins is evident from a study on in vitro embryo development in which approximately $90 \%$ of single cell embryos co- 
cultured with oviduct somatic cells developed to at least the eight cell stage, while only $13 \%$ of those cultured without cells reached the same developmental stage (Gandolfi and Moor, 1987). The type of somatic cell used for co-culture also impacted embryonic development. Embryos co-cultured with either oviductal epithelium or fibroblasts did not appear to have altered growth from day zero (fertilization) to day three, but when transferred back into recipient females only $33 \%$ of those cultured with fibroblasts continued to develop compared to $80 \%$ development in those cultured with oviductal epithelium (Gandolfi and Moor, 1987). Others have demonstrated that including the glycoprotein fraction of oviductal fluid decreases the number of in vitro fertilized embryos that go through the first cleavage division, but including it in culture media increased the number of cloned embryos which developed to the blastocyst stage, which may suggest that it is more influential for older embryos (Nancarrow and Hill, 1995). These experiments are consistent with a role for the oviductal milieu in proper embryonic development and provide a physiological mechanism as to how alterations to the pregnant female very early in pregnancy may permanently alter the embryonic cells.

\section{Uterine Environmental Influences}

The uterine environment can exert its influences through either histotrophic (oviductal and uterine fluid derived nutrients) or hematotrophic (maternal blood derived) nutrition and a gestational stage specific milieu is thought to be essential for normal conceptus growth and survival. Collectively, these two nutrient sources play a major role in embryonic development, 
attachment and placentation (Gray et al., 2001; Spencer and Bazer, 2004).

Histotrophic nutrients are synthesized and secreted by the glandular epithelium of the uterus (i.e., uterine glands). Secretion of historophic nutrients is regulated by maternal and embryonic hormones (progesterone, estrogen and interferon $\tau$ ). The second source of nutrients is hematotrophic, which describes the transfer of nutrients from maternal blood into fetal blood and is altered mainly by changes in uterine and umbilical blood flow (i.e., as uterine blood flow increases the amount of hematotrophic nutrition increases; Gray et al., 2001; Spencer and Bazer, 2004). Histotrophic nutrients bathe the embryo in the uterus and consist of enzymes, growth factors, ions, cytokines, hormones, adhesion molecules and transport proteins (Spencer and Bazer, 2004; Igwebuike, 2006). Different experimental models have been utilized to examine the effects of altered uterine environment on embryonic growth and development and include embryo transfer, advancing the uterine environment and blocking the histogenesis of uterine glands.

It has been understood for a least 50 years that transferring embryos in any species requires a relatively high degree of synchrony between the donor and recipient. In the ewe, the embryo can tolerate uterine asynchrony up to a two day window. This means that the synchrony of the recipient female and the donor embryos must be within two days, but for optimal embryonic survival the donor and recipient should be at the exact same day following estrus (Moore and Shelton, 1964; Rowson and Moor, 1966; Wimut and Sales, 1981; Ashworth and Bazer, 1989). Extending the window of transfer from 48 to 72 hours in either 
direction of the embryonic stage (an additional 24 hours in either direction) decreases the success of embryo transfer by about $65 \%$ ( $8 \%$ survive when transferred at \pm three days; Rowson and Moor, 1966). Not only does the window of opportunity impact success rate, but the stage of embryonic development at the time of transfer impacts overall success rate. A time-dependent increase was observed in that, as the age of the embryo increased the rate of survival increased independent of recipient synchronization within a 48 hour window (Moore and Shelton, 1964). Similar results were found by Rowson and Moor (1966) in which day five embryos (morulas) transferred to day seven recipients had a lower survival rate than day nine embryos (blastocysts) transferred into a day eleven recipient. Zygotes cultured for six days in control conditions, cocultured with granulosa cells, or cultured in synthetic oviductal fluid with or without serum, before being transferred back to day 6 recipients, demonstrated the effect of early environment on fetal growth and development. Fetuses derived from granulosa cell co-culture were $14 \%$ heavier by day 61 of gestation and $18 \%$ larger compared to controls on day 125 . Those cultured with synthetic oviductal fluid plus serum were $18 \%$ heavier, compared to those cultured without serum, by day 125 . There was also an increase in the calculated growth coefficient for the liver and heart for the co-culture and synthetic oviductal fluid plus serum compared to control cultures (Sinclair et al., 1999). These results demonstrate that uterine environment is critical to survival and altering the uterine milieu can alter the natural growth curve and alter fetal development. 
Progesterone administration is one mechanism used to study the impact of the uterine environment on embryonic development. Progesterone administration during early pregnancy has been found to advance the uterine environment and lead to altered embryonic growth. Fetal growth was increased in ewes exposed to progesterone from days $1-3,3-6$ or 1-6 of gestation. Progesterone treatment starting on day one had the greatest impact on fetal growth in that both fetal mass and crown-rump length were increased (Kleeman et al., 1994). Embryos transferred to a more advanced uterine environment were found to be $42 \%$ heavier at day 21 of gestation (Young et al., 1996). When day three embryos were transferred to a uterine environment advanced by three days (i.e., day 6 environment), for three days, and then transferred back to a day six environment, the fetuses that developed had alterations in muscle development. While there was no difference in fetal weight or crown-rump length, those embryos transferred to an asynchronous environment had a greater number of muscle fibers compared to those maintained in a synchronous environment (Maxfield et al., 1998). This indicates that only a small change in the embryonic environment, for a short amount of time, can result in "fetal programming."

\section{Placental Anatomy}

The placenta's function is to provided a physiological exchange mechanism between the fetus and dam removing waste from the fetus, exchanging gas and providing nutrients for proper fetal growth. The sheep placenta has two general regions 1) placentomal region and 2) interplacentomal 
regions (Igwebuike, 2006). The placentomes are areas in which cotyledonary villi (fetal placenta) penetrate deep into the caruncular tissue (maternal attachment points) creating areas for hematotrophic nutrition, as well as gas and waste exchange (Figure 2; Reynolds et al., 2005a). These villi are lined with microvilli that increase surface area for nutrient absorption. Placental growth is exponential from establishment (approximately day 24) with the number of possible placentomes between 60 and 100 per placenta being determined by day 56 of gestation (Renyonlds et al., 2005; Igwebuike, 2006). The placenta, primarily cotyledonary tissue, will continue to proliferate until about day 80 going from $15 \mathrm{~g}$ at day 40 to $770 \mathrm{~g}$ at day 80 of gestation when the mass of the placenta dramatically declines (441g day 100 ), but angiogenesis increases exponentially (Ehdart and Bell, 1995). Placental weight has been correlated with fetal development late in gestation in that $80 \%$ of the variation in fetal weight can be accounted for by variation in placental weight which may indicate that a poorly developed placenta results in a poorly developed fetus (Bell et al., 1999).

As gestation progresses and fetal nutrient demand increases placentome morphology changes to meet these needs. Placentomes are characterized into four different groups (A, B, C and D type) based on cotyledonary tissue growth. Type A are spherical placentomes in which the fetal cotyledonary tissue is completely surrounded by maternal caruncular tissue and are concave in the middle (cotyledonary tissues is sunken into the middle of caruncular tissue). Type B placentomes can be described as those in which fetal tissue is starting to grow over top of the maternal caruncular tissue. Type $C$ placentomes are flat on 
top (cotyledonary tissue has completely filled the caruncle) and cotyledonary tissue only completely covers one surface of the caruncle which means that the sides of the caruncle are still visible. Type $D$ placentomes are flat and everted. Fetal cotyledonary tissue is completely covering the top and sides of the maternal caruncular tissue (Osgerby, et al., 2004; Vonnahme et al., 2006)

Ruminants, including the sheep and cow, have the least intimate contact between maternal and fetal circulation with six tissues layers between the maternal and fetal circulations and this occurs in the area of the placentome which makes up approximately $95 \%$ of the total interactive surface area (Wooding et al., 2005). These layers consist of three layers on the maternal side including endothelium, stroma and epithelium (syncytium) and three fetal layers including epithelium (trophoblast cells), stroma and fetal endothelium (Figure 2; Bjorkman, 1965). This type of placentation is called epitheliochorial because there are two complete and intact layers of epithelium. It is important to note that sheep can have only five layers, in this instance the maternal epithelium is transiently eroded, which can regrow, but it leaves short periods of time when the maternal epithelium is fused with fetal epithelium. As a result sheep are sometimes known as having a syndesmochorial placenta (Reynolds et al., 2005a). 


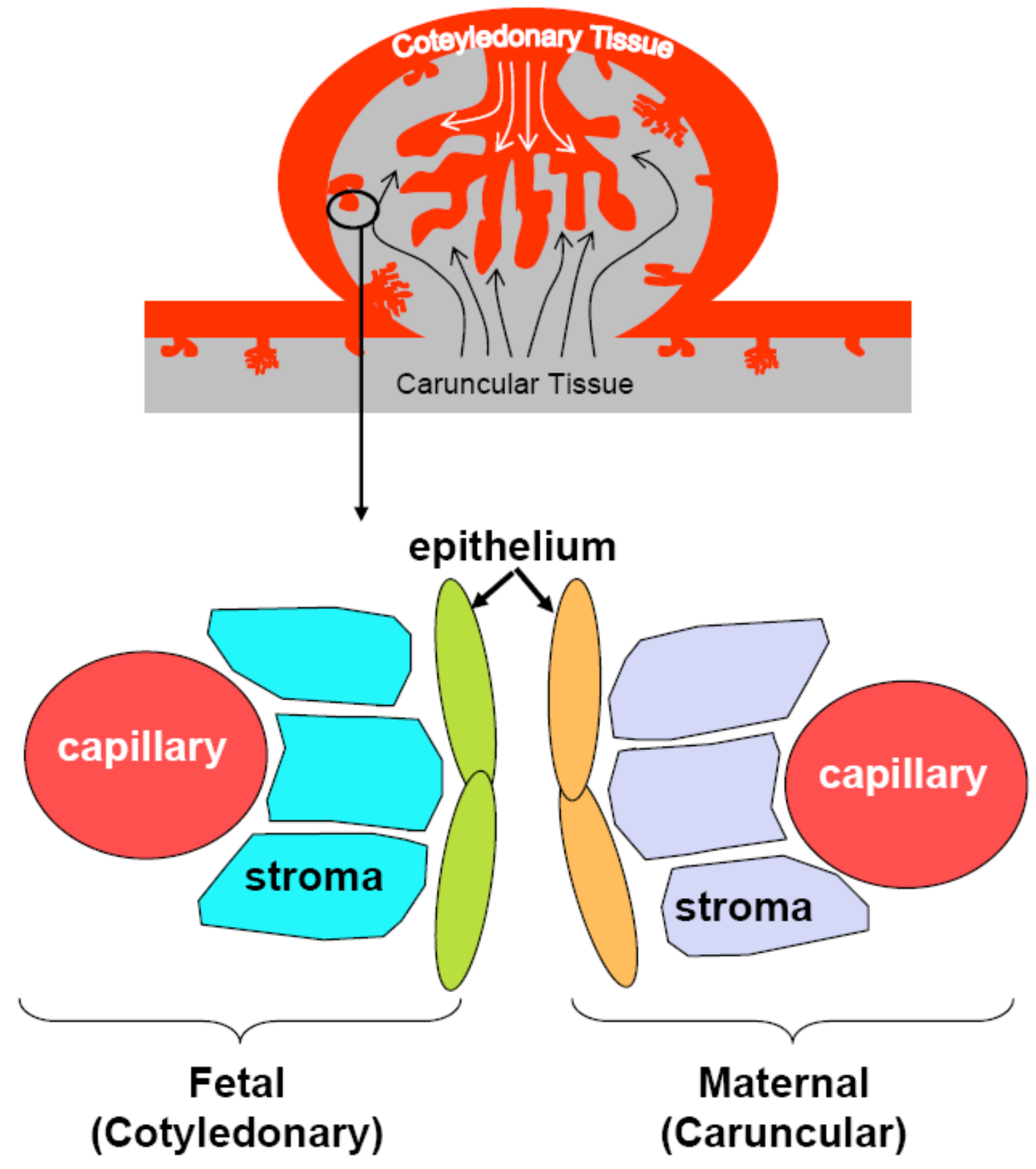

FIGURE 2. Schematic of the sheep placentome including caruncular and cotyledonary tissue layers. The arrows indicate blood flow. (Redrawn from Senger, PL. 1999. 2nd Edition Pathways to Pregnancy and Parturition). The second portion of the schematic includes a close up of the six tissue layers in the epithelialchorial placenta of the sheep. 


\section{Placental Vasculature}

In sheep, placental growth (in terms of weight) slows dramatically around day 80 of gestation yet nutrient delivery and transport must keep up with demands of the developing fetus. Under normal pregnancy conditions, umbilical blood flow, oxygen transport and water transport all increase faster than fetal weight as a way to compensate for growth of the fetus and lack of growth by the placenta (i.e., extraction rate of nutrients increases; Reyonlds and Redmer, 1995). A more influential mechanism to keep up with the exponential growth of the fetus is a three to four fold increase in uterine blood flow between mid to late gestation, which results in an increase in the amount of nutrients available for extraction (Rosenfeld et al., 1974).

Concurrent with the dramatic increase in blood flow is an increase in angiogenesis of the placentome. The number of vascular changes in the maternal caruncular tissue is relatively small compared to vascular growth of fetal cotyledonary tissue, but both have an increase in angiogenesis (Table 1; Reynolds et al., 2005a; Reynolds et al., 2005b). Capillary area density, capillary number density and capillary surface area all increase between day 50 and 140 of gestation in both maternal and fetal tissue (Table 1; Reynolds et al., 2005a; Reynolds et al, 2005b). The major difference between maternal and fetal circulation in the placenta is the type of vessels found. Maternal vessels are larger, with less surface area and are indicative of vessels that have slower velocity to increase time for extraction by the placenta. Fetal cotyledonary vessels on the other hand are smaller, with small branching architecture, which is 
best utilized in systems with high velocity to allow for quick nutrient absorption (Reynolds and Redmer, 1995; Reynolds et al., 2005a). These alterations in blood flow and the capillary networks compensate for the limited growth of the placenta in the second half of gestation by increasing the extraction efficiency of the placenta. Increasing placental efficiency by vascular adaptations is further demonstrated by using carunclectomized sheep. In this model a portion of caruncles are removed from the uterus of the ewe limiting the number of placentomes that can be formed. Late in gestation, uterine and fetal blood flow and placental size are decreased when compared to intact controls, leading to restricted fetal growth. It is speculated that the limited transport of nutrients results from a reduction in the capillary surface area (as a result of reduced placentome number) required for nutrient exchange (Robinson et al., 1995). In some circumstances the limited number of placentomes that do exist undergo extensive proliferation and are able to provide a greater area for nutrient exchange than observed in placentomes of intact controls allowing for normal fetal growth (Robinson et al., 1995). 


\begin{tabular}{|l|l|l|l|l|}
\cline { 2 - 5 } \multicolumn{1}{c|}{} & $\begin{array}{l}\text { Capillary } \\
\text { Area Density }\end{array}$ & $\begin{array}{l}\text { Capillary No. } \\
\text { Density }\end{array}$ & $\begin{array}{l}\text { Capillary } \\
\text { Surface } \\
\text { Density }\end{array}$ & $\begin{array}{l}\text { Area per } \\
\text { Capillary }\end{array}$ \\
\hline $\begin{array}{l}\text { Fetal } \\
\text { (Cotyledonary) }\end{array}$ & $6.2 x$ & $12.3 x$ & $6.0 x$ & $(-) 1.9 x$ \\
\hline $\begin{array}{l}\text { Maternal } \\
\text { (Caruncular) }\end{array}$ & $3.3 x$ & $1.5 x$ & $1.7 x$ & $2.2 x$ \\
\hline
\end{tabular}

TABLE 1. Maternal (caruncular) and fetal (cotyledonary) angiogenic changes that occur between day 50 and 140 of gestation. All measures increase except for area per capillary in cotyledonary tissue (Reynolds et al., 2005a).

\section{Nutrient Transporters}

Nutrients have to be in sufficient supply and delivered to the developing fetus in a timely fashion for proper growth and development. In the last third of gestation, a period in which fetal growth increases exponentially, limiting fetal nutrient availability has been directly linked to intrauterine growth restriction and long term alterations in organ function. The mechanisms by which this occurs includes a decrease in maternally derived nutrients or insufficient transport of nutrients across the placenta (Barker 1995; Ravelli et al. 1999; Godfrey \& Barker 2000; Jensen et al. 2002; Armitage et al. 2004; Wu et al. 2004; Wallace et al. 2005; Wu et al. 2006). Until recently, investigators have suggested that limiting nutrient availability was the cause of fetal growth restriction; however, recently some have argued that if the number of transporters are limited, no matter what the nutrient availability intrauterine growth restriction occurs (Jansson et al., 
2006). There are several mechanisms utilized to transport nutrients across the placenta and include facilitated diffusion, passive transport down a concentration gradient, and endocytosis.

\section{Glucose Transporters}

Glucose is essential to the fetus because it is the primary substrate for fetal energy metabolism and is obtained from maternal circulation via placental transport (Robertson and Karp, 1976; Jansson et al., 1993; Bell et al. 1999). Under normal gestational conditions, in which the dam is well-nourished, glucose accounts for approximately $60 \%$ of the net uptake of carbon to the gravid uterine horn and transport increases five to eight fold in the last third of gestation (Jansson et al. 1993; Carver and Hay 1995; Chung et al. 1998; Bell et al. 1999; Dandrea et al. 2001). Glucose appears to be passively transferred to the fetus by a concentration-dependent mechanism as the transporters identified are all sodium independent (Limesand et al., 2004; Wooding et al., 2005). Because glucose is passively transferred to the fetus, maternal glucose concentration has to remain higher than fetal glucose concentrations (Hay, 1995). This concentration gradient is maintained by two mechanisms. The first is an increasing rate of consumption by the growing fetus and placenta clearing fetal blood of glucose and the second is maternal development of glucose tolerance and insulin resistance raising blood glucose concentrations in maternal blood.

Glucose transporter 1 (GLUT-1) glucose transporter-3 (GLUT-3; both are sodium independent) and glucose transporter 8 (GLUT-8; sodium dependent) are 
the only glucose transporters that have been identified in the sheep placenta. Total placental mRNA expression and protein abundance of GLUT-1 and GLUT3 increase with an increase in the demand for glucose by the fetus. The greatest expression and abundance for GLUT-1 varies with the number of fetuses and the technique used to analyze mRNA. Currie and coworkers (1997) utilized PCR and reported that GLUT-1 expression peaked at day 60 of gestation, whilel Ehrhardt and Bell (1997) used northern blotting and reported an increase in GLUT-1 expression increases from day 75 to 140 in twin pregnancies (Ehrhardt and Bell, 1997). However, both expression and protein abundance for GLUT-3 increased from day 60 till term. Approximately $86 \%$ of all glucose binding sites on day 75 are predicted to be GLUT-1 but by day 140 this drops to only $56 \%$ (Ehrhardt and Bell, 1997). Glucose transporter-3 and not GLUT-1 transports the majority of glucose required by the fetus at the end of gestation. The shift to primarily GLUT-3 transport may be a result of a decrease in glucose binding to GLUT-1 as well as a reduction in both mRNA and protein. Glucose transporter 8 also increased as gestation progressed (Limesand et al., 2004). The increased capacity of the placenta to transport glucose appears to be a function of three things. First is an increase in the total amount of transporter. Second, the increase in capillary density and thereby total surface area leading to a much greater increase in the total number of glucose transporters beyond a simple increase in relative expression. Third the increase in the concentration gradient that occurs in the last third of gestation (Molina et al., 1991; Hay, 1995). 
Glucose transporter-1 has been found on the basal and apical surface of the fetal epithelium (trophoblast; Das et al., 2000; Wooding et al., 2005). The localization of GLUT-3 has been detected on the apical surface of the trophectoderm (Das et al., 2000; Wooding et al., 2005). Glucose transporter-8 has only been localized to the chorionic epithelium without a specific membrane border given (Limesand et al., 2004). It has been speculated that because of the differential localization of these isoforms, glucose must utilize different isoforms sequentially to be able to pass from maternal circulation to fetal circulation in sheep to meet the glucose demands of the growing fetus.

\section{Amino Acid Transporters}

Amino acids are the building blocks of all proteins, including those proteins synthesized in utero by the developing fetus and placenta. The essential amino acids are not synthesized, but extracted from maternal circulation and transported to fetal circulation, via placental amino acid transporters (Cetin, 2001; Kudo and Boyd, 2002). Therefore, alterations in placental amino acid transporter number or transporter function may lead to intrauterine growth restricted fetuses. On the opposite side an increase in the functionality of these transporters may allow for an increase in the amino acid concentration in fetal circulation leading to an increase in fetal growth and development.

Amino acid transporters have been classified into many different categories based on ion-dependence, substrate specificity, kinetics, the type of amino acid transported (i.e., neutral, anionic, cationic, branched chain or 
aromatic) and possible interactions with an additional subunit (Table 2; Jansson, 2001; Kudo and Boyd, 2002; Regnault et al., 2005). Amino acid transporters do not specifically transport just one amino acid, but transport amino acids with similar structural characteristics (Kudo and Boyd, 2002). This also means that net amino acid transport in any direction (maternal to fetal or fetal to maternal) may require the use of more than one amino acid transport system. Amino acid transporters are located in all cell types throughout the body, but not all of these amino acid transporters have been identified in the placenta and the majority of information known about location of amino acid transporters in placental tissue is limited mainly to human and rodent species. The human has a hemochorial placenta in which maternal blood bathes the fetal trophoblast while the rodent has a hemoendothelial in which maternal blood bathes the fetal endothelium. The trophoblast in this instance is the barrier for amino acid transport, but in the sheep, amino acids would have to cross both maternal and fetal epithelia and endothelia before entering fetal circulation. The table provided below summarizes the type of transporters known in human placenta and includes the system type, the gene, substrates moved by the transporter membrane, location in human fetal trophoblast cells and the type of transporter. 


\begin{tabular}{|c|c|c|c|c|}
\hline System & Gene & $\begin{array}{l}\text { Amino Acids } \\
\text { Transported }\end{array}$ & Location & $\begin{array}{c}\text { Type of } \\
\text { Transporter }\end{array}$ \\
\hline A & $\begin{array}{l}\text { SNAT-1, }-2,-4 \\
(\mathrm{SLC} 38 \mathrm{~A} 1,2,4)\end{array}$ & $\begin{array}{c}\text { Neutral AA } \\
\text { (ALA, SER, PRO, } \\
\text { GLN) }\end{array}$ & $\begin{array}{l}\text { Apical \& Basal } \\
\text { Membrane }\end{array}$ & $\mathrm{Na}^{+}$Dependent \\
\hline ASC & $\begin{array}{l}\text { ASCT-1 } \\
\text { (SLC1A4) }\end{array}$ & $\begin{array}{c}\text { Anionic AA } \\
\text { (ALA, SER, CYS) }\end{array}$ & $\begin{array}{l}\text { Apical \& Basal } \\
\text { Membrane }\end{array}$ & $\mathrm{Na}^{+}$Dependent \\
\hline $\mathrm{B}^{0}$ & $\begin{array}{l}\text { ASCT-2 } \\
\text { (SLC1A5) }\end{array}$ & $\begin{array}{l}\text { Neutral AA } \\
\text { Branch Chain }\end{array}$ & Basal Membrane & $\mathrm{Na}^{+}$Dependent \\
\hline$X_{A G}^{-}$ & $\begin{array}{l}\text { EAAT-1, }-2,-3 \\
(\mathrm{SLC} 1 \mathrm{~A} 3,2,1)\end{array}$ & Anionic AA & $\begin{array}{l}\text { Apical \& Basal } \\
\text { Membrane }\end{array}$ & $\mathrm{Na}^{+}$Dependent \\
\hline$b^{0,+}$ & $\begin{array}{c}b^{0,+} / \mathrm{rBAT} \\
\text { SLC7A9/SLC3A1) }\end{array}$ & $\begin{array}{c}\text { Neutral and cationic } \\
\text { AA } \\
\text { (LYS, ARG, LEU) }\end{array}$ & Basal Membrane & $\begin{array}{l}\text { Glycoprotein- } \\
\text { associated }\end{array}$ \\
\hline L & $\begin{array}{l}\text { LAT-1, -2/4F2hc } \\
\text { (SLC7A5, } \\
\text { 8/SLC3A2) }\end{array}$ & $\begin{array}{c}\text { Neutral AA } \\
\text { (LEU, ILE, VAL, } \\
\text { TYR, PHE, MET) }\end{array}$ & $\begin{array}{l}\text { Basal (LAT-1) } \\
\text { Apical (LAT-2) }\end{array}$ & $\begin{array}{l}\text { Glycoprotein- } \\
\text { associated }\end{array}$ \\
\hline $\mathrm{y}^{+}$ & $\begin{array}{c}\text { CAT-1.-2,-4 } \\
(\mathrm{SLC7A} 1,2,4)\end{array}$ & Cationic AA & $\begin{array}{c}\text { Apical (CAT-1, -2) } \\
\text { Basal (CAT-4) }\end{array}$ & $\begin{array}{c}\mathrm{Na}^{+} \\
\text {Independent }\end{array}$ \\
\hline
\end{tabular}

TABLE 2. Amino acid transporter systems, gene name, amino acids transported, the location of transported in fetal trophoblast cells in the human and the type of transport system.

\section{Placental Efficiency}

Placental efficiency is defined as the grams of fetus that can be supported by each gram of placenta and is calculated simply as fetal weight divided by its placental weight. The size of the placenta and more specifically the surface area available for nutrient exchange impacts placental efficiency. When placental weight is used as a crude measure for total placental contact (meaning the larger the placenta the greater likelihood for surface area contacts) it is positively correlated to body weight (Fowden et al., 2006). However, the efficiency of the placenta is more important and it is those placentas that fall above he trend line 
reflects placenta that are the most efficient meaning they produce the greater amount of fetal weight with a smaller placental weight. In sheep average birth weight of twins and triplets is approximately $80 \%(4.4 \mathrm{~kg})$ and $70 \%(3.6 \mathrm{~kg})$ of a singleton lambs $(5.4 \mathrm{~kg})$. The number of placentomes is reduced by approximately $40 \%$ per twin and approximately $75 \%$ per triplet compared to a singleton fetus (total placentome mass $0.7 \mathrm{~kg}$ ), but the placenta is able to change and compensate for the lack of nutrient exchange areas (Gootwine et al., 2007). Placental efficiency and the ability of the placenta to compensate has also been examined under experimental conditions, including uterine ligation and nutrient restriction.

Uterine ligation limits pregnancy to only one uterine horn limiting the number of caruncles available to form placentomes (Bazer et al., 1979; Caton et al., 1984; Ott et al., 1997). Uterine ligation results in a reduction in placentome number between $23 \%$ and $50 \%$. In experiments when the total number of placentomes was reduced $50 \%$, by day 140 of gestation fetal weight, placental weight and cotyledonary weight were reduced (Caton et al., 1984). However, in experiments in which only a $23 \%$ reduction in placentome number was observed in uterine ligated animals, there was no difference in fetal size (crown-rump length or weight), total placentome weight or placentome weight to fetal weight ratios. In fact, individual placentome weight increased by $27 \%$ in ligated animals which was mainly a result of an increase in the cotyledonary portion (Ott et al., 1997). 
Limiting maternal nutrition limits nutrients available to the fetus. In extreme conditions, such as a $50 \%$ reduction in nutrient intake, the placenta compensates by increasing placentome size (specifically the cotyledonary portion) and therefore increasing the surface area available for exchange. These experiments further demonstrate that the placenta has the ability to become more efficient when fetal nutrient demand increases. When pregnant ewes were restricted to $50 \%$ of control diet, the type of placentomes that developed indicated that an increase in angiogenesis had occurred, as a means of attempting to compensate for nutrient restriction. On day 78 of gestation, after 50 days of restriction, the majority of placentomes in control ewes were of the $\mathrm{A}$ type, while the nutrient restricted group had a larger proportion of the $B, C$ and $D$ type placentomes (Vonnahme et al., 2006). In this experiment, placental efficiency was not different between nutrient restricted and control ewes. The placentas ability to compensate for poor nutrition is further demonstrated utilizing the undernourished adolescent ewe model. Maintaining pregnancy during a time of maternal growth and development depletes maternal body stores and adding nutrient restriction, further limits nutrients available to the fetus. On day 90 , under these extreme circumstances, total placentome weight, mean placentome weight and gross anatomy were not different between control and nutrient restricted. By day 130 of gestation, there was a modest reduction in fetal weight. Only a modest reduction in fetal weight compared to the expected extreme reduction may be a result of placental compensation. The placental parameters were not different and similar changes in placentome type from mostly A type 
placentomes to a mix of $A, B, C$ and $D$ type placentomes had occurred by day 130. It was further noted that cotyledonary capillary density increased which increases vessel surface area and cotyledonary number density increased as gestation advanced while caruncular capillary density decreased (Luther et al., 2007). The authors noted that fetal growth was restricted in the nutrient restriction group; however, it was speculated that fetal development would have been further perturbed without proliferation of the cotyledonary capillaries (Luther et al., 2007).

\section{Somatotrophic Axis}

\section{Fetal Growth Axis}

Growth hormone (i.e., somatotropin) is detected as early as day 43 and is at least 20 times higher in concentration in fetal circulation compared to that observed in adults and is secreted in a biphasic pattern (Stokes and Boda, 1968; Basset and Gluckman, 1986; Polkowska et al., 1995). The concentration of growth hormone is high between day $60-70$ of gestation $(148 \mathrm{ng} / \mathrm{ml})$ falling to 49 $\mathrm{ng} / \mathrm{ml}$ by day 100 through 110 and reaching a second peak concentration of 150 $\mathrm{ng} / \mathrm{ml}$ between day 130 and 140 (Gluckman et al., 1979a). However, growth hormone concentration drops $80 \%$ within one hour of birth such that neonatal growth hormone concentration plummets to less than $10 \mathrm{ng} / \mathrm{ml}$ (Gluckman et al., 1979a; Bassett and Gluckman, 1985). The regulation of fetal growth hormone secretion is not known, but is believed to be, in some part, regulated by the somatotrophic axis. Growth hormone synthesis and secretion in the fetus is 
regulated by growth-hormone-releasing hormone and somatostatin, but the regulation of the secretion of these two hormones in the fetus is not yet known. Both hormones are synthesized in the hypothalamus and detectable by mid gestation in the sheep (Polkowska et al., 1995). Growth-hormone-releasing hormone administration to the fetus results in an increase in growth hormone secretion (De Zeghner et al., 1989). Somatostatin inhibits the release of growth hormone when administered to the fetus and removal of somatostatin allows for growth hormone to rise (Gluckaman 1979b). While growth hormone secretion is regulated during fetal development it does not stimulate fetal growth because it does not appear to stimulate insulin like growth factors (IGF) which are the major hormones responsible for stimulating fetal growth. Growth hormone is present but the receptor is expressed at very low levels until right before birth (stimulated by the glucocorticoid surge; Gluckman and Pinal, 2003).

Insulin like growth factor-I is the predominant growth factor late in gestation that stimulates growth along with IGF II, and both are produced by the fetal liver and other tissues during fetal development (Lok et al., 1996). Both IGF-I and IGF-II elicit a growth response by binding to the IGF-I receptor. Insulin like growth factor-II receptor is a clearance receptor decreasing the concentration of IGF-II in circulation but binding does not elicit a response (Gluckman and Pinal, 2003). In fact, birth weight and crown-rump length are highly correlated to IGF-I (Bauer et al., 1998). During gestation the main regulator of IGF-I is glucose availability (Oliver et al., 1996). Nutrients detected in fetal blood obtained after a four hour infusion of IGF-I around day 130 of gestation suggest fetal growth is 
promoted. Insulin like growth factor-I infusion resulted in a decrease in fetal amino acid nitrogen concentrations, a trend for an increase in amino nitrogen uptake and a decrease in fetal urea production (a measure of amino acid oxidation) which all suggest an increase in fetal growth (Harding et al., 1994). In a similar study in which fetal infusion of IGF-I occurred from day 120 to 130 of gestation an increase in internal organ weights were observed in treated fetuses. There was an increase in the weight of the liver, heart, kidney, and spleen and an increase in length of some of the long bones, but no observed difference in muscle weight (Lok et al., 1996).

\section{Postnatal Growth Axis}

Unlike what is observed during fetal development, growth hormone regulates the secretion of IGF-I and is therefore the hormone that stimulates postnatal growth (Gluckman et al., 1986). Growth hormone secretion is regulated by growth hormone releasing hormone, somatostatin and partially by ghrelin. Growth hormone releasing hormone stimulates both synthesis and secretion of growth hormone while, somatostatin inhibits secretion but not synthesis. Ghrelin which is produced by the stomach, intestine and central nervous systems has also been found to stimulate the synthesis and secretion of growth hormone at the level of the hypothalamus and pituitary (Gluckman et al., 1986; Anderson et al., 2004). In sheep, growth hormone secretion is asynchronous and episodic and the pulse patterns are different between males and females. A higher pulse amplitude and higher baseline are typical 
characteristic for a male pattern compared to lower amplitudes with a lower baseline level for females (Gatford et al., 1997).

Insulin like growth factor-I (i.e., somatomedin C) and IGF-II (i.e., somatomedin A) are produced throughout the body with the liver being the main source. Their secretion is stimulated by growth hormone, other hormones and other substances (i.e., insulin, steroids, interleukins and amino acids). Insulin like growth factor-I is the more potent growth stimulator and promotes growth in both a paracrine and endocrine manner (Douglas et al., 1991). Insulin like growth factors bind to insulin like growth factor binding proteins in the blood, which act as a storage mechanism since free IGF-I is not stored in any organ or tissue. The concentration of total IGF-I in plasma is 100 to $1000 \mathrm{mg} / \mathrm{ml}$ which is well above what is required to elicit a response, but this includes all IGF-I (bound and free; Gluckman et al., 1987). In sheep, fetal levels of IGF-I are similar to those observed in the adult $(120 \mathrm{ng} / \mathrm{ml})$. However, at birth IGF-I concentrations rapidly increase to about $400 \mathrm{ng} / \mathrm{ml}$ and remain elevated until about day 50 , at which time they decrease to around adult levels. Insulin like growth factor-II on the other hand drops dramatically the last five days of gestation to the levels observed at birth $(795 \mathrm{ng} / \mathrm{ml}$ to $160 \mathrm{ng} / \mathrm{ml})$ and remains at about the same level from birth through adulthood (Gluckman and Butler, 1983).

\section{Intrauterine Growth Restriction}

Since the original link was made between birth weight and adult onset disease, the fetal origins of adult disease has been extensively examined using 
animal models. Several animal models have been developed to study fetal programming, utilizing maternal dietary manipulation, hyperthermia, hormone administration, uterine artery ligation and embolization of the placenta to establish a detrimental uterine environment (Wallace et al., 2001; Jensen et al. 2002; Armitage et al. 2004; Wu et al. 2004; Wallace et al. 2005; Wu et al., 2006). Dietary manipulation to the dam has been the most widely used experimental paradigm for investigating programming. The specific regimens for applying dietary restriction are numerous, as the specific details and duration of dietary restrictions used are numerous (Wu et al., 2004; Wu et al., 2006; Wallace et al., 2005). The majority of fetal growth restriction models work by inducing placental insufficiency. The link between altered placental growth, vascular development, nutrient transport, placental metabolism and the partitioning of nutrients between the dam and the fetus are all speculated to impact programming of the fetus and adult adaptation to the environment.

The majority of fetal programming/intrauterine growth restriction studies have been developed and performed in rodents, most likely a result of cost and availability. However, a few models utilizing the ewe have been developed and extensively studied. The ovine is one species that is utilized as an animal model for humans for a few reasons. First, they normally only have singles or twins compared to pigs and rodents that have larger litters. Second, nutrient restriction alters nutrient availability to the fetus. In pigs, the dam has the remarkable ability to mobilize maternal body stores to compensate for nutrient intake. In fact, a moderate restriction does not result in intrauterine growth restriction (Wu et al., 
2006). Third, a lamb fetus is large enough to instrument allowing for collection of data from a fetus in a conscious female. These models include the nutrient restriction, overnourished adolescent ewe, maternal heat stress and placental embolization.

\section{Maternal Nutrient Restriction}

Nutrition is speculated to be the major factor influencing placental and fetal growth and development. As a result, maternal nutrition plays a critical role in proper development of the placenta and therefore nutrient availability to the developing fetus. Evidence suggesting such a strong role for the effects of maternal nutrition is found naturally and experimentally. Range animals are subjected to forages which are affected by seasonal climate change and severe weather. In the western United States, ewes are maintained on less than $50 \%$ of the daily nutrients recommended by the National Research Council. Lambs that were born to ewes that were exposed to these harsh conditions appeared to have compromised health (Thomas and Kott, 1993; Vonnahme et al., 2003; Wu et al., 2004). Nutrient restriction in experimental models can vary in the severity, duration and period of pregnancy (i.e., early, mid or late gestation) of the restriction.

The majority of maternal nutrient restriction models impose restriction between day 28 and 80 of gestation. Some nutrient restrictions are extend for longer periods of time, until fetal tissue collection (day 90 or 135). The level of nutrient restriction is highly variable and ranges from $30 \%$ to $50 \%$ of the daily 
nutrient requirement. Fetal weight is reduced approximately $32 \%$ by maternal nutrient restriction from day 28 to day 80 regardless of the level of nutrient restriction (30\% or 50\%; Vonnahme et al., 2003; Kwon et al., 2004;). However, others have observed that nutrient restriction did not have an effect on lamb weight at term (Heasman et al., 1998; Ford et al., 2007). When nutrient restriction was extended to gestational day 135 only a $15 \%$ reduction in fetal weight was observed (Osgerby et al., 2002; Kwon et al., 2004; Osgerby et al., 2004).

Surprisingly, even though nutrient restriction was applied during the time in which the placenta is undergoing rapid growth to day 78 , no difference in placental weight was observed (Vonnahme et al., 2003). However, by term total placental weight, as well as fetal cotyledonary tissue weight was greater in the treated group compared to the controls. This increase in weight may be associated with a decrease in the number of $A$ type placentomes and an increase in the number of $B$ and $C$ type placentomes observed at term (Heasman et al., 1998; Osgerby et al., 2004). Information available on umbilical blood flows are variable in that some research shows an increase while others show no change (Reynolds et al., 2005). Nutrient flux across the placenta appears to be altered by nutrient restriction during early and mid gestation in the ewe. Glucose concentration and 11 of 23 amino acids measured in fetal circulation were decreased in fetuses gestated by ewes subjected to a nutrient restriction compared to those gestated by controls (Osgerby et al., 2002; Kwon et al., 2004). Maternal nutrient restriction appears to alter placental function early in 
gestation which results in limited fetal growth. However, upon removal of the restriction the placenta appears to compensate by its altering growth.

\section{Overnourished Adolescent Ewe Model}

The overnourished adolescent ewe model utilizes the hierarchy of nutrient partitioning to limit fetal placental growth. Normally, nutrition is shunted to the fetus to promote proper growth, but when the dam is still growing (i.e., adolescent) maternal growth takes priority above fetal growth which means nutrients are partitioned to maternal growth at the cost of the gravid uterus. The majority of the reduction in fetal and placental weight comes from altered nutrient partitioning. Overfed growing adolescents gain at least four times as much weight (200-350 g/day) compared to those fed a moderate diet (50-85 g/day). The increase in weight comes from an increase in fat storage and maternal body weight gain (Wallace et al., 2006b). The results of these studies show a reduction of $33 \%$ in the overall feto-placental mass at birth compared to moderately fed controls which correlates to a $29 \%$ reduction in birth weight (Wallace et al., 2001). Fetuses from overnourished ewes are normally small for their gestational age and born premature.

Overnourishing adolescent ewes reduces uterine blood flow and placental function which limits nutrient availability to the developing fetus and results in small lambs at birth. Nutrients available for transport are reduced as a result of a decrease in uterine blood flow by approximately $36 \%$ compared to control. When fetal weight is taken into consideration the uterine blood flow is proportionally the 
same, but umbilical blood flow per gram of fetal weight is reduced by $15 \%$ which is consistent with the suggestion that uterine blood flow regulates fetal growth (Wallace et al., 2002b). In this model established placentomes not only have a smaller mass, but the actual number established per placenta is reduced compared to moderately fed controls (Wallace et al., 2001). Overnourishing adolescent pregnant ewes reduced umbilical amino-acid uptake for 12 of 16 amino acids measured and glucose. The decreased uptake was speculated to result from a reduction in placentome total surface area because when placental uptake was expressed on a placental weight basis, no difference in glucose uptake was observed (Wallace et al., 2002a; Wallace et al., 2004). The reduction in fetal weight, placental weight and nutrient transfer may be a result of a reduction in angiogenesis within the placenta or uterine blood flow. On day 81, (the point when placental growth reaches a plateau but angiogenesis continues to compensate for the continual rapid growth of the fetus) expression of angiogenic factors including vascular endothelial growth factor, angiopoietin 1 , angiopoietin 2 and nitric oxide synthase 3 were decreased by almost $50 \%$ in overnourished adolescent ewes compared to those that were moderately fed (Redmer et al., 2005).

\section{Maternal Heat Stress Model}

In sheep, increasing the external ambient temperature 20 degrees during the middle to final portion of pregnancy results in placental insufficiency and poor fetal development. The general procedure is to place ewes in a hot room around day 35 of gestation, the time when the rapid growth phase of the placenta starts, 
and remove the ewes approximately 60 days later. The duration of exposure to high temperature per day varies among experiments and ranges from only nine hours per day to a constant 24 hour per day exposure. High ambient temperatures were considered $40^{\circ} \mathrm{C}$ compared to controls, $18-20^{\circ} \mathrm{C}$, and the humidity ranged from 30-40\% (Thureen et al., 1992; Galan et al., 1999; Bell et al., 2003). During periods of heat exposure, ewe rectal temperature averages about $40.3^{\circ} \mathrm{C}$ which is one degree higher than those housed at control temperatures (Bell et al., 1989). Exposing a pregnant ewe to extreme ambient temperature reduces fetal weight in a time-dependent manner. In all cases, high ambient temperature exposure resulted in a reduction of at least $17 \%$ to $50 \%$ in fetal body weight compared to those fetuses collected from ewes housed in a thermoneutral temperature.

A 54\% reduction in placental weight was observed following exposure to extreme ambient temperature which is most likely a result of a decrease in placentome weight (Bell et al., 1989; Thureen et al., 1992). Uterine blood flow is not different in pregnant ewes subjected to either a thermoneutral or hyperthermic environment; however, when scaled to either fetal or placental weight (uterine blood flow/weight) uterine blood flow is increased in those ewes exposed to higher ambient temperatures suggesting that uterine blood flow is not reduced in relationship to metabolic demands of the placenta and fetus (Thureen et al., 1992; Regnault et al., 2003). Nutrient delivery via uterine blood flow may not be limiting but, a reduction in umbilical blood flow may be the cause for a decrease in nutrient extraction. Heat stress led to a reduction in fetal glucose 
concentration, fetal uptake of glucose and overall extraction of glucose by the gravid uterus (Regnault et al., 2003). Heat stressed pregnant ewes exhibited altered placental expression of angiongenic factors. In maternal caruncular tissue of heat stressed ewes, expression as well as protein concentration of placental growth factor (PIGF) increased, but no changes were observed for vascular endothelial growth factors. In fetal cotyledonary tissue, vascular endothelial growth factor expression and protein decreased, PIGF was not altered by hyperthermic conditions (Regnault et al., 2003). In this model, the maternal supply of nutrients appears not to be limiting fetal growth, but a limited growth and development of the fetal side of the placenta appears to be the culprit.

\section{Placental Embolization}

Placental embolization is used to study the fetal growth axis in growth restricted fetuses late in gestation. Around day 110 of gestation, pregnant ewes undergo surgery to place catheters in the maternal uterine artery and to chronically catheterize the fetus. Around two days post surgery microspheres between 25 and $50 \mu \mathrm{m}$ in size are injected into the maternal artery catheters twice daily for two days. The duration and amount of microspheres injected daily is then altered based on fetal growth (as measured by a growth catheter placed around the chest of the fetus) and when fetal growth is slowed or stopped for two days then embolization is stopped. Injection of microspheres creates a placental insufficiency limiting blood flow to the placenta and limits the area available for nutrient exchange. In all cases, embolism resulted in a reduction in fetal weight 
ranging from $15 \%$ to $38 \%$ (Jensen et al., 1999; Bloomfield et al., 2002; Bauer et al., 2003; Louey et al., 2005). In the only study that measured placental weight, embolization led to a $30 \%$ reduction in placental weight at birth (Louey et al., 2005). Alterations in placental weight are of limited value, since the majority of placental growth is during the first 80 days of gestation. However, it is not surprising that placental weight decreased because it requires nutrients from maternal blood to meet its metabolic demands.

\section{Impact of Intrauterine Growth Restriction}

The above described models create forms of placental insufficiency and altered nutrient delivery which may lead to temporary or permanent alterations in fetal organ development and function. In intrauterine growth restricted fetuses, blood is shunted to the brain at the expense of other organs including the heart and liver. In humans, for example, the reduced abdominal circumference observed in intrauterine growth restriction may be an indicator of reduced liver growth and development. In fact, smaller abdominal circumference at birth has been correlated with elevated concentrations of total and low density lipoproteins, cholesterol and fibrinogen in the blood, which are risk factors for adult cardiovascular disease. Barker et al. (1995) utilized abdominal girth as way to assess liver development and found that small abdominal circumference at birth was correlated with an increased incidence of coronary heart disease regardless of social status, weight, smoking or alcohol consumption. Below is a table that summarizes general outcomes observed with different models of fetal growth 
restriction. Included are measures of fetal development and organ weights relative to fetal body weight and how they are impacted by models of intrauterine growth restriction (Table 3).

The data presented in the table are summarized from a number of studies and therefore, variation in the general summary may be a result of the exact protocol used to induced fetal growth restriction. All of the studies led to a reduced fetal size as measured by fetal weight, crown-rump length and abdominal girth. However, the information available on fetal organ growth is limited and sometimes contradictory. For example, maternal under nutrition appears to have no effect on abdominal girth at day 78 of gestation but abdominal girth is reduced by day 135 (Osgerby et al., 2002; Vonnahme et al., 2003). Similarly, liver weight relative to fetal weight is increased at day 78 but no difference is observed by day 135 . Data may be influenced by the duration and timing of nutrient restriction. Until day 78 , fetal growth is very slow while placental growth is quite rapid. However, data collected on day 135 is influenced by continual nutrient restriction through the placental growth phase and through the rapid fetal growth phase. Heart weight and ventricular wall thickness may be harder to explain because it has been speculated that heart development is affected by other vascular measures. Fetuses gestated by dams, nutritionally restricted to $50 \%$ of the control group from day 28 to day 78 of gestation, had an increased ventricular weight per gram of fetal body weight (Vonnahme et al. 2003). A hypertrophic increase in the fetal ventricular wall has been suggested to result from an increase in ventricular afterload which is indicative of an 
increase in peripheral arterial pressure (Samson et al. 2000; Vonnahme et al.

2003). A mechanism by which placental vascular resistance may result in altered fetal heart development has been postulated by Vonnahme et al. (2003).

In sheep, intrauterine growth restriction can lead to an increased placental vascular resistance (Vonnahme et al. 2003). 


\begin{tabular}{|c|c|}
\hline \multicolumn{2}{|c|}{ Maternal Nutrient Restriction } \\
\hline Fetal Weight & $\boldsymbol{\nabla}$ at all stages of gestation \\
\hline Crown-rump Length & $\boldsymbol{\nabla}$ at all stages of gestation \\
\hline Abdominal Girth & $\begin{array}{l}\text { No Change at day } 78 \text { of gestation (period of placental } \\
\text { growth) } \\
\nabla \text { by day } 135 \text { of gestation (during the period of rapid fetal } \\
\text { growth) }\end{array}$ \\
\hline Brain Weight & No Change \\
\hline Liver Weight & $\begin{array}{l}\Delta \text { at day } 78 \text { of gestation (period of shunted placental } \\
\text { growth) } \\
\text { No difference by day } 135 \text { (placenta is able to compensate } \\
\text { and increase nutrient flux to the developing fetus increasing } \\
\text { liver growth) }\end{array}$ \\
\hline Heart Weight & $\begin{array}{l}\Delta \text { Right and left ventricular wall weight at day } 78 \text { of } \\
\text { gestation } \\
\nabla \text { in total heart weight at day } 135\end{array}$ \\
\hline \multicolumn{2}{|c|}{ Overnourished Adolescent Ewe } \\
\hline Fetal Weight & $\boldsymbol{\nabla}$ during fetal development and at birth \\
\hline Crown-rump Length & $\boldsymbol{\nabla}$ during fetal development \\
\hline Abdominal Girth & $\boldsymbol{\nabla}$ during fetal development \\
\hline Brain Weight & $\begin{array}{l}\text { No change in two out of three studies (one study found an } \\
\text { increase) }\end{array}$ \\
\hline Liver Weight & No change \\
\hline Heart Weight & No change \\
\hline \multicolumn{2}{|l|}{ Maternal Heat Stress } \\
\hline Fetal Weight & $\boldsymbol{\nabla}$ during fetal development \\
\hline Crown-rump Length & $\begin{array}{l}\text { No difference was observed when heat stress was applied } \\
\text { early in gestation } \\
\nabla \text { when heat stress was induced around the time of rapid } \\
\text { fetal growth }\end{array}$ \\
\hline Brain Weight & $\begin{array}{l}\text { No change in two out of three studies (one study found an } \\
\text { increase) }\end{array}$ \\
\hline Liver Weight & $\begin{array}{l}\text { No difference was observed in two out of three studies (the } \\
\text { one study that detected a decrease started applying heat } \\
\text { stress late in gestation }\end{array}$ \\
\hline Heart Weight & No change \\
\hline \multicolumn{2}{|c|}{ Placental Embolization } \\
\hline Fetal Weight & $\boldsymbol{\nabla}$ following embolization \\
\hline Crown-rump Length & $\nabla$ following embolization \\
\hline Abdominal Girth & $\boldsymbol{\nabla}$ following embolization \\
\hline Brain Weight & No change \\
\hline Liver Weight & $\begin{array}{l}\text { No change was observed in two out of three studies but one } \\
\text { of three observed a reduction in fetal liver weight }\end{array}$ \\
\hline Heart Weight & $\begin{array}{l}\text { No change was found in two of four studies } \\
\nabla \text { in heart weight in two out of four studies } \\
\nabla \text { Right and left ventricular wall thickness }\end{array}$ \\
\hline
\end{tabular}

TABLE 3. Impact of nutrient restriction models on fetal components and organ weights. 


\section{Statement of the Problem}

The use of animal models has allowed extensive investigation in the field of fetal programming, specifically critical assessment of the effect of uterine environment (i.e. secretion, timing and space) on embryonic development, fetal growth and ultimately adult life. Using animals models, researchers have been able to link a deleterious uterine environment during specific stages of fetal development to altered development and function (i.e., programming) of the cardiovascular, respiratory, endocrine, reproductive, immune and central nervous systems as well as the function of the kidneys and liver and bone density (Godfrey and Barker, 2000; Wu et al., 2004). However, the majority of studies conducted in the area of fetal programming have been limited to only the effects of a negative uterine environment. Few studies have tried to ameliorate the impact of experimentally induced intrauterine growth restriction by administering growth promoters, but again the basis of the experiment is to first inhibit fetal growth. However, the growth that is stimulated is only transient.

Therefore, we endeavored to investigate a recent observation from our laboratory that reported that a single injection of growth hormone given at breeding results in lambs that are $\sim 10 \%$ larger at birth (Costine et al., 2005). Determining how a single injection of growth hormone at breeding promotes growth throughout gestation leading to heavier lambs 145 days later may ultimately change how we think about fetal programming. The present studies were designed to specifically address three important questions. First, how is the 
early uterine environment altered by a single injection of growth hormone given that this environment can potentially program the developing embryo? Second, how does the placenta that develops from the conceptus exposed to an altered uterine environment become more efficient and able to transport more nutrients to the developing fetus late in gestation when fetal demand for nutrients increases? Third, do lambs born to ewes treated with growth hormone, have altered growth and development, including programmed alterations of the growth hormone axis of the lambs born to ewes treated with growth hormone? 


\title{
Peri-Conceptional Growth Hormone Treatment Alters Early Uterine Environment
}

\author{
J. M. Koch ${ }^{1}$, C. O. Lemley ${ }^{1}$, R. R. Magness ${ }^{2}$, M. E. Wilson ${ }^{1,3}$ \\ ${ }^{1}$ Division of Animal and Nutritional Sciences, Davis College of Agriculture, \\ Forestry and Consumer Sciences, West Virginia University Morgantown, West \\ Virginia, USA \\ ${ }^{2}$ Perinatal Research Labs, Departments of Obstetrics and Gynecology and \\ Department of Animal Science, University of Wisconsin, Madison, Wisconsin, \\ USA
}

This work is published with the approval of the Director of West Virginia Agriculture and Forestry Experiment Station as scientific paper XXXXXX. This project was supported by Hatch project 468 (NE 1007) and a West Virginia University Faculty Senate Research Grant, USDA-NRICGP-xxxx

${ }^{3}$ Correspondence: G048 Agricultural Sciences Building (phone: (304) 293-2406 ext. 4425; fax: (304) 293-2232; email: mwilso25@wvu.edu) 


\section{Abstract}

We have shown that an injection of sustained release growth hormone $(\mathrm{GH})$, given just prior to breeding, results in lambs that are $10 \%$ heavier at birth, with an altered body composition as evidenced by an increased abdominal girth, but no difference in crown-rump length. The mechanisms by which these differences occur from a single periconceptional injection are not yet known. Therefore, the objective of this experiment was to determine the effect of an injection of $\mathrm{GH}$ given prior to breeding on the composition of the uterine environment at the time of blastocyst formation and the trophectoderm to inner cell mass ratio. Ewes were synchronized with two injections of prostaglandin given eight days apart. On the day of the second injection, ewes were randomly assigned to be given an injection of sustained release $\mathrm{GH}$ or remain as controls and penned with a ram. On day 6.5 following breeding embryos were surgically collected by flushing each oviduct. Prior to surgery a jugular blood sample was taken to determine plasma progesterone and urea concentrations. The uterine content of urea, prostaglandin $F_{2} \alpha$, prostaglandin $E_{2}$, transforming growth factor ß-1 (TGF ß), nitric oxide metabolites and total protein were measured. Collected embryos were differentially stained to calculate a trophectoderm to inner cell mass ratio. The uterine content of urea in the GH group was lower $(p<0.05)$ than that of the control group. There was a trend for TGF $\beta$ to be increased in the $\mathrm{GH}$ treated group compared to control $(p=0.07)$. There was no difference in the total uterine content of prostaglandin $\mathrm{F}_{2} \alpha$, prostaglandin $\mathrm{E}_{2}$, protein or nitric oxide metabolites. The concentration of progesterone and insulin in maternal 
plasma was greater in the treated group compare to controls, but blood urea nitrogen was not different between groups. The trophectoderm to inner cell mass ratio or the total number of blastomeres was not different between treatment groups. Thus, we suggest that the observed difference in fetal development following periconceptional growth hormone administration just prior to breeding may be a result of an alteration in the uterine environment, which may alter the cellular program of the conceptus and later development, beyond the embryonic stage.

Key Words: growth hormone, uterine environment, embryo 


\section{Introduction}

Exposure to an insult or a stimulus during critical periods of development can result in long lasting and possibly permanent physiological alterations, a phenomenon known as programming (Godfrey \& Barker, 2000). The uterine environment in which the conceptus and developing fetus are exposed to has been extensively studied. Particularly in the sheep, studies range from the effects of early uterine environment through late gestational treatments. However, the majority of these studies focus on negatively impacting fetal growth and development and only a limited number of studies have tried to promote fetal growth and development.

It has been understood for at least 50 years that altering the early embryonic environment can greatly impact embryonic growth and survival (Moore and Shelton, 1964). The success of embryo transfer drops below $10 \%$ if the embryos are transferred to a uterine environment that is more than 48 hours ahead or behind that from which the embryo was collected (Rowson and Moor, 1966). The stage of embryonic development also impacts the success of embryonic survival as a time-dependent increase. Specifically as the age of the embryo increased the rate of survival increased (Moore and Shelton, 1964; Rowson and Moor 1966).

Embryo transfer into an advanced uterine environment has been found to alter early fetal development (Kleeman et al., 1994; Young et al., 1996). Fetal growth was increased in ewes exposed to progesterone during the first six days 
of gestation (Kleeman et al., 1994). Similarly, Young et al. (1996) found that fetuses derived from embryos transferred to an advanced uterine environment were $42 \%$ heavier by gestational day 21 . Recently, we demonstrated that a single injection of growth hormone given at or just prior to breeding increases birth weight by 10 (Costine et al., 2005).

Therefore, the objective of this experiment was to determine the effect of an injection of sustained release growth hormone given just prior to breeding on the composition of the uterine environment at the time of blastocyst formation. Additionally the ratio of trophectoderm to inner cell mass is altered and the total number of blastomeres was determined to possible alterations in embryonic growth.

\section{Materials and Methods}

Ewes $(n=59)$, primarily of Suffolk breeding, from the West Virginia University farm were used for the experiment. All procedures were approved by the West Virginia University Animal Care and Use Committee (ACUC No. 050805).

Estrus was synchronized by administering two injections of $20 \mathrm{mg}$ (i.m.) of prostaglandin $\mathrm{F}_{2} \alpha$ (Lutalyse, Pfizer; New York, NY) eight days apart. Ewes were randomly assigned to either a control group $(n=35)$ or a growth hormone treated group $(\mathrm{n}=24)$. The growth hormone treated group received a single $500 \mathrm{mg}$ 
injection of sustained release recombinant bovine growth hormone subcutaneously (Posilac; Monstanto, St. Louis, MO) at the same time as the second prostaglandin $\mathrm{F}_{2} \alpha$ injection. This dose was previously reported to increase uterine luminal insulin like growth factor-I (IGF-I) 4-fold on day 7 of gestation and result in larger lambs at birth (Costine et al., 2005). Ewes were penned with a fertile ram fitted with a marking harness and ewes were checked twice daily for the appearance of new marks which occurred two to three days (day 0 ) following the second prostaglandin $F_{2} \alpha$ injection.

\section{Embryo Collection}

On day 6.5 , ewes underwent surgery for embryo collection. Briefly, all ewes were anesthetized and maintained on a 10\% ketamine drip (Vedco; Columbus Serum, Columbus, $\mathrm{OH}$ ) and $50 \mathrm{mg} / \mathrm{ml}$ sodium pentobarbital to effect (Sigma; St. Louis, MO). A midventral incision was made in the abdominal wall to expose the uterus and the oviducts. The right and left uterine horn were flushed separately as follows. A small incision was made at the base of the uterine horn and a glass cannula was inserted into uterine horn. A blunted needle, attached to a glass syringe, was inserted into the oviduct through the infundibulum. Pinching off around the needle, $10 \mathrm{ml}$ of phosphate buffered saline $(\mathrm{pH} 7.4)$ was flushed through the oviduct and uterine horn to the glass cannula and collected in petri dish. Embryos were removed from the flushings and processed for immunosurgical lysis. Flushings were centrifuged at 2,000 $\mathrm{xg}$ to pellet any 
cellular debris and the remaining flushing was aliquoted into microcentrifuge tubes and stored at $-20^{\circ} \mathrm{C}$ until further analysis.

\section{Immunosurgical Lysis}

Immnunosurgical lysis allows for the differential staining of the two main cell types of the blastocyst, the trophectoderm and the inner cell mass. Embryos were stained using a procedure previously used to stain pig embryos but modified to allow for proper staining of sheep embryos (Rivera et al., 1996). Embryos were incubated in Tyrode's Solution $(0.8 \% \mathrm{NaCl}, 0.4 \%$ polyvinyl pyrrolidone, $0.24 \% \mathrm{CaCl}_{2} \cdot \mathrm{H}_{2} \mathrm{O}, 0.1 \%$ glucose, $0.02 \% \mathrm{KCl}$, and $0.01 \%$ $\mathrm{MgCl}_{2} \cdot 6 \mathrm{H}_{2} \mathrm{O} ; \mathrm{pH} 2.5$ ) for $45 \mathrm{~s}$ at $39^{\circ} \mathrm{C}$ to remove the zona pellucida. Embryos were then rinsed three times in modified phosphate buffered saline (mPBS; $1 \%$ penicillin-streptomycin, $0.4 \%$ BSA, $0.0036 \%$ sodium pyruvate and $0.0023 \% \mathrm{~L}-$ glutamine). Embryos were then incubated with $10 \mathrm{nmol} / \mathrm{L}$ trinitrobenzene sulfonic acid (Sigma, St. Louis, MO) for $30 \mathrm{~min}$ on ice. Trinitrobenzene sulfonic acid labels the surface of the trophectoderm cells with trinitrophenol groups. Embryos were then washed three times in $\mathrm{mPBS}$ and then placed in $0.1 \mathrm{mg} / \mathrm{ml}$ anti-dinitrophenol (Sigma, St. Louis, MO) for $30 \mathrm{~min}$ at $39^{\circ} \mathrm{C}$. Anti-dintrophenol is antiserum against dintrophenol and cross reacts with trinitrophenol groups which form on the surface of the trophectoderm following exposure to trinitrobenzene. Embryos were then washed three times in mPBS and placed into a mPBS solution containing a 1:5 dilution of guinea-pig complement (Sigma, St. Louis, MO) and $0.01 \mathrm{mg} / \mathrm{ml}$ propidium iodide (Sigma, St. Louis, MO) for $30 \mathrm{~min}$ at $39^{\circ} \mathrm{C}$ 
in the dark. Guinea pig complement interacts with the antibodies attached to the trophectodermal cells and lyses the trophectoderm cells allowing propidium iodide into the cell. The nuclei of these cells are thus stained red. Embryos were then washed two times in mPBS before being incubated for 15 min in the dark at $39^{\circ} \mathrm{C}$ in $0.05 \mathrm{mmol} / \mathrm{L}$ Hoechst 33258 in mPBS (Sigma; St. Louis, MO). After 15 min embryos were moved into a $0.05 \mathrm{mmol} / \mathrm{L}$ Hoechst 33258 in $100 \%$ ethanol protected from light and incubated overnight at $4^{\circ} \mathrm{C}$. Hoechst can cross all membranes and stains nuclei blue. Therefore, the nuclei of the inner cell mass appear blue, and the nuclei of the trophectoderm appear pink because they are stained with both propidium iodide and Hoechst (Figure 3). Embryos were then incubated in $100 \%$ ethanol for 30 mins at $4^{\circ} \mathrm{C}$. Following fixation in ethanol embryos were transferred to a slide with $5 \mu$ of glycerol and covered with a glass cover slip.

The number of inner cell mass and trophectoderm cells for each embryo ( $n=27$ control, $n=17 \mathrm{GH}$ ) were counted using an inverted microscope (Nikon TE2000) equipped with a mercury vapor lamb and a UV filter set which illuminated the embryo at $380 \mathrm{~nm}$, which is the wave length of excitation for both dyes and a barrier filter at $420 \mathrm{~nm}$. The two types of nuclei were counted by two different counters independently and these numbers were averaged together. The total number of cells was calculated by adding all the red and blue cells together. 


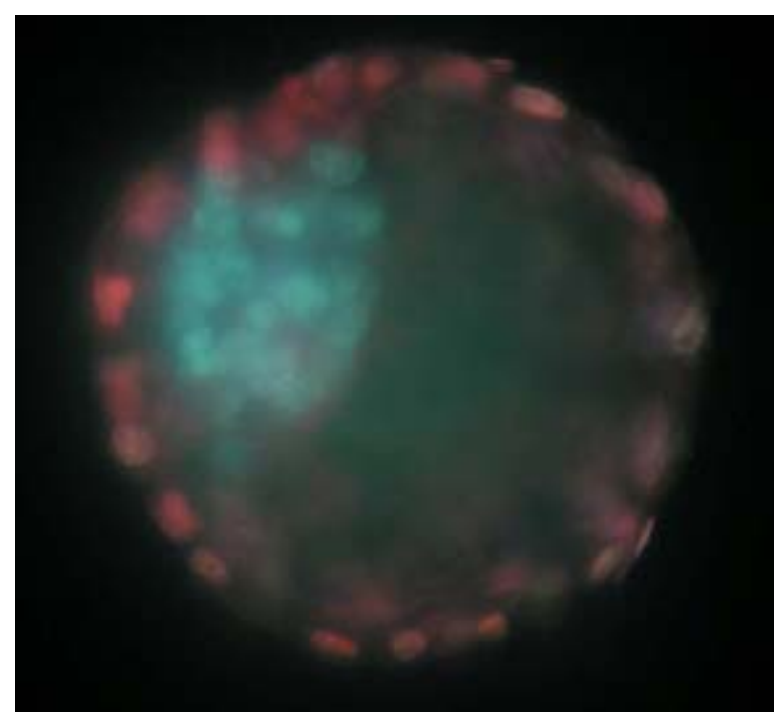

FIGURE 3. Differential staining of a blastocyst collected on day 6.5 by immunosurgical lysis. The inner cell mass cells are stained blue while the trophectoderm is stained pink.

\section{Uterine Flushings}

Prostaglandins

Prostaglandin $E_{2}$ and prostaglandin $F_{2} \alpha$ were analyzed by commercially available EIA (Cayman Chemical Company; Ann Arbor, MI) and validated in our laboratory to detect prostaglandins in uterine flushing.

$T G F \beta-1$

The TGF $\beta-1$ in the uterine flushings was determined using a human TGF $\beta-1$ Duo Set enzyme linked immuno-sorbent assay (ELISA) kit (R\&D Systems, Minneapolis, MN) and ELAST ${ }_{\circledast}$ ELISA amplification system 
(PerkinElmer Life Sciences, Boston, MA) following manufacturers' instructions and altered for uterine flushings (Holaskova, 2007). Briefly, flat bottom 96 well Nunc-Immuno plates with MaxiSorp surface treatment (Fisher Scientific, PA), were coated with capture antibody (mouse anti- TGF $\beta-1 ; 2 \mu \mathrm{g} / \mathrm{mL}$ ) and incubated overnight at room temperature. After a wash, plates were blocked by adding the blocking buffer for a minimum of 1 hour, washed, and $100 \mu \mathrm{l}$ of acid-treated uterine flushing (1N HCl for TGF $\beta-1$ activation, 1.2 N NaOH/0.5 M HEPES for neutralization), or standards were added in duplicate. An eight-point standard curve consisted of 2-fold serial dilutions of recombinant human TGF $\beta-1$, starting at $125 \mathrm{pg} / \mathrm{mL}$ for the high stanard. Plates were incubated overnight at $4^{\circ} \mathrm{C}$, washed, and the detection antibody was applied (biotinylated chicken anti-human TGF $\beta-1,300 \mathrm{ng} / \mathrm{mL}$ ) for 2 hours at room temperature. Streptavidin conjugated to horseradish peroxidase was added to each well, incubated for $20 \mathrm{~min}$ at room temperature in the dark, washed, and was followed by substrate solution $\left(\mathrm{H}_{2} \mathrm{O}_{2}\right.$ mixed 1:1 with tetramethylbenzidine, R\&D Systems, Minneapolis, MN) for 20 min at room temperature in the dark. A biotinyl-tyramide amplification step was inserted into the ELISA procedure (ELAST ${ }_{\circledast}$ ELISA Amplification System; Perkin Elmer, Boston, MA), which increased the sensitivity to $2 \mathrm{pg} / \mathrm{mL}$. The reaction was stopped with $2 \mathrm{~N} \mathrm{H}_{2} \mathrm{SO}_{4}(50 \mu \mathrm{L} /$ well $)$ and plates were analyzed with a microplate spectrophotometer (SPECTRAmax ${ }_{\circledast}$ PLUS $_{384}$, Molecular Devices, Sunnyvale, CA). Readings at $540 \mathrm{~nm}$ were subtracted from those at $450 \mathrm{~nm}$ for the wavelength correction, and plotted against the standard curve using the SoftMax ${ }_{\circledast}$ Pro software (version 4.6, Molecular Devices, Sunnyvale, CA). The 
unknown fluid validation protocol resulted in detection of $82 \%$ of recombinant TGF $\beta-1$ in the uterine flushing samples. Duplicate values with less than a $20 \%$ coefficient of variation were accepted for statistical analysis.

Urea

The urea concentration in uterine flushing and maternal plasma were determined by a commercial assay kit for measuring urea in biological samples (BioAssay Systems; Hayward, CA). Duplicate values with less than a $20 \%$ coefficient of variation were accepted for statistical analysis.

\section{Nitric Oxide Metabolites}

One way of assessing nitric oxide production is to measure its two metabolites nitrite $\left(\mathrm{NO}_{2}{ }^{-}\right)$and nitrate $\left(\mathrm{NO}_{3}{ }^{-}\right)$. Nitrite in uterine flushing was determined using a commercially available assay (Griess Reagent System; Promega; Madison, WI). The concentration of nitrite and nitrate in uterine flushing was subsequently determined using a commercial assay kit in biological samples (BioAssay Systems; Hayward, CA) in which nitrate is reduced to nitrite and total nitrite is determined.

Protein

The Bradford assay was used to determine protein content in uterine flushing. A standard curve was generated using BSA (Pierce, Rockford, IL) and Coomassie blue dye (Pierce, Rockford, IL), which upon binding to protein changes absorbance from $465 \mathrm{~nm}$ to $598 \mathrm{~nm}$. The absorbance at $598 \mathrm{~nm}$ is directly proportional to the amount of protein in the sample. Duplicate values 
with less than a $20 \%$ of coefficient of variation were accepted for statistical analysis.

\section{Maternal Plasma}

Progesterone

Progesterone concentrations from jugular plasma samples were determined using RIA (Sheffel et al., 1982) with a sensitivity of $100 \mathrm{pg} / \mathrm{ml}$ and intra- and interassay CV of 4.3 and $7.7 \%$, respectively. Insulin

Jugular plasma insulin was measured using an insulin RIA kit (Diagnostic Products Corporation, Los Angeles, CA) with a sensitivity of $0.05 \mathrm{nM}$ and intraassay $\mathrm{CV}$ of $3.1 \%$. The assay was validated to measure sheep insulin in our laboratory. Briefly, plasma dilutions from two ewes were assayed separately for insulin and found to be parallel with the standard curve (Lemley et al., 2008a)

\section{Statistical Analysis}

The effect of periconceptional growth hormone treatment to the dam on the concentration of protein, urea, prostaglandin $E_{2}$, prostaglandin $F_{2} \alpha$, TGF $\beta 1$ in uterine flushings was analyzed by analysis of variance, utilizing the general linear models procedure in SAS. The effect of periconceptional growth hormone treatment on maternal progesterone concentration was analyzed by analysis of variance, utilizing the general linear models procedure in SAS. The correlation 
between trophecoderm to inner cell mass ratio and uterine flushing components was determined using the correlation procedures of SAS.

\section{Results}

Periconceptional GH treatment increased maternal progesterone $(p<$ 0.05; Figure 4) and insulin ( $p<0.05$; Figure 5$)$ concentrations. However, GH treatment did not alter maternal blood urea nitrogen $(51.03 \pm 3.11 \mathrm{mg} / \mathrm{ml})$.

Periconceptional growth hormone treatment did decrease uterine luminal urea $(p<0.05)$ content on day 6.5 of pregnancy (Figure 6$)$. There was a trend for an increase in TGF- $\beta 1$ ( $p=0.07$; Figure 7). Growth hormone treatment did not alter uterine content of prostaglandin $F_{2} \alpha(1677.02 \pm 97.23 \mathrm{ng} / \mathrm{ml})$, prostaglandin $\mathrm{E}_{2}(763.48 \pm \mathrm{ng} / \mathrm{ml})$, nitrite and nitrate $(86.35 \pm 4.11 \mu \mathrm{M})$ or nitrite $(7.39 \pm 0.41 \mu \mathrm{M})$. Overall $\mathrm{GH}$ treatment did not alter the trophectoderm to inner cell mass ratio $(4.26 \pm 0.60)$ or the total number of blastomeres per embryo $(40.38 \pm 3.37)$. 


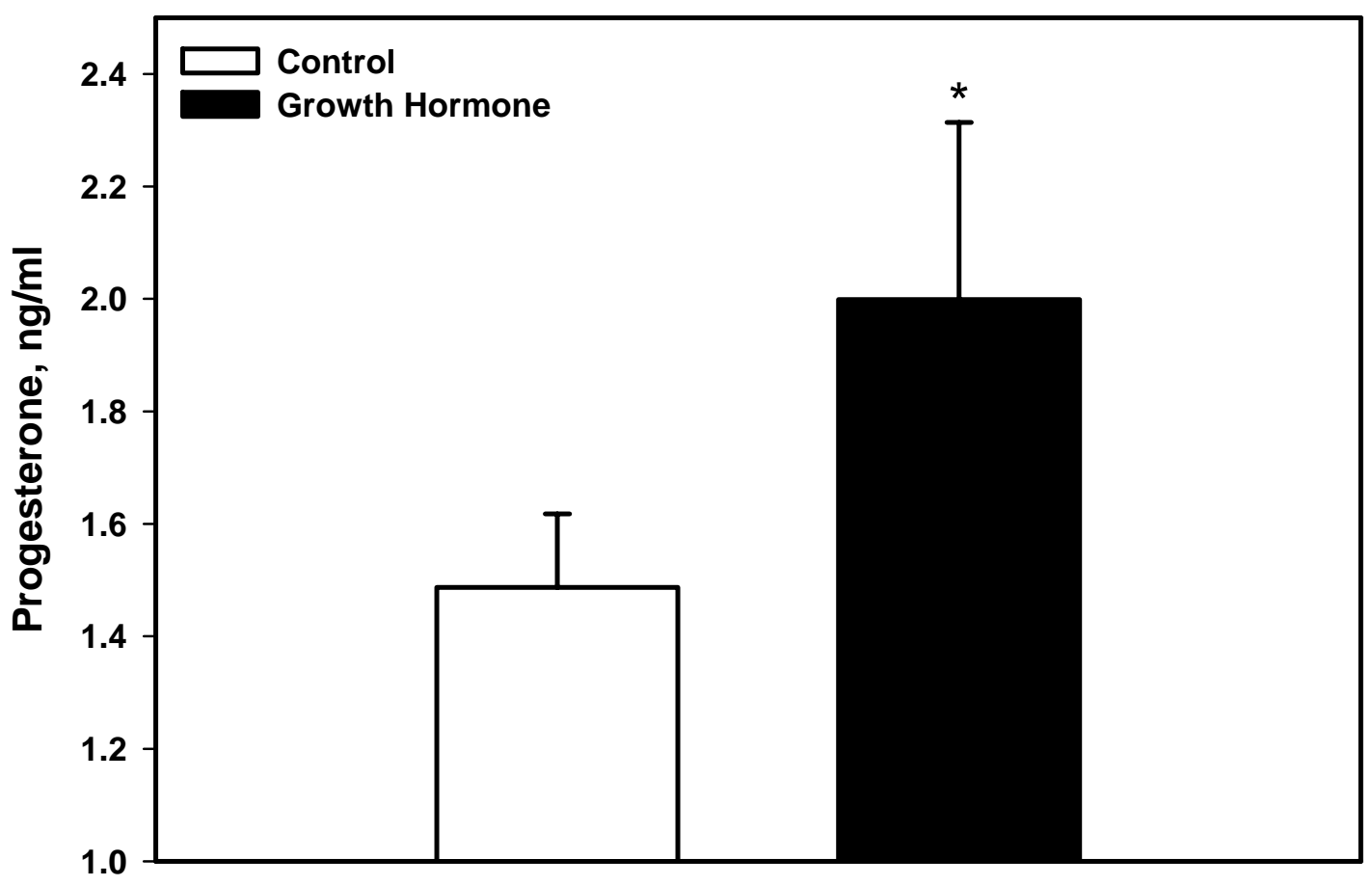

FIGURE 4. Maternal progesterone concentration on day 6.5 of gestation in control ewes and those treated with a periconceptional GH injection. * Indicates a treatment difference $p<0.05$. 


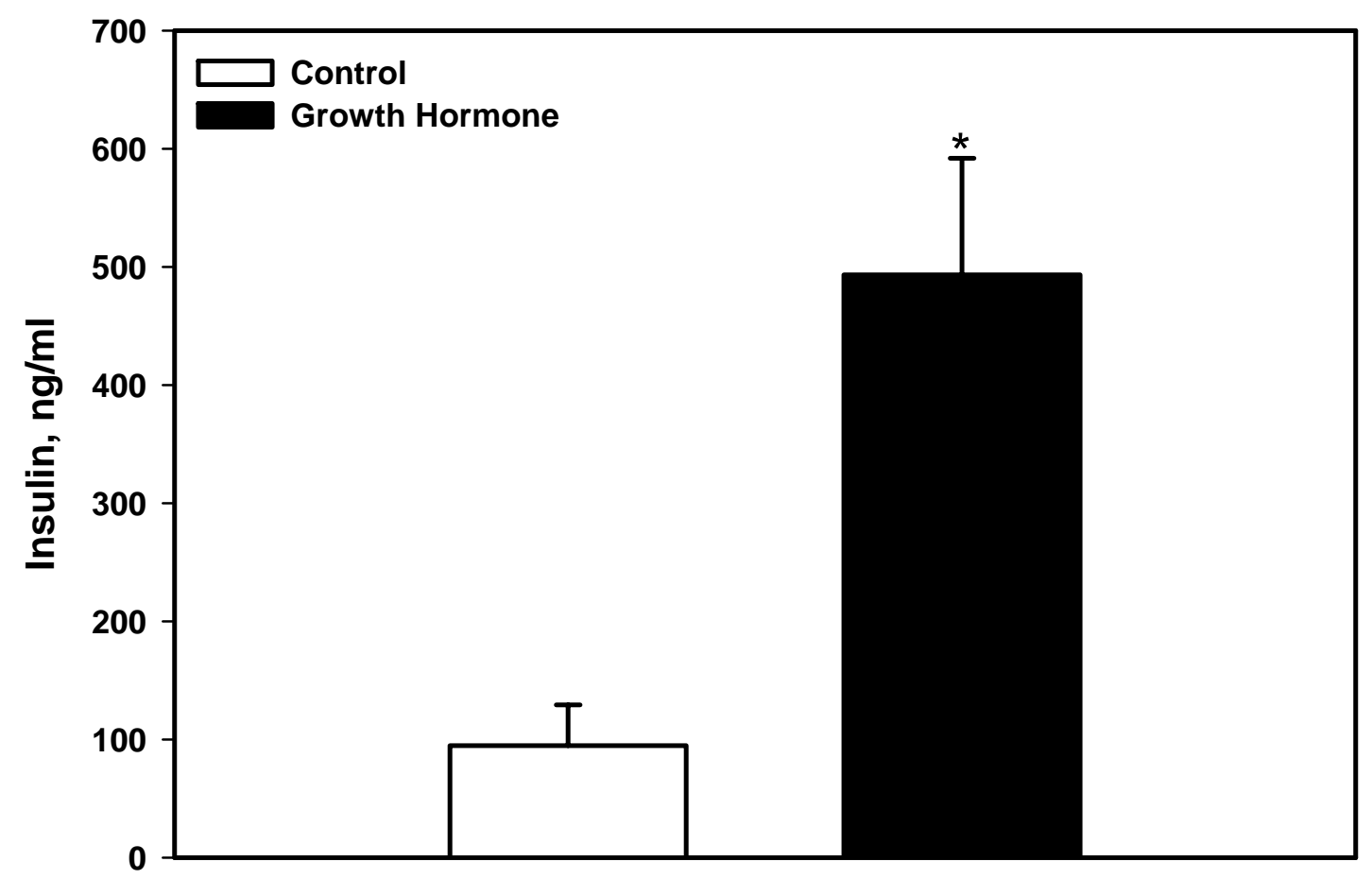

FIGURE 5. Maternal insulin concentration on day 6.5 of gestation in control ewes and those treated with a periconceptional $\mathrm{GH}$ injection. ${ }^{*}$ Indicates a treatment difference $p<0.05$. 


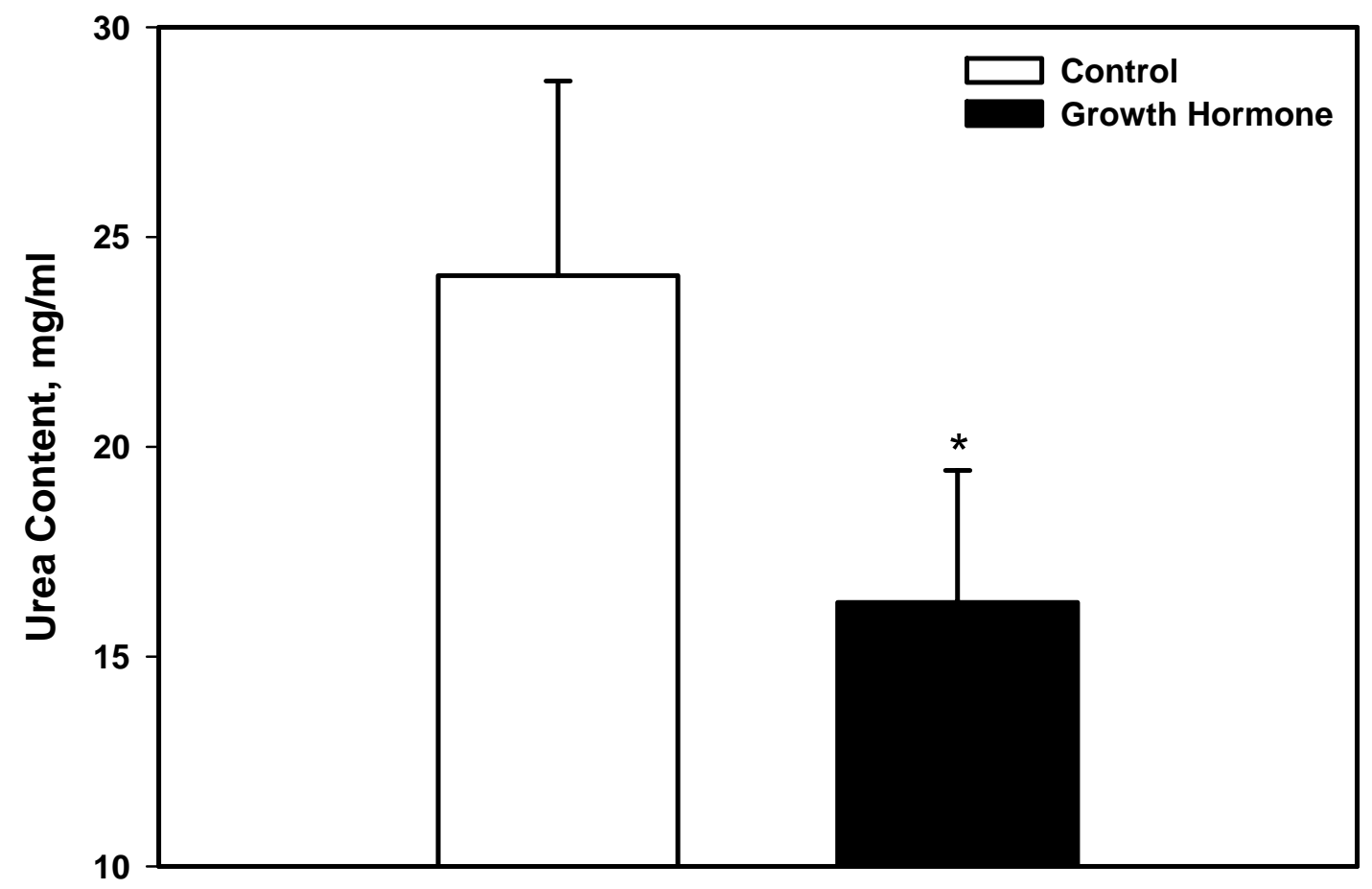

FIGURE 6. Uterine luminal urea content on day 6.5 of gestation in control ewes and those treated with a periconceptional GH injection. ${ }^{*}$ Indicates a treatment difference $p<0.05$. 


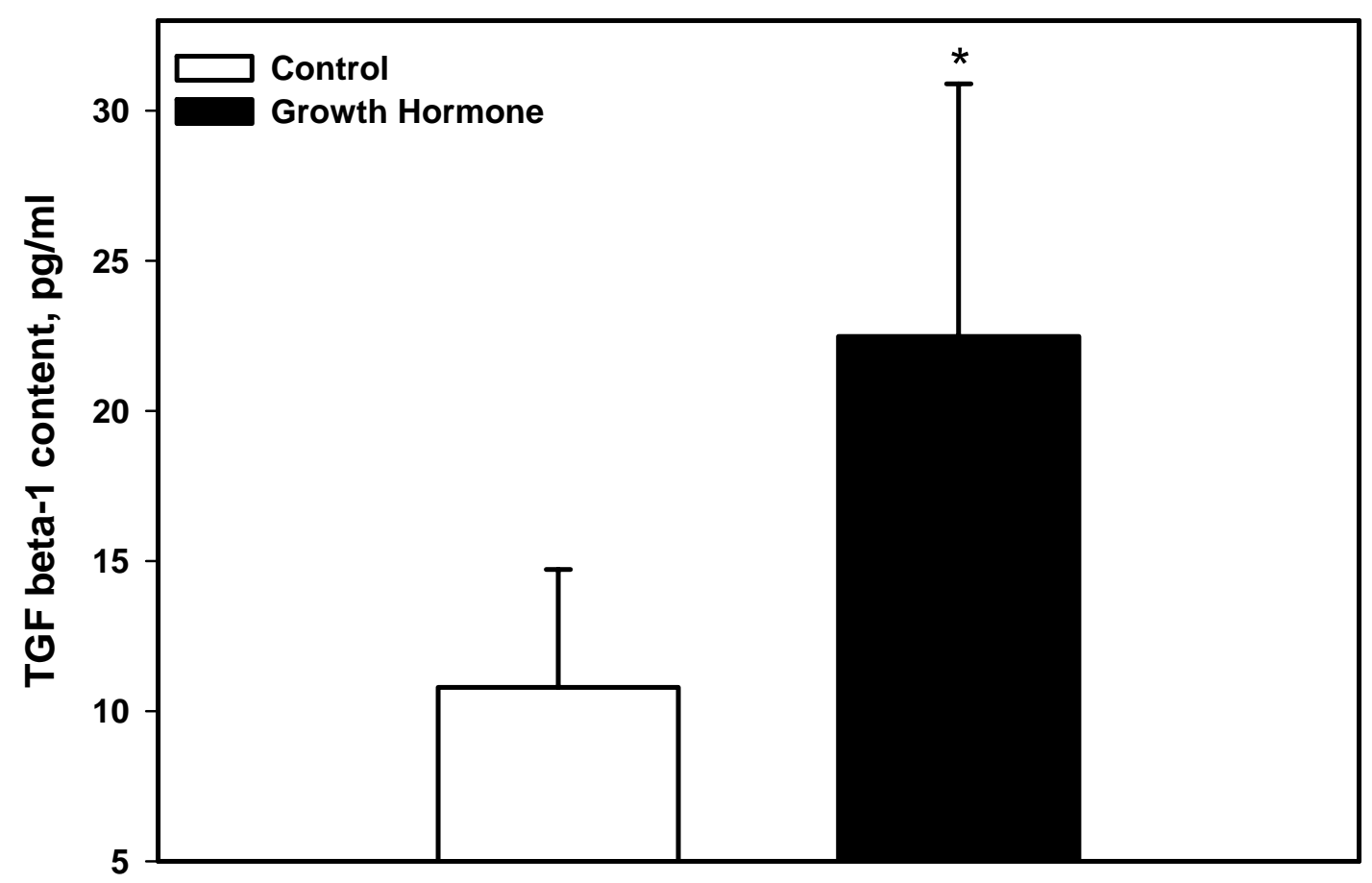

FIGURE 7. Uterine luminal TGFß-1 content on day 6.5 of gestation in control ewes and those treated with a periconceptional GH injection. ${ }^{*}$ Indicates a treatment difference of $p<0.05$. 


\section{Discussion}

The concentration of progesterone and insulin in the $\mathrm{GH}$ treated group were greater than the concentration observed in the control group. Progesterone administration is one tool used to study the impact of the uterine environment on embryonic development. Progesterone treatment during early pregnancy has been shown to increase both fetal mass and crown-rump length later in gestation. Fetal growth was increased in ewes exposed to progesterone from days 1-3, 3-6 or 1-6 of gestation (Kleemann et al., 1994). Progesterone treatment starting on day one had the greatest impact on fetal growth in that both fetal mass and crown-rump length increased (Kleemann et al., 1994).

Progesterone exposure on only days 3-6 increased fetal mass, but not to the extent of that observed when treatment was started on day one, and fetal crownrump length was not different (Kleeman et al., 1994). Embryos transferred into a recipient uterine environment on day 3 , which was previously primed by progesterone administration starting on days $1-3$, had approximately $7 \%$ greater fetal mass on day 76 compared to control fetuses (Kleemann et al., 1994). Day 3 embryos transferred to a more advanced uterine environment on (i.e., a day 6 uterine environment) for three days before being transferred back into their original uterine environment (i.e., now a day 6 ) were found to be $42 \%$ heavier at day 21 of gestation (Young et al., 1996). Maxfield et al. (1998) utilized the same transfer methods in which day three embryos were transferred to a uterine environment advanced by three days (i.e., day 6 environment), for three days, 
and then transferred back to a day six environment. The fetuses collected from this experiment had altered muscle development. While there was no difference in fetal weight or crown-rump length, those embryos transferred to an asynchronous environment had a greater number of muscle fibers compared tothose maintained in the synchronous environment (Maxfield et al., 1998). This indicates that only a small change in the embryonic environment, for a short time, can result in "fetal programming."

The observed elevation in progesterone concentrations in ewes treated with growth hormone may be explained by an increase in production of progesterone, a decrease in catabolism of progesterone or a combination of both. Recent studies in the ewe and dairy cow have shown an inverse relationship with insulin and progesterone catabolic enzymes. In this study growth hormone treatment resulted in increased peripheral concentrations of insulin and progesterone, those ewes treated with growth hormone probably had alterations in progesterone catabolism. Progesterone is converted into 21hydroxyporgesteron or 6ß-hydroxyprogesterone via hepatic cytochrome P450 2C and 3A, respectively (Murray 1991, 1992). Smith et al., (2006) found that anestrus ewes had decreased progesterone clearance when orally gavaged with propionate, a gluconeogenic substrate that stimulates insulin secretion in ruminants. Ewes supplemented with sodium propionate had elevated insulin concentrations and a 45\% reduction in hepatic cytochrome P450 $2 \mathrm{C}$ and $3 \mathrm{~A}$ activity at 1 hour after feeding compared to an energy control group (Lemley et al., 2008a). Progesterone catabolism may be altered acutely by a reduction in 
cytochrome P450 activity during hepatic exposure to elevated insulin

concentrations. Lemley et al., (2008b) found that dairy cows chronically exposed to a hyperinsulinemic-euglycemic clamp had a dose-dependent descrease in hepatic cytochrome P450 2C and 3A mRNA expression versus insulin dosage.

In the current experiment, no difference was observed in the total number of blastomeres or the trophectoderm to inner cell mass ratio even though lambs born to ewes treated with a periconceptional injection of $\mathrm{GH}$ are approximately 10\% larger at birth (Costine et al., 2005). It may not be surprising that no difference was found considering that progesterone treatment from days 1-3 advanced embryonic development as measured by the number of blastomeres per embryo on day 3 (Kleemann et al., 1994). In a similar study in which progesterone was administered from day 4-9 of gestation, no difference was found in conceptus development on day 10 (Ashworth and Bazer, 1989).

Histotrophic nutrients bathe the embryo in the uterus and consist of enzymes, growth factors, ions, cytokines, hormones, adhesion molecules and transport proteins (Spencer and Bazer, 2004; Aguilar and Reyley, 2005; Igwebuike, 2006). In this study, TGFß-1 was elevated in uterine flushings of ewes treated with a periconceptional injection of GH. Previously, our laboratory reported that periconceptional injection of GH increased IGF-I in a dose dependent manner on day 7 (Costine et al., 2005). Growth factors play an important role in embryonic and fetal growth and appear to be differentially secreted into a uterine environment from the time an embryo is a single cell through term (Watson et al., 1994). In particular, IGF-I is known to be the most 
important fetal growth promoter and is correlated with birth weight and crownrump length (Bauer et al., 1998). Further investigation into other growth factors that are secreted by the oviductal and uterine epithelium that are differentially expressed in response to a periconceptional GH injection may provide additional insight into what factors program embryonic cells leading to a more efficient placenta and larger lambs at birth.

In the current experiment, the concentration of urea was decreased in uterine flushing in those animals treated with a periconceptional injection of $\mathrm{GH}$. This finding may be a result of changes in amino acid metabolism. Growth hormone can stimulate the accretion of protein which would lead to a reduction in amino acid oxidation and overall less urea production. The increase in amino acid utilization may be from an increase in uterine gland secretion or production of other uterine proteins. While urea may not directly program the embryo, it may be correlated with a reduction in the overall amino acids in circulation and in uterine flushings. Unfortunately the methods used in this experiment to collect embryos diluted uterine flushings by $20 \mathrm{ml}$ and made it difficult to detect amino acids.

In conclusion, periconceptional GH administration appears to alter some aspects of uterine environment which may be mediated through an increase in maternal progesterone, but further investigation into changes in uterine environment following periconceptional GH treatment is required. The changes that were observed did not appear to alter embryonic growth as determined by total cell number or trophectoderm to inner cell mass ratio. Future studies should 
investigate the possible mechanisms in which programming of the embryo occurs leading to an increased placental efficiency and larger lambs at birth as a result of a single periconceptional growth hormone treatment. 


\section{References}

Aguilar, J, M Reyley. 2005. The uterine tubal fluid: secretion, composition and biological effects. Animal Reproduction. 2:91-105.

Ashworth, CJ, FW Bazer. 1989. Changes in ovine conceptus and endometrial function following asynchronous embryo transfer or administration of progesterone. Biology of Reproduction. 40:425-433.

Bauer, MK, JE Harding, NS Bassett, BH Breier, MH Oliver, BH Gallaher, PC Evans, SM Woodall, PD Gluckman. 1998. Fetal growth and placental function. Molecular and Cellular Endocrinology. 140:115-120.

Costine, BA, EK Inskeep, ME Wilson. 2005. Growth hormone at breeding modifies concetpus development and postnatal growth in sheep. Journal of Animal Science. 83:810-815.

Godfery, KM, DJP Barker. 2000. Foetal nutrition and adult disease. American Journal of Clinical Nutrition. 71:1344S-1352S.

Holaskova, I. 2007. I. Distribution of Transforming Growth Factor Beta 1, TGF receptor II and Decorin in the Sheep Uterus Shortly After Breeding II. Effect of TGF Beta 1 on Gene Expression in the Sheep Uterus at the Time of Embryo Attachment III. Concentration of TGF Beta 1, 2, and 3 in Beef Bull and Ram Seminal Plasma, Dissertation, West Virginia University.

Igwebuike, UM. 2006. Trophoblast cells of ruminant placentas-A minireview. Animal Reproduction Science. 93:185-198.Kleemann, DO, SK Walker, RF Seamark. Enhanced fetal growth in sheep administered progesterone during the first three days of pregnancy. Journal of Reproduction and Fertility. 102:411-417.

Lemley, CO, JM Koch, KP Blemings, KM Krause, ME Wilson. 2008a. Concomitant changes in progesterone catabolic enzymes, cytochrome P450 2C and 3A, with plasma insulin concentrations in ewes supplemented with sodium acetate or sodium propionate. Animal (In Press).

Lemley CO, ST Butler, WR Butler, ME Wilson. 2008b. Short communication: insulin alters hepatic progesterone catabolic enzymes, cytochrome P450 2C and 3A, in dairy cows. Journal of Dairy Science. 91:641-645.

Maxfield, EK, KD Sinclair, LD Dunne, PJ Broadbent, $\mu$ Robison, E Steward, DG Kyle, CA Maltin. 1998. Temporary exposure of ovine embryos to an advanced uterine environment does not affect fetal weight but alters fetal muscle development. Biology of Reproduction. 59:321-325. 
Moore, NW, JN Shelton. 1964. Egg transfer in sheep: Effect of degree of synchronization between donor and recipient, age of egg, and site of transfer on the survival of transferred eggs. Journal of Reproduction and Fertility. 7:145-152.

Murray, M. 1991. Microsomal cytochrome P450-dependent steroid metabolism in male sheep liver. Quantitative importance of 6ß-hydroxylation and evidence for the involvement of a P450 from the IIIA subfamily in the pathway. Journal of Steroid Biochemistry and Molecular Biology. 38:611619.

Murray, M. 1992. Participation of a cytochrome P450 enzyme from the 2C subfamily in progesterone 21-hydroxylation in sheep liver. Journal of Steroid Biochemistry and Molecular Biology. 43:591-593.

Rivera, RM, CR Youngs, SP Ford. 1996. A comparison of the number of inner cell mass and trophectoderm cells of preimplantation meishan and Yorkshire pig embryos at similar developmental states. Journal of Reproduction and Fertility. 106:111-116.

Rowson, LEA, RM Moor. 1966. Embryo transfer in the sheep: The significance of synchronizing oestrus in the donor and recipient animal. Journal of Reproduction and Fertility. 11:207-212.

Sheffel, CE, BR Pratt, WL Ferrell, EK Inskeep. 1982. Induced corpora lutea in the postpartum beef cow. II. Effects of treatment with progestogen and gonadotropins. Journal of Animal Science. 54:830-836.

Smith, DL, BM Stinefelt, KP Blemings, ME Wilson. 2006. Diet-induced alterations in progesterone clearance appear to be mediated by insulin signaling in hepatocytes. Journal of Animal Science. 84:1102-1109.

Spencer, TE, FW Bazer. 2004. Uterine and placental factors regulating conceptus growth in domestic animals. Journal of Animal Science Suppl. 82:E4-E13.

Watson, AJ, PH Watson, M Arcellanal-Panlilio, D Warnes, SK Walker, GA Schultz, DT Armstrong, RF Seamark. 1994. A Growth phenotype map for ovine preimplantation and development. Biology of Reproduction. 50:725733.

Young, LE, SC Butterwith, I Wilmut. 1996. Increased ovine foetal weight following transient asynchronous embryo transfer is not associated with increased placental weight at day 21 of gestation. Theriogenology. 45:231. 


\title{
Periconceptional Growth Hormone Treatment Alters the Expression of Nutrient Transporters in the Ovine Placenta
}

\author{
J. M. Koch ${ }^{1}$, K. P. Blemings ${ }^{1}$, M. E. Wilson ${ }^{1,2}$ \\ ${ }^{1}$ Division of Animal and Nutritional Sciences, Davis College of Agriculture, \\ Forestry and Consumer Sciences, West Virginia University, Morgantown, West \\ Virginia, USA
}

This work is published with the approval of the Director of West Virginia Agriculture and Forestry Experiment Station as scientific paper XXXXXX. This project was supported by Hatch project 468 (NE 1007) and a West Virginia University Faculty Senate Research Grant

${ }^{3}$ Correspondence: G048 Agricultural Sciences Building (phone: (304) 293-2406 ext. 4425; fax: (304) 293-2232; email: mwilso25@wvu.edu) 


\section{Abstract}

Fetal growth is limited by the ability of the placenta to provide the proper nutrients required for growth, including glucose, which is the primary source of energy and amino acids which are required for protein accretion. These nutrients move from maternal circulation to fetal circulation by a variety of nutrient transporters. We have demonstrated that sustained release growth hormone $(\mathrm{GH})$ given to ewes at breeding increases placental efficiency and birth weight. The objective of this experiment was to determine if $\mathrm{GH}$ at breeding alters the expression of placental nutrient transporters, including glucose transporters (GLUT)-1 and -3, as well as amino acid transporters EAAT-1, EAAT-3, LAT-1, LAT-2, CAT-1 and SNAT-2. Ewes were mated at estrus and half of the ewes were given $500 \mathrm{mg}$ of sustained release $\mathrm{GH}$ at the time of breeding. On days 80 and 140 of gestation an umbilical blood sample and cotyledonary tissue were collected. The RNA from cotyledonary tissue was extracted and used to determine the expression of nutrient transporters by real-time RT-PCR. Treatment with GH did not alter the expression of GLUT-1 or GLUT-3; however, GLUT-3 expression increased from day 80 to 140 of gestation. There was a treatment by day interaction for both EAAT-1 and EAAT-3. Expression in the controls increased from day 80 to 140 of gestation, but those in the $\mathrm{GH}$ group had similar expression on day 80 and 140 of gestation which was similar to controls on day 140. Treatment did not alter the expression of LAT-2, CAT-1 and SNAT-2, however, expression increased from day 80 to 140 of gestation. There 
was no effect of treatment or day on the expression of LAT-1. A positive correlation was observed between fetal size as measured by fetal weight, with GLUT-3, EAAT-3 and SNAT-2. A positive correlation was also observed between crown-rump length, and EAAT-3 and LAT-1. The increase in live weight observed in lambs born to ewes treated with $\mathrm{GH}$ at breeding may be a result of increased uptake of amino acids transported by EAAT's from maternal circulation, which are essential for protein accretion. This may be one reason why lambs born to ewes treated with growth hormone are larger at birth.

Key Words: Growth Hormone, Glucose Transporters, Amino Acid Transporters 


\section{Introduction}

Nutrients need to be delivered in sufficient supply to the developing fetus in a timely fashion for proper growth and development. In the last third of gestation, a period in which fetal growth increases exponentially, limiting fetal nutrient availability has been directly linked to intrauterine growth restriction and long term alterations in organ function. Until recently, investigators have suggested that limiting nutrient availability was the cause of fetal growth restriction; however, some have argued that if the number of transporters are limited, no matter what the nutrient availability, intrauterine growth restriction occurs (Jansson et al., 2006). Therefore, the efficiency of the placenta may play a major role in the developmental potential of the fetus.

Nutrients, including glucose and amino acids, are shuttled from maternal to fetal circulation by specific transporters. Both GLUT-1 and GLUT-3 are present in placental tissue and expression increases for both transporters until about mid gestation, but GLUT-3 expression continues to increase till term (Currie et al., 1997; Ehrhardt and Bell, 1997). Several amino acid transporter families have been identified in placental tissue; including those in the A, ASC, $\mathrm{B}^{0}, \mathrm{X}_{\mathrm{AG}}^{-}, \mathrm{b}^{0,+}, \mathrm{L}$ and $\mathrm{y}^{+}$. These systems work together to transport amino acids across epithelial layers of both the maternal and fetal placenta.

Previously, our laboratory demonstrated that growth hormone $(\mathrm{GH})$ administered at breeding alters both fetal and placental growth (Costine et al., 2005). Lambs are at least $10 \%$ heavier at birth and the weight difference is 
maintained when reared as singles. The placental growth pattern in $\mathrm{GH}$ treated ewes is dramatically altered in that placental growth does not plateau at midgestation but instead growth is linear. As a result of this altered growth pattern placentae of in the growth hormone group are more efficient (fetal weight/ chorioallantoic weight) compared to controls (Costine et al., 2005). Therefore the objective of the current experiment was to determine if $\mathrm{GH}$ treatment at the time of breeding alters the expression of nutrient transporters in cotyledonary tissue.

\section{Materials and Methods}

Ewes, of mixed breeding, from the West Virginia University farm were used for the experiment. All procedures were approved by the West Virginia University Animal Care and Use Committee (03-1012).

The cotyledonary tissue and fetal samples utilized in this experiment were collected previously by Costine et al. (2005). Briefly, ewes were randomly assigned to either a control group or a $\mathrm{GH}$ treated group. The $\mathrm{GH}$ treated group received a single $500 \mathrm{mg}$ injection of sustained release recombinant bovine $\mathrm{GH}$ subcutaneously (Posilac; Monstanto, St. Louis, MO) at the time of mating. On day 80 or 140 of gestation dams were euthanized with a lethal injection of sodium pentobarbital (Sigma; St. Louis, MO) and the pregnant uterus was removed. The fetuses were removed from the uterus and fetal body weight and crown-rump length were determined (Costine et al., 2005). Cotyledons were 
physically removed from caruncular tissue. The cotyledonary tissue was snap frozen and stored at $-80^{\circ} \mathrm{C}$ until further analysis.

\section{Real-Time RT PCR}

Placental RNA was extracted using TRIzol as described by Koch et al. (2007). This procedure includes two back extractions against acid phenol:chloroform (5:1; $\mathrm{pH}=4.5$; Ambion, Austin, TX) followed by two back extractions against phenol:chloroform: isoamyl alcohol $(25: 24: 1 ; \mathrm{pH}=6.6)$ to remove additional proteins, DNA and lipids. The RNA was reconstituted in $30 \mu \mathrm{l}$ of nuclease free water and the concentration was determined spectrophotometrically at $260 \mathrm{~nm}$. The quality of RNA was determined by the appearance of bands corresponding to $28 \mathrm{~S}$ and $18 \mathrm{~S}$ rRNA and a distribution of mRNA of high molecular weight on a $3 \%$ agarose gel with ethidium bromide. Complementary DNA (cDNA) was synthesized from $2 \mu \mathrm{g}$ of RNA which was reverse transcribed using random hexamers and Moloney Murine Leukaemia Virus reverse transcriptase (Promega, Madison, WI). Real-Time RT PCR (iCycler, Bio-Rad Laboratories, Hercules, CA) was utilized to quantify the abundance of cDNA as previously described (Koch et al., 2007). Primers specific for all nutrient transporters and the control gene, acidic ribosomal protein, (FOR: CAACCCAGCTCTGGAGAAAC; REV: GTGAGGTCCTCCTTGGTGAA with 100\% efficiency) were designed using Biology Work Bench (http://workbench.sdsc.edu/) and synthesized (Table 4; Integrated Diagnostics Systems, Coralville, IA). All primer sets were optimized (all reactions were annealed at $58.7^{\circ} \mathrm{C}$ ) using a pooled RNA sample which was created by combining RNA from both treatment groups. The efficiency (E) of 


\begin{tabular}{|c|c|c|c|c|}
\hline Gene & $\begin{array}{l}\text { System } \\
\text { Name }\end{array}$ & $\begin{array}{l}\text { Substance } \\
\text { Transported }\end{array}$ & Primer Sequence & Efficiency \\
\hline \multirow{2}{*}{$\begin{array}{l}\text { EAAT-1 } \\
\text { (SLC1A3) }\end{array}$} & \multirow[t]{2}{*}{$\mathrm{X}_{\mathrm{AG}}{ }^{-}$} & \multirow{2}{*}{$\begin{array}{c}\text { Anionic Amino } \\
\text { Acids (GLU, } \\
\text { ASP) }\end{array}$} & FOR: TTTTTATCGGAGGGTTGCTG & \multirow[t]{2}{*}{$82 \%$} \\
\hline & & & REV: ATCTGGTAACGCGTTTGTCC & \\
\hline \multirow{2}{*}{$\begin{array}{l}\text { EAAT-3 } \\
\text { (SLC1A1) }\end{array}$} & \multirow[t]{2}{*}{$\mathrm{X}_{\mathrm{AG}} \mathrm{B}^{-}$} & \multirow{2}{*}{$\begin{array}{c}\text { Anionic Amino } \\
\text { Acids (GLU, } \\
\text { ASP) }\end{array}$} & FOR: GGCTTACTCTCTGGTGGCTG & \multirow[t]{2}{*}{$87 \%$} \\
\hline & & & REV: TGCTGCTCACCAACTCATTC & \\
\hline \multirow{2}{*}{$\begin{array}{c}\text { LAT-1 } \\
\text { (SLC7A5) }\end{array}$} & \multirow[t]{2}{*}{$\mathrm{L}$} & \multirow{2}{*}{$\begin{array}{l}\text { Neutral Amino } \\
\text { Acids (LEU, } \\
\text { ILE, VAL, TYR, } \\
\text { PHE, MET) }\end{array}$} & FOR: TACTTCCTTGGGGTCTGGTG & \multirow[t]{2}{*}{$99 \%$} \\
\hline & & & REV: TCTGGTCGCTTACGTCTCCT & \\
\hline \multirow{2}{*}{$\begin{array}{c}\text { LAT-2 } \\
\text { (SLC7A8) }\end{array}$} & \multirow[t]{2}{*}{ L } & \multirow{2}{*}{$\begin{array}{l}\text { Neutral Amino } \\
\text { Acids (LEU, } \\
\text { ILE, VAL, TYR, } \\
\text { PHE, MET) }\end{array}$} & FOR: CACCAGCGACATATACACGC & \multirow[t]{2}{*}{$83 \%$} \\
\hline & & & REV: CTTAATGGGGCGATTGATGT & \\
\hline \multirow{2}{*}{$\begin{array}{c}\text { CAT-1 } \\
\text { (SLC7A1) }\end{array}$} & \multirow[t]{2}{*}{$y^{+}$} & \multirow{2}{*}{$\begin{array}{c}\text { Cationic Amino } \\
\text { Acids }\end{array}$} & FOR: TCAACCAGCCTCCTAGCACT & \multirow[t]{2}{*}{$97 \%$} \\
\hline & & & REV: AGGCAGAGCCCATGAGTAGA & \\
\hline \multirow{2}{*}{$\begin{array}{l}\text { SNAT-2 } \\
(\text { SLC38A2) }\end{array}$} & \multirow[t]{2}{*}{ A } & \multirow{2}{*}{$\begin{array}{c}\text { Neutral Amino } \\
\text { Acids (ALA, } \\
\text { SER, PRO, } \\
\text { GLN) }\end{array}$} & FOR: AGTGCTCCATTGGGTGAAAC & \multirow[t]{2}{*}{$95 \%$} \\
\hline & & & REV: CCGTCTTCTCACTGCCTTTC & \\
\hline \multirow{2}{*}{$\begin{array}{c}\text { GLUT-1 } \\
\text { (SLC2A1) }\end{array}$} & \multirow{2}{*}{\multicolumn{2}{|c|}{ Glucose }} & FOR: AACTGTGCGGACCCTATGTC & \multirow[t]{2}{*}{$102 \%$} \\
\hline & & & REV: GTCACTTTGGCTTGCTCCTC & \\
\hline \multirow{2}{*}{$\begin{array}{l}\text { GLUT-3 } \\
\text { (SLC2A3) }\end{array}$} & \multirow{2}{*}{\multicolumn{2}{|c|}{ Glucose }} & FOR: CTGAGATGGAGGGATTGCAT & \multirow[t]{2}{*}{$91 \%$} \\
\hline & & & REV: TGAAGAGCCCAGTCTCCACT & \\
\hline
\end{tabular}

TABLE 4. Nutrient transporter primer sequences and the efficiency for each primer set. 
each primer set was determined utilizing this pool prior to assaying any samples, and was used to standardize the target gene ratio. The efficiency of amplification was determined by raising 10 to the power of (-1/slope), for which the slope was obtained by plotting the log of the concentration of cDNA against the critical threshold (Ct) values (Koch et al., 2007).

The PCR reaction contained $25 \mu \mathrm{l}$ of iQ SYBR green supermix (Bio-Rad Laboratories), $2 \mu \mathrm{l}$ of cDNA diluted to $1: 2$, and $3 \mu \mathrm{l}$ each of $5 \mu \mathrm{M}$ forward and reverse primer and $17 \mu \mathrm{l}$ of water to reach a final reaction volume of $50 \mu \mathrm{l}$ for GLUT-1, GLUT-2, LAT-2, EAAT-1 and EAAT-3 or $3 \mu \mathrm{l}$ of cDNA diluted 1:2 and 3 $\mu \mathrm{l}$ each of $5 \mu \mathrm{M}$ forward and reverse primer and $16 \mu \mathrm{l}$ of water to reach a final reaction volume of $50 \mu \mathrm{l}$ for CAT-1, SNAT-2 and LAT-1. A single product per amplification was determined by examining both the melting curve and by a $1.5 \%$ agarose gel with ethidium bromide. The expression of each gene is reported as

a ratio (ratio $\left.=\left[\mathrm{E}^{\Delta \mathrm{Ct} \text { target gene (pool-sample) }} / \mathrm{E}^{\Delta \mathrm{Ct} \text { control gene (pool-sample) }}\right]\right)$ which was previously described by Koch et al. (2007).

\section{Statistical Analysis}

The main effect of growth hormone treatment, day and the treatment by day interaction on the cotyledonary expression of GLUT-1, GLUT-3, EAAT-1, EAAT-3, LAT-1, LAT-2, CAT-1, SNAT-2 was analyzed by analysis of variance, utilizing the general linear models procedure in SAS. The correlation between 
nutrient transporters, body weight and crown-rump length of the fetus were determined using the correlation procedures of SAS.

\section{Results}

Periconceptional treatment of ewes with $\mathrm{GH}$ did not alter the expression of either GLUT-1 or GLUT-3 $(0.52 \pm 0.08 ; 0.78 \pm 0.11)$ in the placenta. However, expression of GLUT-3 was greater $(p<0.05)$ on day 140 compared to day 80 (Figure 7).

Periconceptional treatment of ewes with GH altered the expression of EAAT-1 and EAAT-3. The expression of EAAT-1 increased $(p<0.05)$ in the control group from day 80 to 140 of gestation. However, the GH treated group had similar expression on day 80 and 140 of gestation, which was similar to the expression of the control group on day 140 (Figure 8). A similar pattern of expression was observed for EAAT-3 in that expression in the control group was greater $(p<0.05)$ on day 140 than day 80 . However, the GH group had an elevated expression on day 80 compared to the controls and maintained the same level of expression on day 140 (Figure 9).

Expression of the other amino acid transporters that were studied including CAT-1, SNAT-2 and LAT-2 were not affected by GH treatment, but had an increase $(p<0.05)$ in expression from day 80 to day 140 (Figure 10, 11, and 12). The expression of LAT-1 was not affected by treatment or day $(1.18 \pm 0.09)$. 
A positive correlation between fetal weight and GLUT-3 $(r=0.49, p<$ 0.05), EAAT-3 $(r=0.49, p<0.05)$ and SNAT-2 $(r=0.41, p<0.05)$ was observed. Similarly a positive correlation was detected between crown-rump length and EAAT-3 $(r=0.35, p<0.05)$ and LAT-1 $(r=0.38, p<0.05)$. 


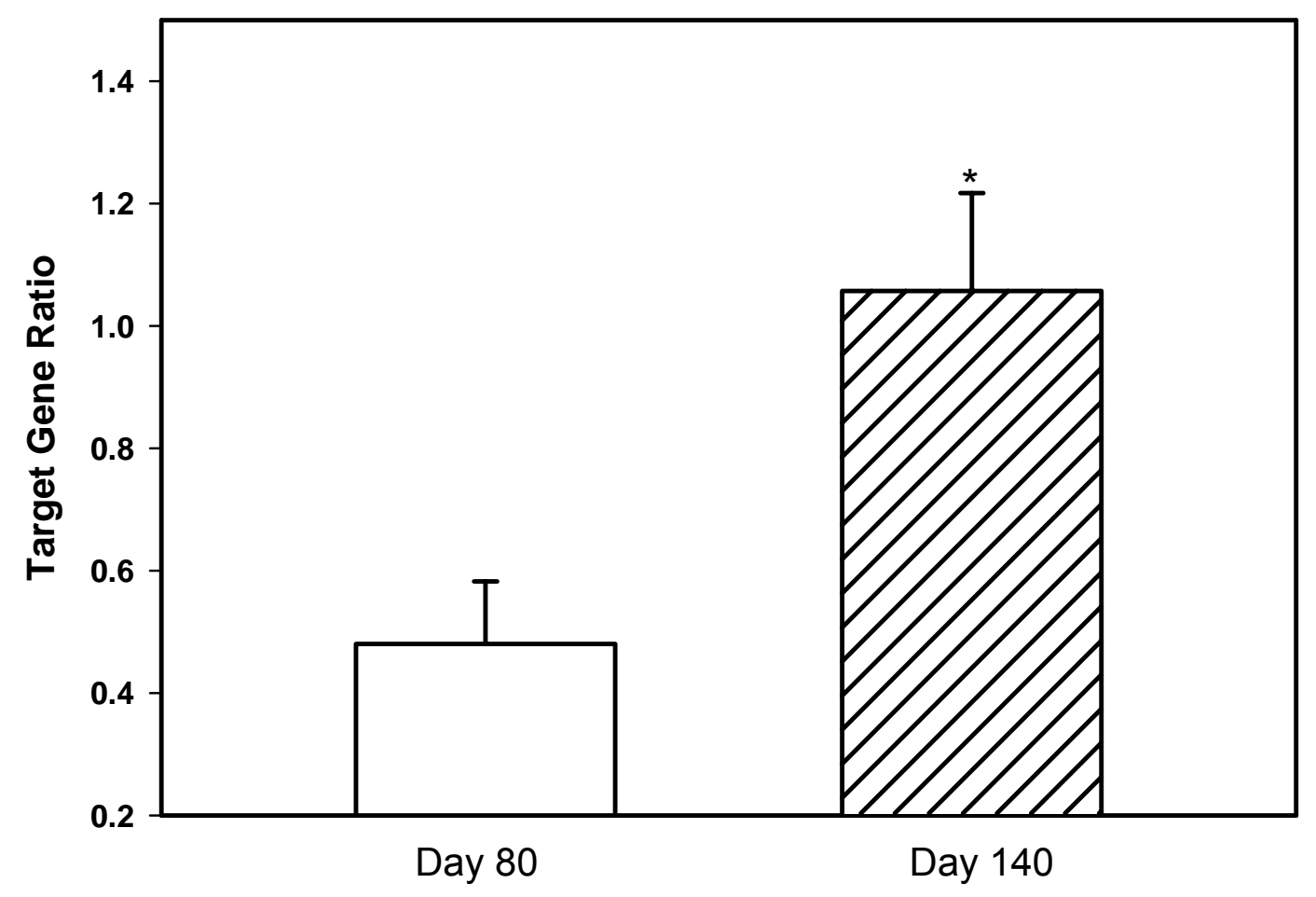

FIGURE 8. The expression of GLUT-3 in cotyledonary tissue collected on day 80 and 140 of gestation. ${ }^{*}$ Indicates a difference between days $(p<0.05)$. 


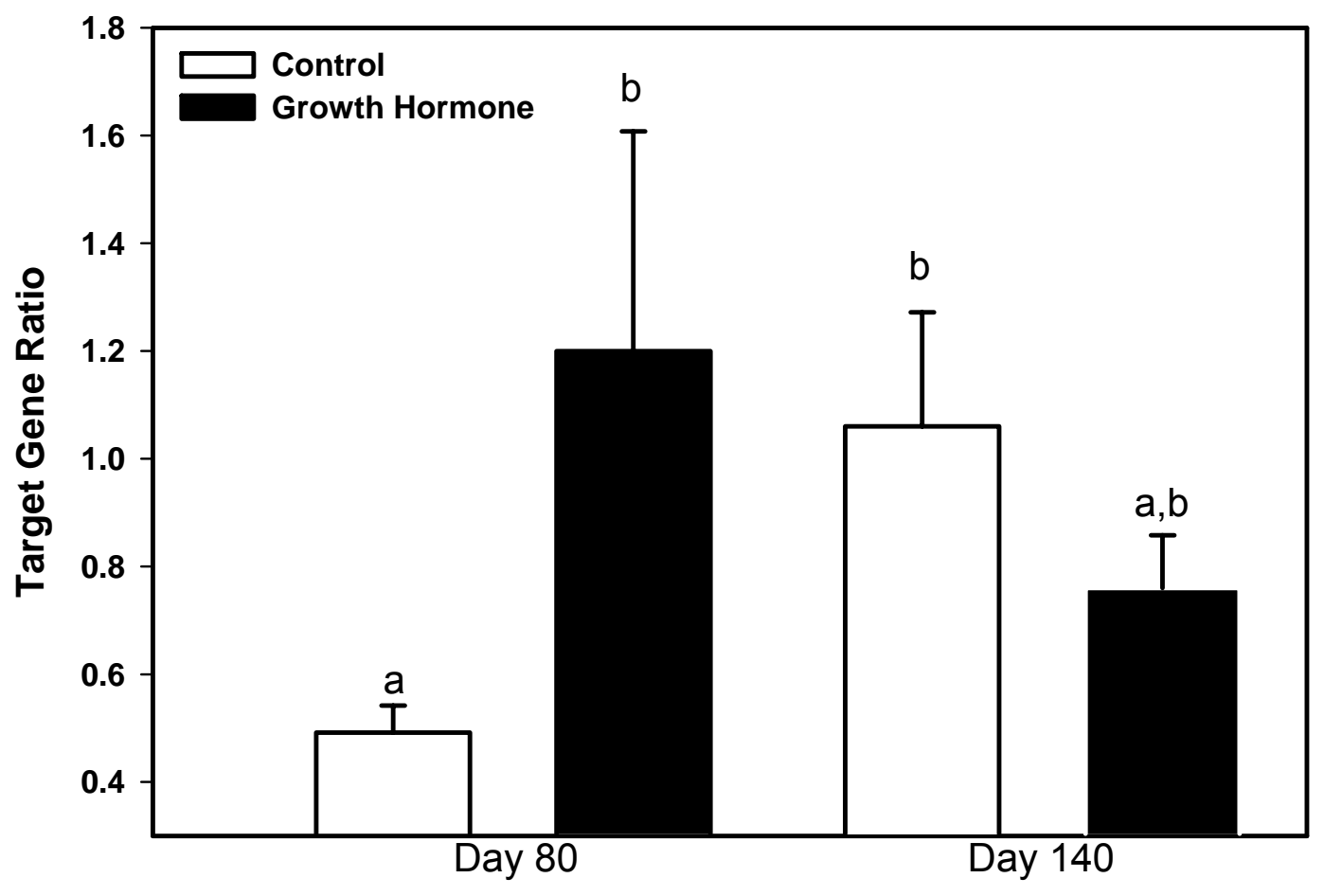

Figure 9. Expression of EAAT-1 in cotyledonary tissue collected on day 80 and 140 of gestation from conceptuses gestated by control ewes or ewes treated with sustained release growth hormone at breeding. Means with different letters differ $(p<0.05)$. 


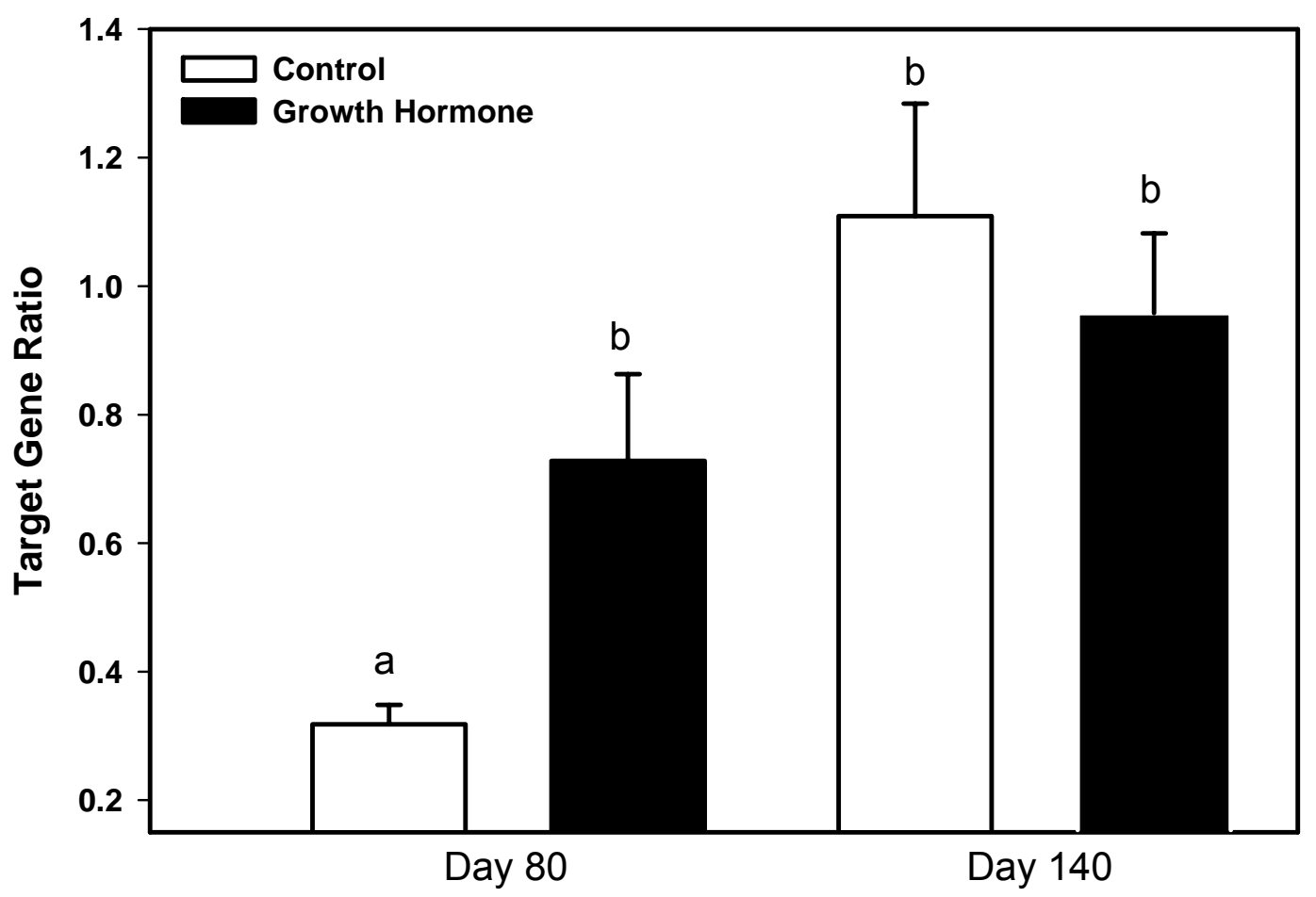

Figure 10. Expression of EAAT-3 in cotyledonary tissue collected on day 80 and 140 of gestation from conceptuses gestated by control ewes or ewes treated with sustained release growth hormone at breeding. Means with different letters differ $(p<0.05)$. 


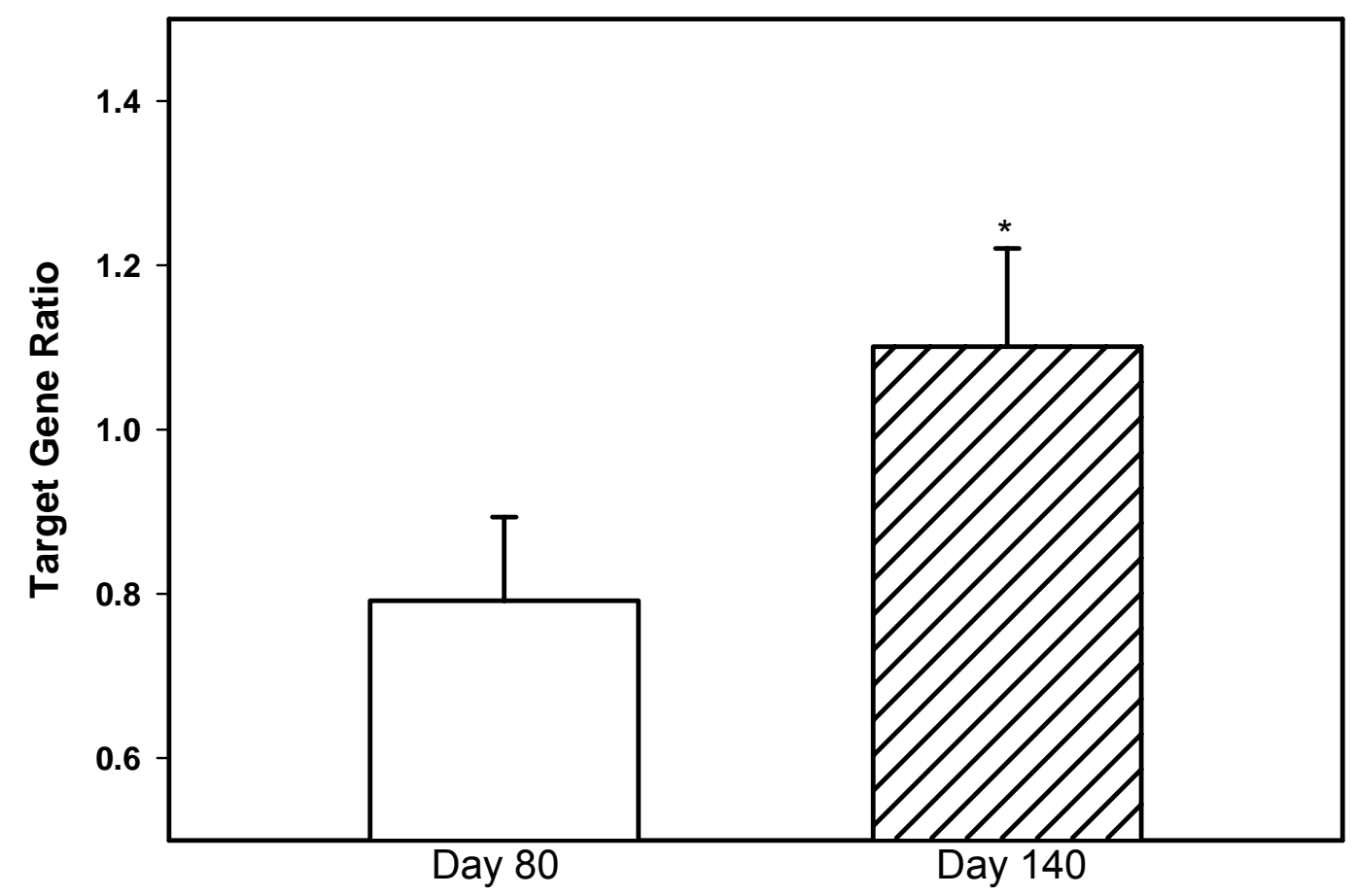

Figure 11. The expression of CAT-1 in cotyledonary tissue collected on day 80 and 140 of gestation. ${ }^{*}$ Indicates a difference between days $(p<0.05)$. 


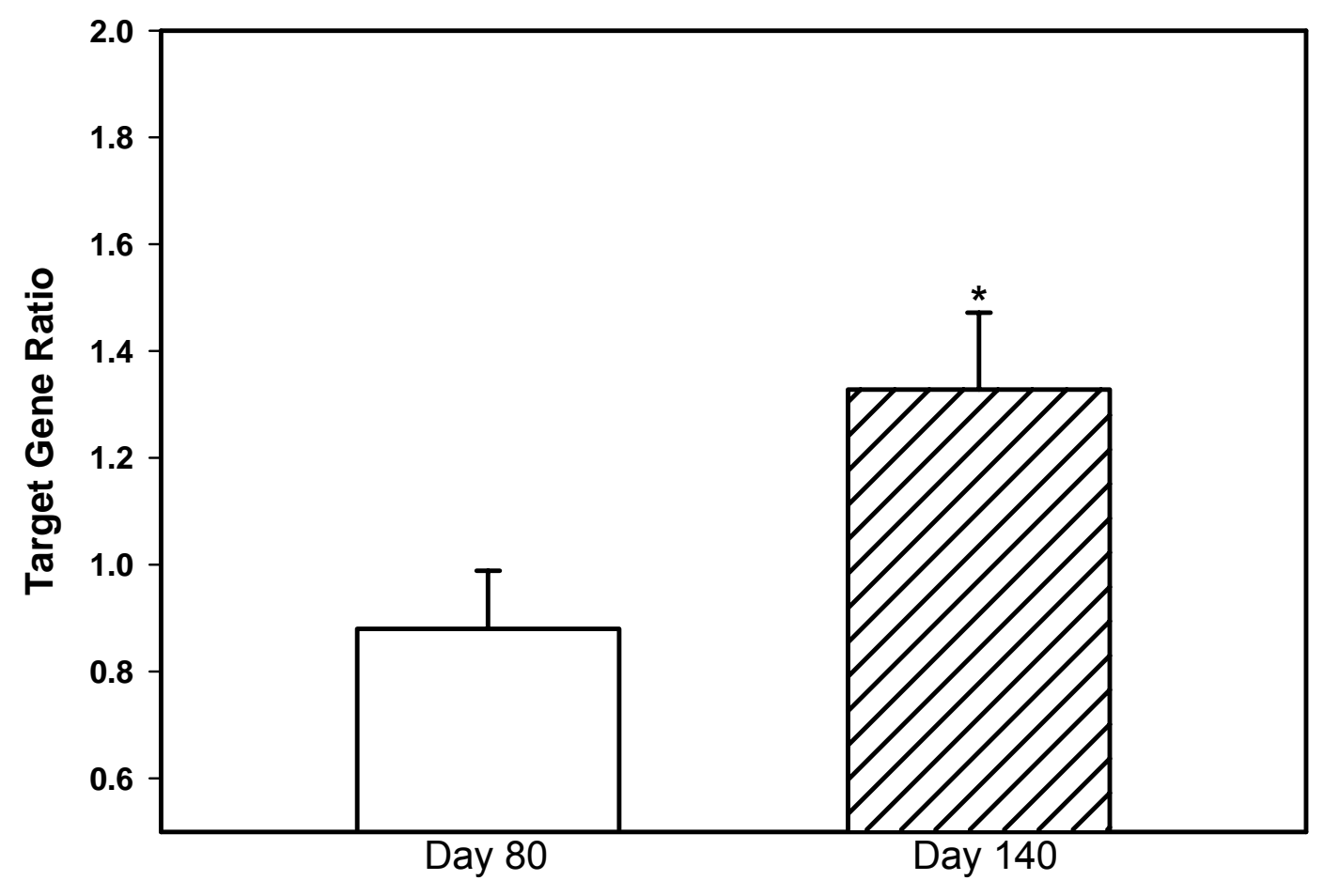

Figure 12. The expression of SNAT-2 in cotyledonary tissue collected on day 80 and 140 of gestation. ${ }^{*}$ Indicates a difference between days $(p<.05)$. 


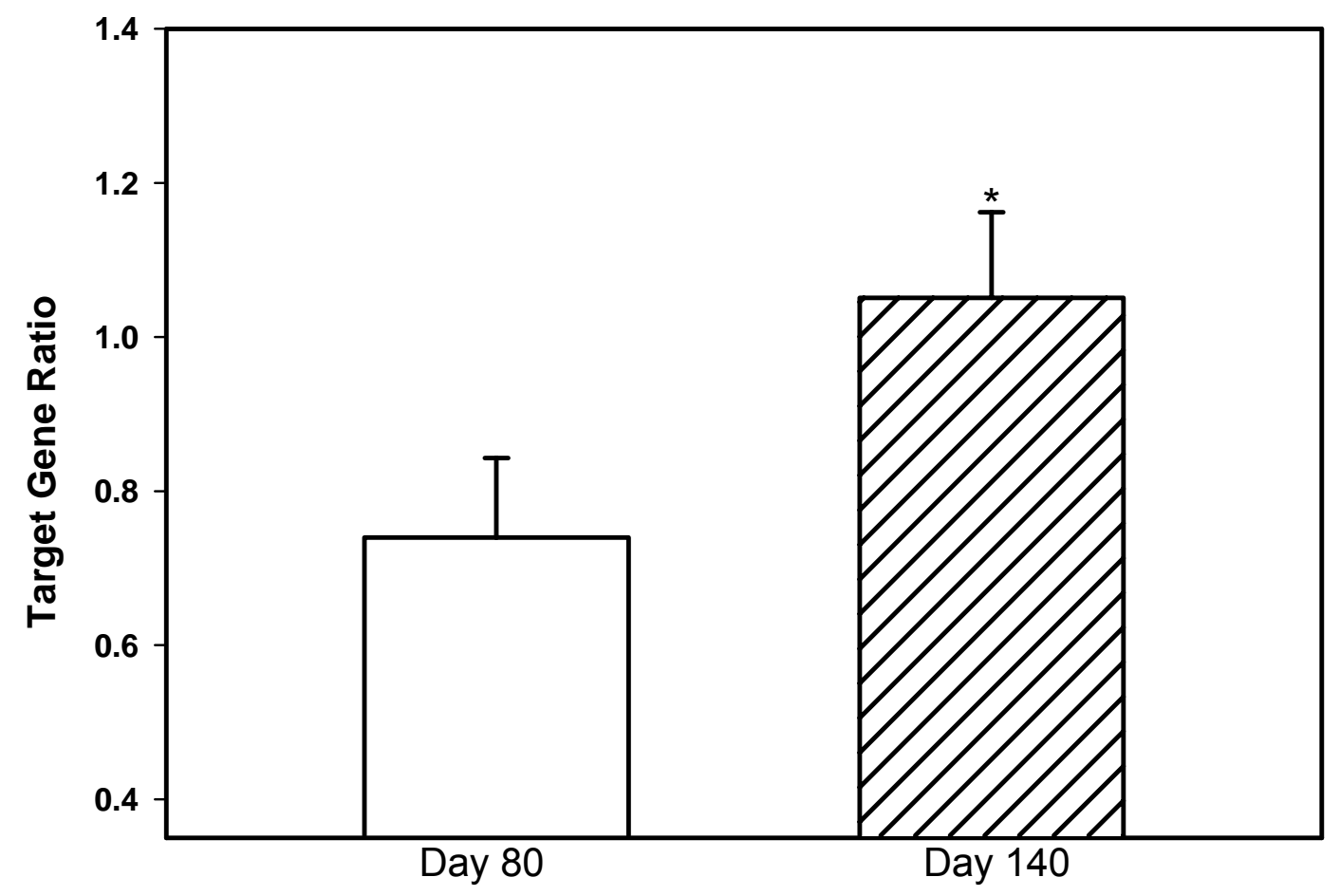

Figure 13. The expression of LAT-2 in cotyledonary tissue collected on day 80 and 140 of gestation. ${ }^{*}$ Indicates a difference between days $(p<0.05)$. 


\section{Discussion}

Cotyledonary expression of GLUT-3 increased from day 80 to 140 of gestation and was positively correlated with fetal weight. However, no difference in the expression of GLUT-1 was observed in this experiment. Glucose is essential to the fetus because it is the primary substrate for fetal energy and metabolism and is passively transferred from maternal circulation to the fetal circulation by a concentration-dependent mechanism via sodium independent transporters GLUT-1 and GLUT-3 (Robertson and Karp, 1976; Jansson et al., 1993; Bell et al. 1999; Limesand et al., 2004; Wooding et al., 2005).

The increase in GLUT-3 mRNA expression with an increase in gestational age observed in this experiment is similar to previous data in which total placental mRNA expression continued to increase as the day of gestation increased (Currie et al., 1997; Ehrhardt and Bell, 1997). The expression of GLUT-1 in this experiment is similar to the expression data observed by Currie and coworkers (1997) in which GLUT-1 expression did not increase between day 60 and 140 of gestation. However, Ehrhardt and Bell (1997) using twin pregnancy and northern blotting, reported an increase in GLUT-1 expression from day 75 to 140 . The magnitude of change in GLUT-1 expression observed by Ehrhardt and Bell (1997) was relatively small (1.8 times), compared to the change in GLUT-3 expression (3.9 times). Data available on for GLUT-1 expression is not consistent and may vary because of fetal number or the methodology used to determine expression. 
The majority of information available on amino acid transporters in the placenta comes from human studies and has been reviewed in great detail (Roberston et al., 1976; McGivan and Pastor-Anglada, 1994; Jansson, 2001; Kudo and Boyd, 2001; Regnault). However, what information is available on amino acid transport in the sheep is limited to uptake of nonmetabolizable amino acids, or amino acid flux into fetal circulation, from chronically instrumented fetuses, and not on transporter expression or location (Lemons et al., 1976; Jozwik et al., 2004; Vrijer Kwon et al., 2004; et al., 2004).

Nutrients have to be in sufficient supply and delivered to the developing fetus in a timely fashion for proper growth and development. In the last third of gestation, a period in which fetal growth increases exponentially limiting fetal nutrient availability, has been directly linked to intrauterine growth restriction and long term alterations in organ function. The mechanisms by which this occurs includes a decrease in maternally derived nutrients or insufficient transport of nutrients across the placenta (Barker 1995; Ravelli et al. 1999; Godfrey \& Barker 2000; Jensen et al. 2002; Armitage et al. 2004; Wu et al. 2004; Wallace et al. 2005; Wu et al. 2006). Until recently, investigators have suggested that limiting nutrient availability was the cause of fetal growth restriction; however, recent evidence suggests that if the number of transporters is limited, no matter what the nutrient availability is, intrauterine growth restriction occurs (Jansson et al., 2006).

Cotyledonary expression for both EAAT- 1 and EAAT-3 was affected by treatment and day. The expression for both EAAT-1 and EAAT-3 increased from 
day 80 to 140 of gestation in the control group. However, $\mathrm{GH}$ treatment led to an increased expression of both transporters on day 80 of gestation, which was similar to the expression observed on day 140. The elevated expression observed on day 80 of gestation in the growth hormone group may be just one reason why lambs are larger at birth. This information further supports the concept that growth hormone alters placental efficiency. As previously reported, placental efficiency as measured by fetal weight divided by chorioallantoic weight is greater on day 80 of gestation in ewes that were treated with growth hormone at breeding (Costine et al., 2005). The increase in EAAT-1 and EAAT-3 on day 80 , which is similar the level of expression on day 140 in the controls, may be just one mechanism by which these placentas are capable of transporting more nutrients compared to control placenta and therefore more efficient.

Cotyledonary expression of CAT-1, SNAT-2, LAT-1 and LAT-2 were not altered by growth hormone treatment at breeding. However, expression of all of the transporters, except LAT-1, increased from day 80 to 140 of gestation. This observation is not surprising in that as fetal growth rate increases the amount of nutrients required to support growth increases as well. Therefore, an increase in transporter number may occur just to meet fetal nutrient demands.

In conclusion, growth hormone treatment at breeding increases cotyledonary expression of EAAT-1 and EAAT-3 in the sheep at midgestation, which is maintained throughout the rest of gestation. While this is only one transporter, it may give further insight into a possible mechanism by which 
growth hormone treatment to the ewe at breeding leads to a more efficient placenta during gestation and therefore, larger lambs at birth. 


\section{References}

Armitage, JA, YK Imran, PD Taylor, PW Nathanielsz, L Poston. 2004.

Developmental programming of the metabolic syndrome by maternal nutritional imbalance: how strong is the evidence from experimental models in mammals. Journal of Physiology. 561:355-377.

Bell, AW, WW Hay Jr., RA Ehrhardt. 1999. Placental transport of nutrients and its implications for fetal growth. Journal of Reproduction and Fertility Supplement. 54:401-410.

Costine, BA, EK Inskeep, ME Wilson. 2005. Growth hormone at breeding modifies concetpus development and postnatal growth in sheep. Journal of Animal Science. 83:810-815.

Currie, MJ, NS Bassett, PD Gluckman. 1997. Ovine glucose transporter-1 and-3: cDNA partical sequences and developmental gene expression in the placenta. Placenta. 18:393-401.

Ehrhardt, RA, AW Bell. 1997. Developmental increases in glucose transporter concentration in sheep placenta. American Journal of Physiology. 273:R1132-R1141.

Godfery, KM, DJP Barker. 2000. Foetal nutrition and adult disease. American Journal of Clinical Nutrition. 71:1344S-1352S.

Jansson, T. 2001. Amino acid transporters in the human placenta. Pediatric Research. 49:141-147.

Jansson, T, M Wennergren, NP Illsley. 1993. Glucose transportere protein expression in human placenta throughout gestation and in intrauterine growth retardation. Journal of Clinical Endocrinology and Metabolism. 77:1554-1562.

Jensen, EC, JE Harding, MK bauer, PD Gluckman. 1999. Metabolic effects of IGF-I in the growth retarded fetal sheep. Journal of Endocrinology. 161:485-494.

Jozwik, M, C Teng, RB Wilkening, G Meschia, FC Battaglia. 2004. Reciprocal inhibition of umbilical uptake within groups of amino acids. American Journal of Physiology. 286:E376-E383.

Koch, JM, JS Moritz, DC Lay Jr, ME Wilson. 2007. Effect of melengestrol acetate as an alternative to induce molting in hens on the expression of yolk proteins and turnover of oviductal epithelium. Animal Reproduction Science. 102:14-23. 
Kudo, Y, CAR Boyd. 2002. Human placental amino acid transporter genes: expression and function. Reproduction. 124:593-600.

Kwon, H, SP Ford, FW Bazer, TE Spencer, PW Nathanielsz, MJ Nijland, BW Hess, G Wu. 2004. Maternal nutrient restriction reduces concentrations of amino acids and polyamines in ovine maternal and fetal plasma and fetal fluids. Biology of Reproduction. 71:901-908.

Lemons, JA, EW Adcock III, D Jones Jr. MA Naughton, G Meschia, FC Battaglia. 1976. Umbilical uptake of amino acids in the unstressed fetal lamb. The Journal of Clinical Investigation. 58:1428-1434.

Limesand, SW, TRH Regnault, WW Hay Jr. 2004. Characterization of glucose transporter $8\left(\mathrm{GLUT}^{*}\right)$ in the ovine placenta of normal and growth restricted fetuses. Placenta. 25:70-77.

McGivan, JD, M Pastor-Anglada. 1994. Regulatory and molecular aspects of mammalian amino acid transport. Biochemistry Journal. 299:321-334.

Ravelli, AC, JH Meulen, C Osmond, DP Barker, OP Bleker. 1999. Obesity at the age of $50 \mathrm{y}$ in men and women exposed to famine prenatally. American Journal of Clinical Nutrition. 70:811-816

Regnault, TRH, JE Friedman, RB Wilkening, RV Anthony, WW Hay Jr. 2005. Fetoplacental transport and utilization of amino acids in IUGR-a review. Placenta. 26:S52-S62.

Robertson, AF, WB Karp. 1976. Placental Transport of Nutrients. Southern Medical Journal. 69:1358-1362.

de Vrijer, B, TRH Regnault, RB Randall, B Wilkening, G Meschia, FG Battaglia. 2004. Pladntal uptake and transport of ACP, a neutral nonmetabolizable amino acid, in an ovine model of fetal growth restriction. American Journal of Physiology. 287:E1114-E1124.

Wallace, JM, TRH Regnault, SW Limesand, WW Hay Jr, RV Anthony. 2005. Investigating the cause of low birth weight contrasting ovine paradigms. Journal of Physiology. 565 19-26.

Wooding, FBP, AL Fowden, AW Bell, RA Ehrhardt, SW Limesand, WW Hay. 2005. Localisation of glucose transport in the ruminant placenta: Implications for sequential use of transporter isoforms. Placenta. 26:626640.

Wu, G, FW Baze,r TA Cudd, CJ Meininger, TE Spencer. 2004. Maternal nutrition and foetal development. Journal of Nutrition. 134 2169-2172. 
Wu, G, FW Bazer, JM Wallace, TE Spencer. 2006. BOARD-INIVTED REVIEW: Intrauterine growth retardation: Implications for the animal sciences. Journal of Animal Science. 84 2316-2337. 


\title{
Peri-Conceptional Growth Hormone Treatment Alters Fetal Growth and Development
}

\author{
J. M. Koch ${ }^{1}$ M. and E. Wilson ${ }^{1,2}$ \\ ${ }^{1}$ Division of Animal and Nutritional Sciences, Davis College of Agriculture, \\ Forestry and Consumer Sciences, West Virginia University Morgantown, West \\ Virginia, USA
}

This work is published with the approval of the Director of West Virginia Agriculture and Forestry Experiment Station as scientific paper XXXXXX. This project was supported by Hatch project 468 (NE 1007) and a West Virginia University Faculty Senate Research Grant

${ }^{2}$ Correspondence: G048 Agricultural Sciences Building (phone: (304) 293-2406 ext. 4425; fax: (304) 293-2232; email: mwilso25@wvu.edu). 


\section{Abstract}

Altering the fetal environment can modify the composition or growth rate of the fetus, a concept known as fetal programming. A majority of the research in this area has focused on intrauterine growth restriction (IUGR), which has been linked to adult diseases. A few studies have attempted to ameliorate the negative effects of IUGR, by applying growth promoters late in gestation. The objective of this study was to determine the effects of a single treatment of sustained release growth hormone given during the periconceptional period on fetal growth and development. Ewes assigned to treatment received $500 \mathrm{mg}$ of sustained release growth hormone. Birth weight, crown-rump length and abdominal girth were determined and a serum sample collected to determine IGF-I concentrations in all lambs. In a subset of male lambs, liver, heart and brain weights, as well as left and right ventricular wall thickness and liver IGF-I and growth hormone receptor mRNA expression were determined. On postnatal day 100 a subset of ewe lambs were weighed and challenged with growth hormone releasing hormone to assess the functionality of the growth hormone axis. Lambs from treated ewes had increased birth weight and abdominal girth compared to control lambs; however, there was no difference in crown-rump length. Hepatic mRNA expression of growth hormone receptor was increased, and IGF-I tended to increase, in lambs gestated by growth hormone treated ewes compared to controls. The left ventricular wall was thinner from lambs in the growth hormone treated group compared to controls. On postnatal day 100, those ewe lambs born to ewes treated with growth hormone were heavier and 
had a reduced IGF-I response to growth hormone releasing hormone challenge. In conclusion, treating ewes with sustained release growth hormone not only increased lamb birth weight but also resulted in alteration in lamb growth and altered growth hormone axis.

Key Words: growth hormone, fetal growth, GHRH challenge 


\section{Introduction}

The concept of "fetal programming" is described as any stimulus, either positive or negative, that occurs in utero which has a permanent affect and alters the physiology of the offspring (Armitage et al., 2004). The list of systems in which fetal programming has been found to impact is lengthy and includes the cardiovascular, respiratory, endocrine, reproductive, central nervous, skeletal and immune systems as well as kidney and liver function (Godfrey \& Barker 2000; Wu et al., 2004). The observation that adult onset diseases are directly linked to fetal programming has brought about investigations of a number of animal models in an attempt to mimic the pathophysiology observed in humans (Wallace et al., 2005; Wu et al., 2006).

Models developed to date to investigate fetal programming exclusively induce intrauterine growth restriction (IUGR). Intrauterine growth restriction is an alteration in the uterine environment at any time point during gestation that is detrimental to the growth and development of the fetus. The methods for inducing IUGR can involve maternal dietary manipulation and/or induction of placental insufficiency (Armitage et al., 2004; Wu et al., 2006). Maternal dietary manipulation includes a range of approaches from nutrient restriction to overnourishing adolescent ewes. Both models result in decreased nutrient availability to the developing fetus, but the overnourished adolescent ewe model appears to induce IUGR by reducing placental efficiency (Armitage et al., 2004; Wallace et al., 2005; Wu et al., 2006). In addition to the overnourished 
adolescent ewe, other placental insufficiency models alter the placenta's ability to transport nutrients to the fetus and include, uterine artery ligation, placental embolism, carunclectomy and maternal hyperthermia (Bell et al., 1989; Thureen et al., 1992; Regnault et al., 2003; Amitage et al., 2004; Wallace et al., 2004; Louey et al., 2005).

Many models that lead to IUGR have been studied in detail, and the specific alterations in fetal physiology that result from the environmental insult are well documented. However, only a few studies have tried to ameliorate the impact of experimentally induced IUGR by administering growth promoters. The limited number of studies that have attempted to attenuate the negative impact on fetal physiology have examined growth hormone treatment to the dam or infusing the fetus directly with growth hormone or insulin like growth factor (IGF; Harding et al., 1997; Bauer et al., 2003; Wallace et al., 2004; Wallace et al., 2006). In these studies the effects of growth hormone, given during either mid or late gestation, only appear to have a transient effect (i.e., they were not able to overcome the negative impact IUGR had on growth and development of the offspring).

Few researchers have attempted to promote fetal growth and development under normal uterine conditions. Growth hormone administered to either the fetus or the dam, late in gestation under normal gestational conditions, did not alter fetal growth and development (Stelwagen et al., 1994; Bauer et al., 2000). However, these experiments may have two potential flaws. First growth hormone is not the primary stimulator for growth during fetal development 
because hepatic growth hormone receptors are in very low abundance and do not appear to stimulate the secretion of IGF, which is the primary growth promoter (Gluckman and Pinal, 2003). Second, growth hormone was administered following the majority of placental growth and altering placental development may limit fetal growth because it regulates the nutrient supply. In sheep, placental size increases exponentially until day 80 , and from that point, further development is mainly due to increased vascular complexity (Reynolds et al., 2005a; Reynolds et al., 2005b; Borowicz et al., 2007). Recently we have shown that a single injection of sustained release growth hormone administered at breeding altered the uterine environment at day seven of gestation and increased birth weight by $10 \%$ (Costine et al., 2005). At day 80 of gestation, placental mass in the growth hormone group was lower than controls, but by day 140 both had similar placental weights (Costine et al., 2005). Comparing the results of experiments in which growth hormone was administrated in mid or late gestation with that at the time of breeding has led us to suggest that early growth hormone administration alters the uterine environment during a developmental window in which the embryo, including the trophectoderm (which will become the outer layer of the fetal placenta), and in inner cell mass (which will become the embryo proper and later fetus and contribute to the placenta) can be altered.

Therefore, the objective of the current study was to determine how a single injection of sustained release growth hormone, given immediately prior to conception, alters: 1) fetal growth and development 2) postnatal growth and development of the growth hormone axis. 


\section{Materials and Methods}

Ewes $(n=50)$, primarily of rambouillet breeding, from the West Virginia University farm were used for the experiment. All procedures were approved by the West Virginia University Animal Care and Use Committee (ACUC No. 031012).

Estrus was synchronized by administering $20 \mathrm{mg}$ of prostaglandin $\mathrm{F}_{2} \alpha$ (Lutalyse, Pfizer) on day 0 and a second injection of prostaglandin $F_{2} \alpha$ on day 8. Ewes were randomly assigned to either a control group $(n=27)$ or a growth hormone treated group $(\mathrm{n}=23)$. The growth hormone treated group received a single $500 \mathrm{mg}$ injection of sustained release recombinant bovine growth hormone subcutaneously (Posilac; Monstanto, St. Louis, MO) at the same time as the second prostaglandin $\mathrm{F}_{2} \alpha$ injection. This dose was previously reported to increase uterine luminal insulin like growth factor-I (IGF-I) on day 7 of gestation and result in larger lambs at birth (Costine et al., 2005). Following the second injection of prostaglandin $F_{2} \alpha$, ewes were penned with a fertile ram. At term, all lambs $(n=84)$ born alive were processed shortly after birth (average gestation was 145 days).

\section{Lamb Data}

Shortly following birth, and before nursing, all lambs were processed. Each lamb was weighed, measured for crown-rump length, abdominal girth and crown width and a blood sample was collected for IGF-I concentration. A subset 
of males $(n=22)$ were further processed for tissue collection. Each male was euthanized with an intravenous overdose of sodium pentobarbital $(1.5 \mathrm{~g}$, Sigma, St. Louis, MO). The liver was removed, weighed and a portion was snap frozen in liquid nitrogen for further analysis of hepatic expression of growth hormone receptor and IGF-I. The heart was removed and weighed before the ventricles were separated from the atria and fixed in $10 \%$ formalin. Following fixation the right and left ventricular wall thickness was determined using calipers. The brain was also removed from the skull to determine brain weight.

\section{Growth Hormone Releasing Hormone Challenge}

A subset of ewe lambs $(n=14)$ were weighed at 100 days-of-age and a blood sample was collected $(0 \mathrm{~min})$. The lambs were then subjected to a growth hormone releasing hormone challenge ( $3 \mu \mathrm{g} / \mathrm{kg}$ body weight; GHRH factor-29; Simga, St. Louis, MO; Suttie et al., 1991) and blood samples were collected 10, $20,30,45,60$ and 90 min following challenge.

Insulin Like Growth Factor-I

The concentration of IGF-I in plasma was determined using a commercially available Enzyme-Linked ImmunoSorbent Assay, previously validated in our laboratory (Diagnostic Systems Laboratories Inc., Webster, TX; Costine et al.,, 2005). Briefly, this assay utilizes two antibodies in a sandwichtype immunoassay. The enzyme horseradish peroxidase is linked to the secondary antibody and in the presence of tetramethylbenzidine, a substrate for 
horseradish peroxidase, the absorbance is directly proportional to the concentration of IGF-I.

\section{Gene Expression}

Liver RNA was extracted using TRIzol as described by Koch et al. (2007). This procedure includes two back extractions against acid phenol:chloroform (5:1; $\mathrm{pH}=4.5 ;$ Ambion, Austin, TX) followed by two back extractions against phenol:chloroform: isoamyl alcohol $(25: 24: 1 ; \mathrm{pH}=6.6)$ to remove additional proteins, DNA and lipids. The RNA was reconstituted in $40 \mu \mathrm{l}$ of nuclease free water and the concentration was determined spectrophotometrically at $260 \mathrm{~nm}$. The quality of RNA was determined by the appearance of bands corresponding to $28 \mathrm{~S}$ and $18 \mathrm{~S}$ rRNA and a distribution of mRNA of high molecular weight on a $3 \%$ agarose gel with ethidium bromide. Complementary DNA (cDNA) was synthesized from $2 \mu \mathrm{g}$ of RNA which was reverse transcribed using random hexamers and Moloney Murine Leukaemia Virus reverse transcriptase (Promega, Madison, WI). Real-Time RT PCR (iCycler, Bio-Rad Laboratories, Hercules, CA) was utilized to quantify the abundance of cDNA as previously described (Koch et al., 2007). Primers specific for growth hormone receptor, IGF-I and acidic ribosomal protein (which was used as a control gene), were designed using Biology Work Bench (http://workbench.sdsc.edu/) and synthesized (Integrated Diagnostics Systems, Coralville, IA). Primers for growth hormone receptor (forward CATGTCACTGGACAGATGGG; reverse TGTTTTCACCAGCAGAGACG), IGF-I (forward GCCAAAACGGTCAAAGGTGA; 
reverse AGGCATAATTGGGGAGCTTT) and acid ribosomal protein (forward CAACCCAGCTCTGGAGAAAC; reverse GTGAGGTCCTCCTTGGTGAA) were optimized (all reactions were annealed at $58.7^{\circ} \mathrm{C}$ ) using a pooled RNA sample which was created by combining RNA from both treatment groups. The efficiency $(E)$ of each primer set was determined utilizing this pool prior to assaying any samples, and was used to standardize the target gene ratio. The efficiency of amplification was determined by raising 10 to the power of ($1 /$ slope), for which the slope was obtained by plotting the log of the concentration of cDNA against the critical threshold (Ct) values (Koch et al., 2007). Efficiencies for growth hormone receptor, IGF-I and acid ribosomal protein were 1.84, 1.85 and 1.94 , (i.e., $92 \%, 93 \%$ and $97 \%$ theoretical yield) respectively.

Each PCR reaction contained $25 \mu \mathrm{l}$ of iQ SYBR green supermix (Bio-Rad Laboratories), $2 \mu$ l of cDNA diluted to $1: 2$, and $3 \mu$ l each of $5 \mu \mathrm{M}$ forward and reverse primer and $17 \mu \mathrm{l}$ of water to reach a final reaction volume of $50 \mu \mathrm{l} . \mathrm{A}$ single product per amplification was determined by examining both the melting curve and by a $1.5 \%$ agarose gel with ethidium bromide. The expression of each gene is reported as a ratio (ratio $=\left[\mathrm{E}^{\Delta \mathrm{Ct} \text { target gene (pool-sample) }} / \mathrm{E}^{\Delta \mathrm{Ct} \text { control gene (pool- }}\right.$ sample)]) previously described by Koch et al. (2007).

\section{Statistical Analysis}

The effect of growth hormone treatment to the dam during the periconceptional period on lamb birth weight, crown-rump length, abdominal 
girth, crown width, IGF-I concentration, brain weight, right and left ventricular wall thickness and hepatic expression of IGF-I and growth hormone receptor was analyzed by analysis of variance, utilizing the general linear models procedure in SAS. The effect of GH treatment to the dam on IGF-I concentrations following GHRH challenge was analyzed by repeated measures ANOVA utilizing the mixed models procedure in SAS. The relationships among variables were determined by the correlation procedure of SAS. Insulin like growth factor-I concentrations following growth hormone releasing hormone challenge were analyzed by repeated measures ANOVA.

\section{Results}

Both weight and abdominal girth at birth were greater $(P<0.05)$ in the group of lambs born to ewes treated with growth hormone compared to those born to control ewes (Figure 13a and 13b). However, no difference in crownrump length $(48.51 \pm 1.44 \mathrm{~cm} ; \mathrm{P}>0.05$; Figure $13 \mathrm{c})$ or crown width $(8.82 \pm 0.20$ $\mathrm{cm}$ ) was detected.

The thickness of the left ventricular wall at birth was decreased $(P<0.05)$ in male lambs born to ewes treated with growth hormone compared to male lambs born to control ewes (Figure 14). However, no difference in the thickness of the right ventricular wall was detected (Figure 14). No difference in heart weight at birth was detected between the control and growth hormone groups 
$(34.7 \pm 2.1 \mathrm{~g} ; \mathrm{p}>0.05)$. Brain weights were also not different $(50.4 \pm 2.1 \mathrm{~g} ; \mathrm{p}>$ $0.05)$.

Relative expression of growth hormone receptor was increased $(p<0.05)$ in liver tissue of male lambs born to ewes treated with growth hormone compared to control (Figure 15). Similarly, there was a trend $(p=0.06)$ for an increase in IGF-I expression in the growth hormone group compared to controls (Figure 15). However, liver weight at birth was not different between control male lambs and male lambs born to ewes treated with growth hormone at breeding (108.9 \pm 5.1 $g ; p>0.05)$. Plasma IGF-I at birth was not different in lambs from either treatment group ( $38 \pm 6.6 \mathrm{pM}$ ). However, there was a positive correlation $(r=0.48 ; p<0.05)$ between birth weight and IGF-I concentration.

On postnatal day 100 , ewe lambs born to ewes treated with growth hormone where still $20 \%$ heavier than those born to control ewes (Figure 16). Ewe lambs born to dams treated with growth hormone had a reduced IGF-I response following the growth hormone releasing hormone challenge on day 100 (Figure 17). 


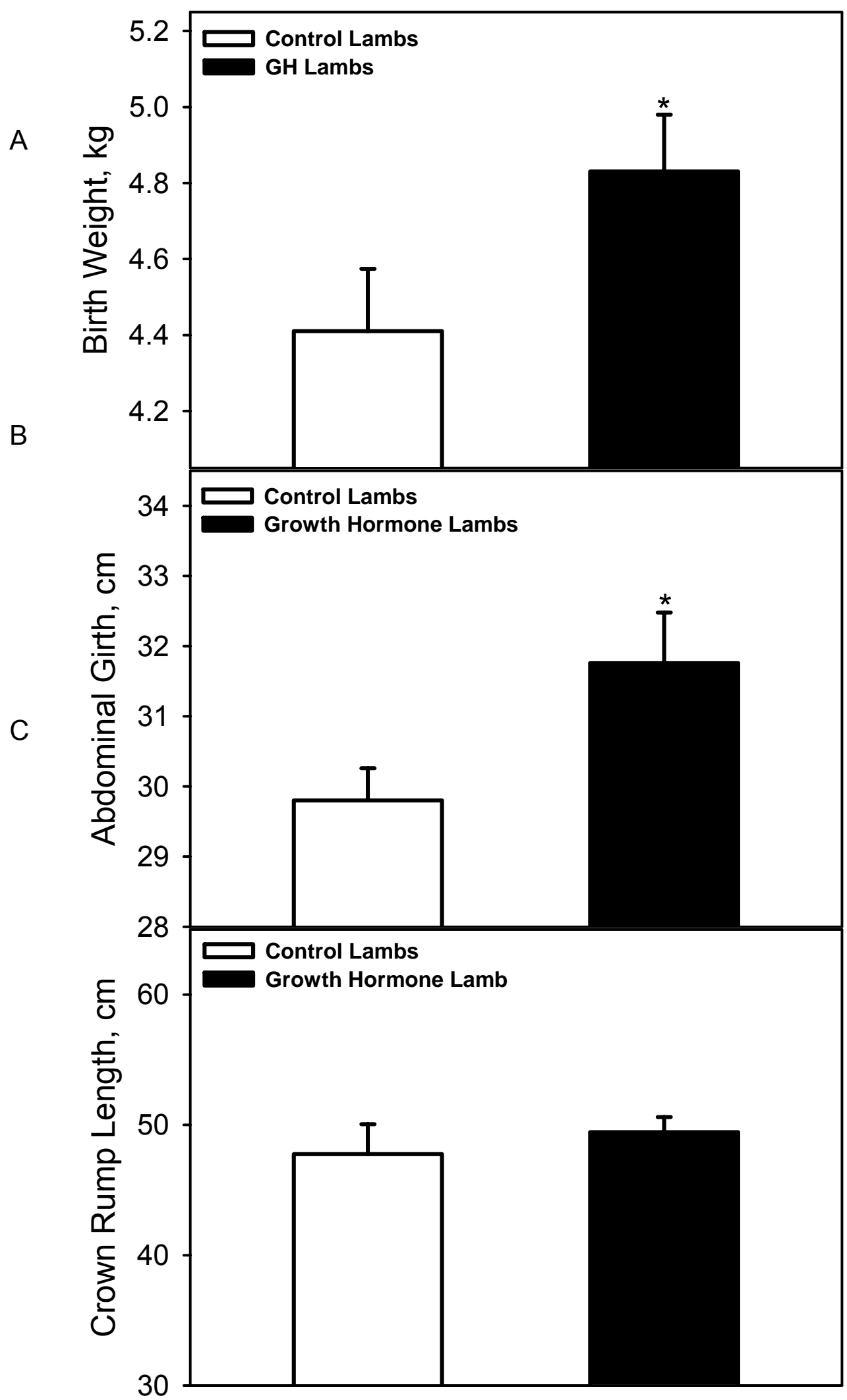

FIGURE 14. Birth data of lambs born to control ewes and ewes treated with sustained release growth hormone at breeding a) birth weight $b$ ) abdominal girth c) crown-rump length. ${ }^{*}$ Indicates that treatment means differ $(p<0.05)$. 


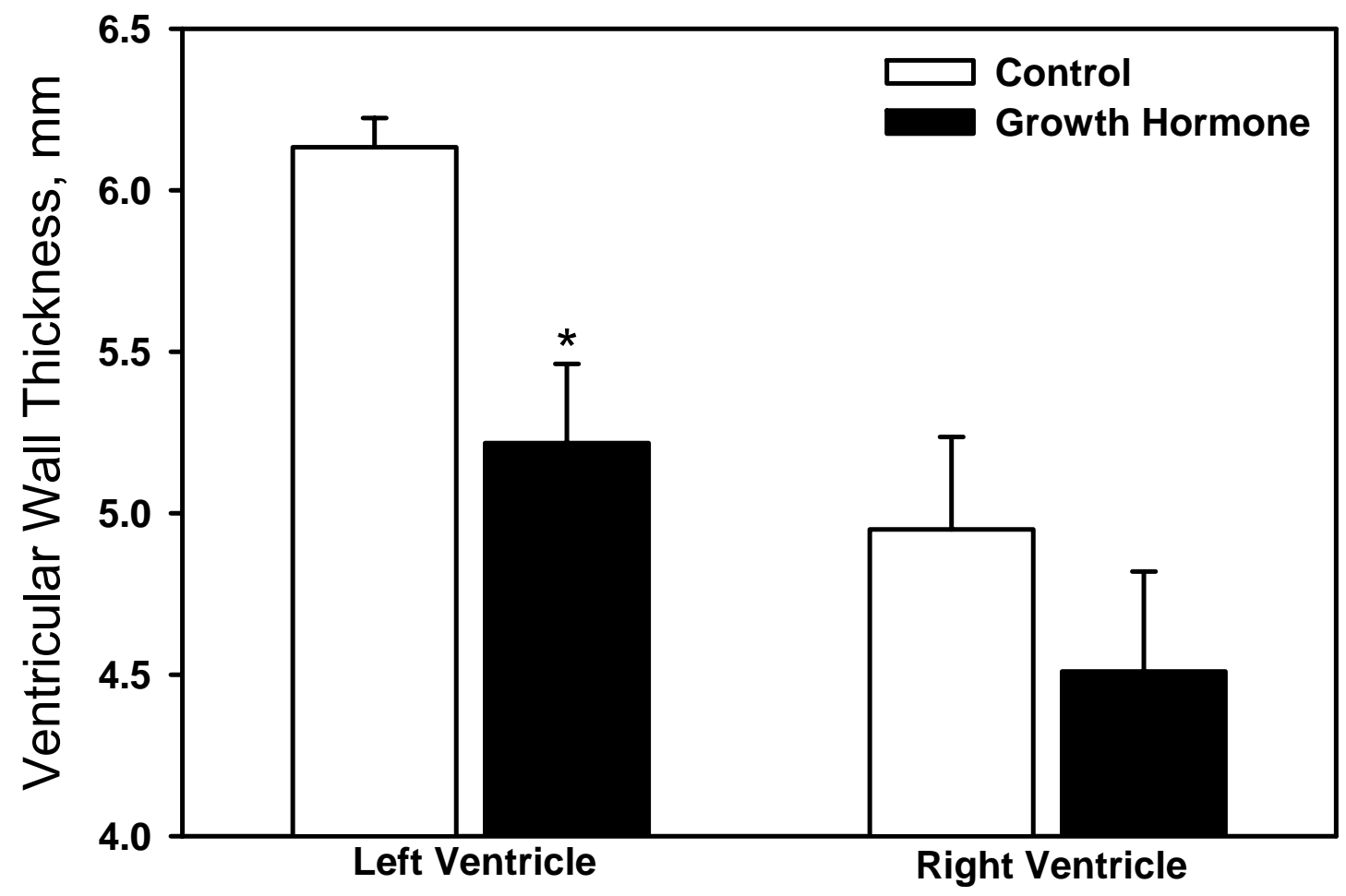

FIGURE 15. Ventricular wall thicknesses of fetal hearts in ram lambs born to control ewes and ewes treated with sustained release growth hormone at breeding. ${ }^{*}$ Indicates that treatment means differ $(p<0.05)$. 


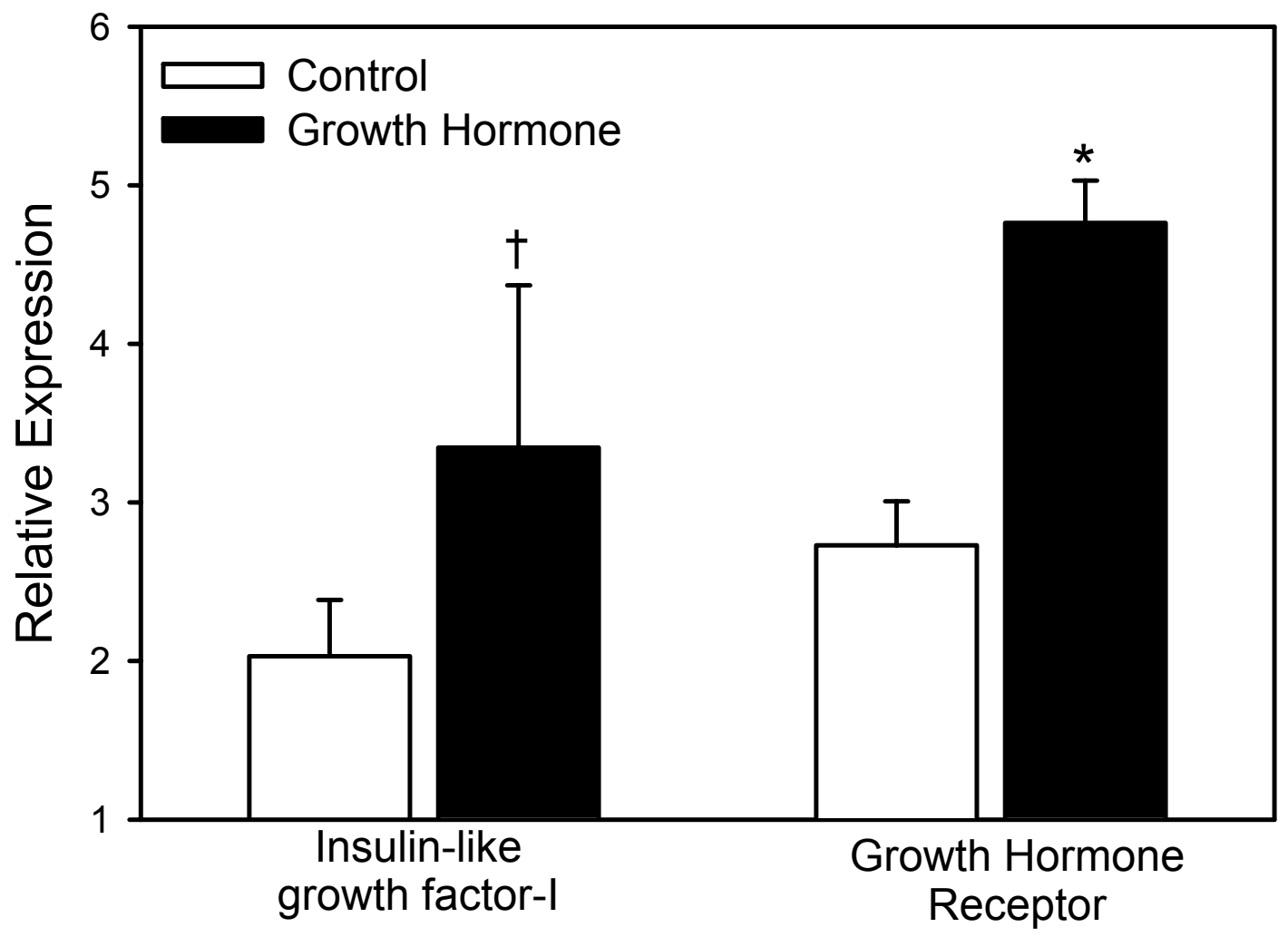

FIGURE 16. Neonatal hepatic mRNA expression of IGF-I and growth hormone receptor from ram lambs born to control ewes and ewes treated with sustained release growth hormone at breeding. ${ }^{*}$ Indicates that treatment means differ $(p<$ $0.05)$. Hndicates that treatment means tend to differ $(p=0.06)$. 


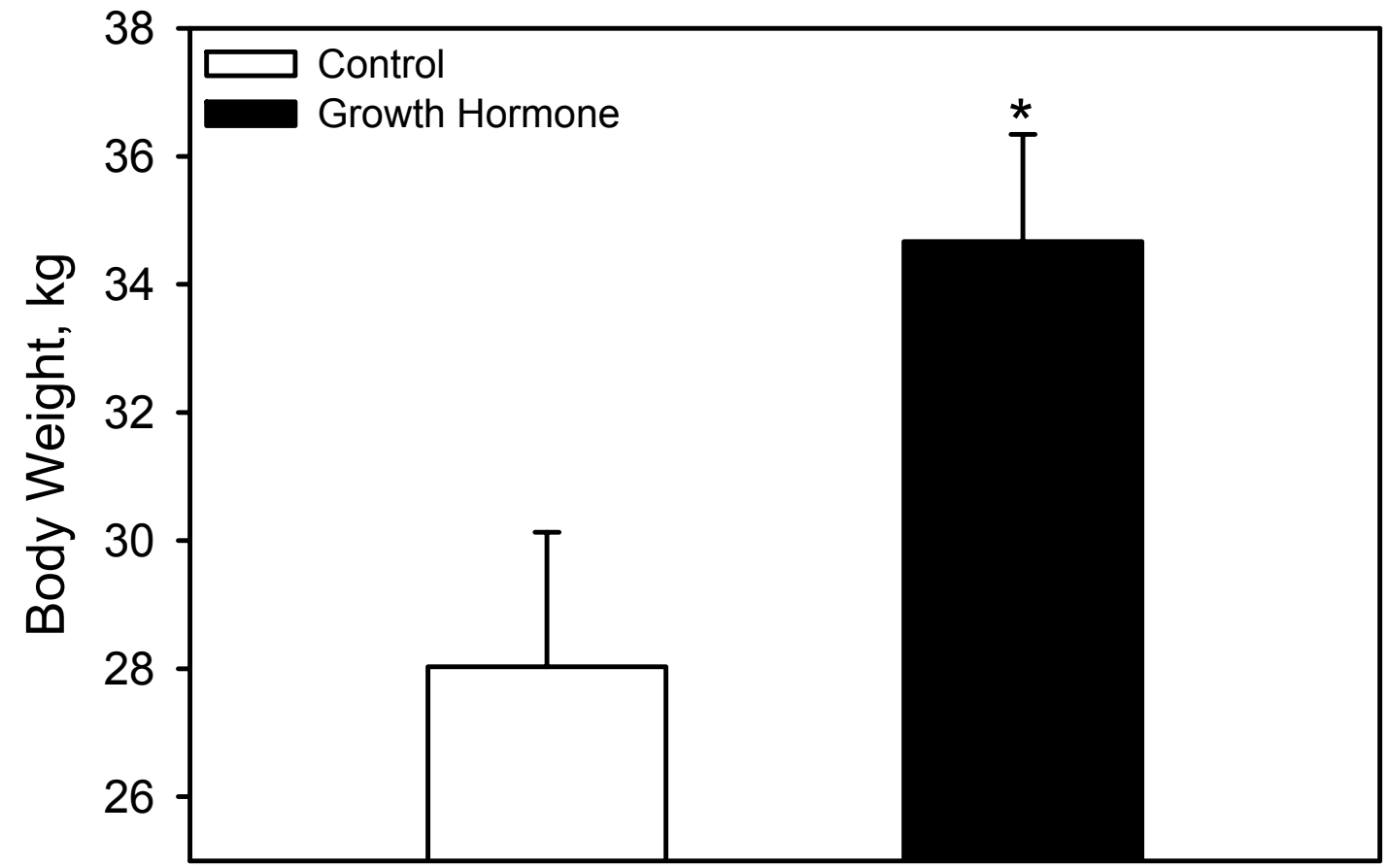

FIGURE 17. Weight of ewe lambs at postnatal day 100 that were either born to control ewes or ewes treated with growth hormone. ${ }^{*}$ Indicates that treatment means differ $(p<0.05)$. 


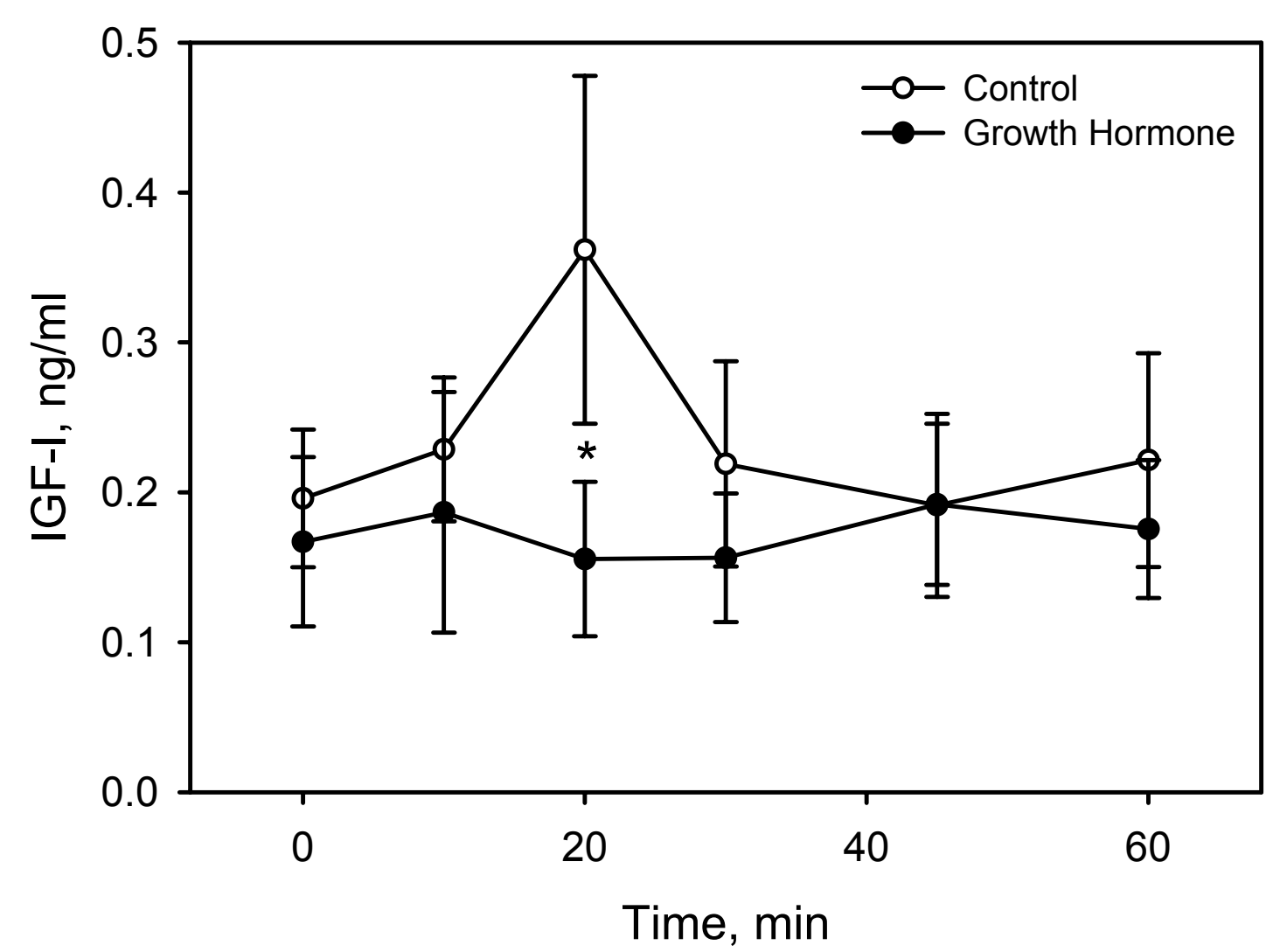

FIGURE 18. Pattern of secretion of IGF-I following growth hormone releasing hormone challenge on postnatal day 100 by ewe lambs born to control ewes and ewes treated with sustained release growth hormone at breeding. ${ }^{*}$ Indicates that treatment means differ $(p<0.05)$. 


\section{Discussion}

Administering a single injection of sustained release growth hormone prior to breeding alters fetal growth and development of lambs. Lambs born to ewes treated with growth hormone at breeding are $25 \%$ heavier at birth compared to controls. Lambs in the growth hormone group appear to have an altered composition, as indicated by the observed increased abdominal circumference without a difference in crown-rump length, leading us to suggest that the stature of the growth hormone group is unaltered.

The increase in birth weight of lambs born to ewes treated with growth hormone in the current experiment is in agreement with those found previously in which $500 \mathrm{mg}$ of sustained release growth hormone given at the time of breeding increased lamb weight by $10 \%$ (Costine et al., 2005), even though in the current experiment growth hormone was given at the time of the second prostaglandin $\mathrm{F}_{2} \alpha$ injection. In contrast, administration of $0.1 \mathrm{mg} / \mathrm{kg}$ growth hormone twice daily to the dam for 10 days or once daily for 27 day in late gestation did not affect fetal growth (Stelwagen et al., 1994; Harding et al., 1997).

Several researchers have attempted to ameliorate the effects of intrauterine growth restriction by administering growth hormone during the latter portion of fetal development, but to our knowledge only Costine et al. (2005; from this laboratory) and the current experiment have administered growth hormone during the periconceptional period or in early gestation. For example, in an experiment conducted by Bauer et al. (2003) intrauterine growth restriction was 
induced by placental embolization on days 110-116 which was followed by direct infusion of growth hormone to the fetus at a rate of $3.5 \mathrm{mg} /$ day late in gestation. Growth hormone infusion did not alter fetal weight, crown-rump length, chest girth or fetal growth rate (Bauer et al., 2003). Wallace et al. (2004) utilized the over-nourished pregnant adolescent ewe model as a means to induce fetal growth restriction and examined whether $0.14 \mathrm{mg} / \mathrm{kg}$ growth hormone administered daily to the dam in mid gestation (i.e., days 35-80) might alter fetal development. In their study, growth hormone treatment appeared to have no affect on either fetal weight or umbilical girth (Wallace et al., 2004). Utilizing the same adolescent ewe model, growth hormone was administered late in gestation to the dam at a rate of $0.14 \mathrm{mg} / \mathrm{kg} /$ day from days $95-125$. At day 130 , growth hormone treatment appeared to increase fetal weight and girth in the growth restricted group making them equivalent to non-growth restricted. However, at birth the effect of growth hormone treatment was no longer observed, leading to the suggestion that late in gestation growth hormone treatment only elicits a transient response (Wallace et al., 2006).

It is not surprising that administration of growth hormone during mid or late gestation does not increase fetal growth rate or ameliorate the effects of intrauterine growth restriction. This is because fetal growth is generally limited by the ability of the placenta to supply nutrients. The placenta grows in size during the first 80 days of gestation and then for the remainder of gestation it develops a larger, more complex vascular network to allow for the increased nutrient demand of the rapidly growing fetus (Reynolds et al., 200a; Reynolds et al., 
200b; Borowicz et al., 2007). Apparently, growth hormone administration in mid to late gestation only temporarily influences placental efficiency.

During fetal development, the impact of growth hormone is very minimal even though the concentration of growth hormone is 10 - to 20 -fold higher than postnatal levels (Bloomfield et al., 2006). Growth hormone's inability to stimulate fetal growth has been associated with a lack of growth hormone receptor expression. Growth hormone receptor expression is low during fetal development, but is induced by the glucocorticoid surge at parturition and remains elevated in lambs (Li et al., 1996; Gluckman \& Pinal 2003; Bloomfield et al., 2006). The apparent failure of GH to ameliorate growth restriction should not be expected since $\mathrm{GH}$ is not the main regulator of fetal growth.

Administration of growth hormone during mid gestation to adolescent pregnant sheep more than doubled the concentration of glucose in fetal circulation, although expression of both glucose transporters found in the placenta were not altered (Wallace et al., 2004). In the uteroplacental embolism model, growth hormone administration restored the glucose concentration of the intrauterine growth restricted group to control concentrations (Bauer et al., 2003).

In the current experiment, growth hormone administration occurred immediately prior to breeding. We have speculated that the observed increase in fetal weight and abdominal girth in the current study are a result of altered embryo growth that leads to altered placental development and function allowing for an increased placental efficiency late in gestation. This early embryonic 
programming may be a result of an altered uterine environment which has been observed with growth hormone treatment at breeding (Costine et al., 2005). Exogenous progesterone administered during embryonic development appears to advance the uterine environment and increase fetal growth. Those embryos exposed to an altered uterine environment by early progesterone administration had a greater fetal mass and larger crown-rump length compared to controls (Keelmann et al., 1994). Similarly embryos that are co-cultured with granulosa cells before being returned to the recipient female were $14 \%$ heavier by day 61 of gestation and $18 \%$ larger by day 125 compared to those that were just cultured in media and not exposed to granulosa cells (Sinclair et al., 1999).

As in the neonate, IGF-I is the major growth factor responsible for fetal growth, but the main stimulator for IGF-I secretion in utero is nutrients, not growth hormone (Oliver et al., 1996; Bloomfield et al., 2006). The postnatal drop in growth hormone concentration, to that of an adult, is accompanied by an increase in both the expression of growth hormone receptor and IGF-I, which together lead to growth hormone regulated IGF-I secretion after birth (Fowden, 1995; Breier et al., 1994).

A positive correlation between placental efficiency and fetal IGF-I concentrations has previously been observed in ewes treated with sustained release growth hormone at breeding (Costine et al., 2005). The current study found that treatment with growth hormone prior to breeding tended to increase the hepatic mRNA expression of both IGF-I and growth hormone receptor at birth. The major fetal growth promoter, IGF-I, is mainly regulated by nutrients 
(Bloomfield et al., 2006). Fetal expression of IGF-I and growth hormone receptor can be influenced by maternal nutrition as well. A $60 \%$ maternal nutrient restriction from day 28 to 80 followed by re-feeding to a control level until day 140 resulted in a decrease in fetal-hepatic IGF-I and growth hormone receptor at day 80 of gestation. However, in the nutrient restriction growth that was returned to a control diet fetal-hepatic expression of both IGF-I and growth hormone receptor were increased by day 140 suggesting regulation by nutrient availability (Brameld et al., 2000).

Treatment with growth hormone prior to breeding also appeared to alter the postnatal growth and development of lambs. At day 100 following birth lambs born to ewes treated with growth hormone were still $20 \%$ heavier than lambs born to controls. Ewe lambs born to growth hormone treated ewes also had a suppressed response to growth hormone releasing hormone challenge compared to controls.

Little information has been collected on the effects of growth hormone administration during gestation on postnatal development in lambs and more specifically how the growth hormone axis of these lambs may be altered. In the current experiment plasma IGF-I levels immediately following birth were not different between the treated and control groups. These results are similar to those found by Stelwagen et al., (1994), in which the concentration of IGF-I immediately following birth was not different between control lambs and those exposed for 27 days to growth hormone late in gestation at a concentration of 0.1 $\mathrm{mg} / \mathrm{kg}$ ewe body weight. In an IUGR environment induced by placental 
embolization, growth hormone treatment was able to elevate the concentration of IGF-I in fetal circulation of the IUGR fetuses but only to control levels (Bauer et al., 2003). These data agree with hepatic expression data, in which growth hormone treatment late in gestation increased hepatic growth hormone receptor expression, but not IGF-I (Bloomfield et al., 2006). The current experiment only examined hepatic expression in newborn lambs and cannot be directly compared to Bloomfield et al., (2006); however, it may be important to note that the observed increase in hepatic mRNA expression of growth hormone receptor and the trend of an increased IGF-I expression in the growth hormone group may indicate an altered growth hormone axis.

The current study also determined ventricular wall thickness because during fetal development, the heart can undergo adaptive changes to compensate for alterations in fetal physiology. The observed decrease in left ventricular wall thickness leads us to suggest that during fetal development those offspring gestated by dams treated with growth hormone at breeding have reduced peripheral vascular resistance. In sheep, under normal uterine conditions, cardiomyocyte growth is primarily hyperplastic until terminal differentiation, with the majority of hypertrophic growth occurring only after birth (Burrell et al., 2003). This pattern of development is changed in models of intrauterine growth restriction. For example, when placental embolization was utilized to induce fetal growth restriction late in gestation, an increase in heart weight, ventricular wall thickness and the right ventricular cardiomyocyte proteinto-DNA ratio (i.e., cell size) was observed in growth restricted fetuses compared 
to controls at day 130 (Murotsuki et al., 1997). Utilizing the same model, growth restriction reduced relative heart weight (when corrected to fetal weight) and retarded growth of the left ventricle as measured by a decreased proportion of binucleated cardiomyocytes (i.e., inhibited maturation) at day 130 of gestation (Bubb et al., 2007). A different intrauterine growth restriction model, in which dams were nutritionally restricted to $50 \%$ of the control group from day 28 to day 78 of gestation, resulted in an increase in ventricular weight per gram of fetal body weight (Vonnahme et al., 2003). A hypertrophic increase in the fetal ventricular wall has been suggested to result from an increase in ventricular afterload which is indicative of an increase in mean arterial pressure (Samson et al., 2000; Vonnahme et al., 2003). A mechanism in which placental vascular resistance may be increased in intrauterine growth restriction resulting in altered fetal heart development has been postulated by Vonnahme et al. (2003). We suggest that the reduced left ventricular wall thickness observed in the current study is consistent with a decrease in mean arterial pressure in fetuses gestated in ewes treated with growth hormone prior to breeding.

In conclusion, treating ewes with a single injection of sustained release growth hormone prior to breeding alters fetal growth and development. Lambs born to ewes treated with growth hormone are larger, they have a reduced ventricular wall thickness (which is indicative of a reduced mean arterial pressure) and they have what appear to be alterations in the growth hormone axis. Impacting or programming the early embryo, specifically the developing placenta, potentially alters fetal development throughout gestation. The placenta 
is responsible for supplying nutrients for proper growth, it influences mean arterial pressure which impacts cardiovascular development, and its efficiency may directly impact the growth hormone axis. The current work may stimulate a new line of thinking when examining developmental programming of the conceptus and how it ultimately alters postnatal growth and development of the offspring. 


\section{References}

Armitage, JA, YK Imran, PD Taylor, PW Nathanielsz, L Poston. 2004.

Developmental programming of the metabolic syndrome by maternal nutritional imbalance: how strong is the evidence from experimental models in mammals. Journal of Physiology. 561:355-377.

Bauer, MK, BB Breier, FH Bloomfield, EC Jensen, PD Gluckman, JE Harding. 2003. Chronic pulsatile infusion of growth hormone to growth-restricted fetal sheep increases circulating foetal insulin-like growth factor-I levels but not foetal growth. Journal of Endocrinology. 177:83-92.

Bauer, MK, JE Harding, BH Breier, PD Gluckman. 2000. Exogenous GH infusion to late-gestational foetal sheep does not alter foetal growth and metabolism. Journal of Endocrinology. 166:591-597.

Bell, AW, BW McBride, R Slepetis, RJ Early, WB Currie. 1989. Chronic heat stress and prenatal development in sheep: I. Conceptus growth and maternal plasma hormones and metabolites. Journal of Animal Science. 67:3289-3299.

Bloomfield, FH, PL van Zijl, MK Bauer, HH Phua, JE Harding. 2006. Effect of pulsatile growth hormone administration to the growth-restricted fetal sheep on somatotrophic axis gene expression in fetal and placental tissues. American Journal of Physiology. 291:E333-E339.

Borowicz, PP, DR Arnold, ML Johnson, AT Grazul-Bilska, DA Redmer, LP Reynolds. 2007. Placental growth throughout the last two thirds of pregnancy in sheep: vascular development and angiogenic factor expression. Biology of Reproduction. 76:259-267.

Brameld, JM, A Mostyn, J Dandrea, TJ Stephenson, JM Dawson, PJ Buttery, ME Symonds. 2000. Maternal nutrition alters the expression of insulin-like growth factors in fetal sheep liver and skeletal muscle. Journal of Endocrinology. 167:429-437.

Breier, BH, GR Ambler, H Sauerwein, A Surus, PD Gluckman. 1994. The induction of hepatic somatotrophic receptors after birth in sheep is dependent on parturition-associated mechanisms. Journal of Endocrinology. 141:101-108.

Bubb, KJ, ML Cock, MJ Black, M Dodic, WM Boon, HC Parkington, R Harding, M Tare. 2007. Intrauterine growth restriction delays cardiomyocyte maturation and alters coronary artery function in the fetal sheep. Journal of Physiology. 578:871-881. 
Burrell, JH, AM Boyn, V Kumarsamy, A Hsieh, SI Head, ER Lumbers. 2003. Growth and maturation of cardiac myocytes in fetal sheep in the second half of gestation. Anatomical Research. 274A:952-961.

Costine, BA, EK Inskeep, ME Wilson. 2005. Growth hormone at breeding modifies concetpus development and postnatal growth in sheep. Journal of Animal Science. 83:810-815.

Fowden, A. 1995. Endocrine regulation of foetal growth. Reproduction Fertility and Development. 7:351-363.

Gluckman, PD, GS Pinal. 2003. Regulation of fetal growth by the somatotrophic axis. Journal of Nutrition. 133:1741S-1746S.

Godfery, KM, DJP Barker. 2000. Fetal nutrition and adult disease. American Journal of Clinical Nutrition. 71:1344S-1352S.

Harding, JE, PC Evans, PD Gluckman. 1997. Maternal growth hormone treatment increases placental diffusion capacity but not fetal or placental growth in sheep. Endocrinology. 138:5352-5358.

Kleemann, DO, SK Walker, RF Seamark. 1994. Enhanced fetal growth in sheep administered progesterone during the first three days of pregnancy. Journal of Reproduction and Fertility. 102:411-417.

Koch, JM, JS Moritz, DC Lay Jr, ME Wilson. 2007. Effect of melengestrol acetate as an alternative to induce molting in hens on the expression of yolk proteins and turnover of oviductal epithelium. Animal Reproduction Science. 102:14-23.

Lang, U, RS Baker, J Khoury, KE Clark. 2000. Effects of chronic reduction in uterine blood flow on fetal and placental growth in the sheep. American Journal of Physiology. 279:R53-R59.

Li, J, JA Owens, PC Owens, JC Saunders, AL Fowden, RS Gilmour. 1996. The ontogeny of hepatic growth hormone receptor and insulin-like growth factor I gene expression in the sheep fetus during late gestation: Developmental regulation by cortisol. Endocrinology.137:1650-1657.

Louey, S, ML Cock, R Harding. 2005. Long term concsequences of low birthweight on postnatal growth, adiposity and brain weight at maturity in sheep. Journal of Reproduction and Development. 51:59-68

Murotsuki, J, JRG Challis, VKM Han, LJ Fraher, R Gagnon. 1997. Chronic fetal placental embolization and hypoxemia cause hypertension and myocardial hypertrophy in fetal sheep. American Journal of Physiology. 272:R201R207. 
Oliver, MH, JE Harding, BH Breier, PD Gluckman. 1996. Foetal insulin-like growth factor (IGF)-I and IGF-II are regulated differently by glucose or insulin in the sheep foetus. Reproduction and Fertility. 8:167-172.

Regnault, TRH, B De Vrijer, HL Galan, ML Davidsen, KA Trembler, FC Battaglia, RB Wilkensing, RV Anthony. 2003. The relationship between transplacental $\mathrm{O}_{2}$ diffusion and placental expression of PIGF, VEGF and their receptors in a placental insufficiency model of fetal growth restriction. Journal of Physiology. 550:641-656.

Reyonlds, LP, PP Borowicz, KA Vonnahme, ML Johnson, AT Gazul-Bilska, DA Redmer, JS Caton. 2005a. Placental angiogenesis in sheep models of compromised pregnancy. Journal of Physiology. 565:43-58.

Reyonlds, LP, PP Borowicz, KA Vonnahme, ML Johnson, AT Gazul-Bilska, JM Wallace, JS Caton, DA Redmer. 2005b. Animal models of placental angiogenesis. Placenta. 26:689-708.

Samson, F, F Bonnet, M Heimburger, C Rucker-Martin, DO Levitsky, GM Mazmanian, JJ Mercadier, A Serraf. 2000. Left ventricular alterations in a model of fetal left ventricular overload. Pediatric Research. 48:43-49.

Sinclair, KD, TG McEvoy, EK Maxfield, CA Maltin, LE Young, I Wilmut, PJ Broadbent, JJ Robinson. 1999. Aberrant fetal growth and development after in vitro culture of sheep zygotes. Journal of Reproduction and Fertility. 116:177-186.

Stelwagen, K, DG Grieve, JS Walton, JL Ball, BW McBride. 1994. Effects of bovine somatotropin administration during the last trimester of gestation on maternal growth, and fetal and placental development in primigravid ewes. Animal Production. 58:87-94.

Suttie, JM, EA Lord, PD Gluckman, PF Fennessy, RP Littlejohn. Genetically lean and fat sheep differ in their growth hormone response to growth hormonereleasing factor. Domestic animal Endocrinology. 8:323-329.

Thureen, PJ, KA Trembler, G Meschia, EL Makowski, RB Wilkening. 1992. Placental glucose transport I heat-induced fetal growth retardation. American Journal of Physiology. 263:R578-R585.

Vonnahme, KA, BW Hess, TR Hansen, RJ McCormick, DC Rule, GE Moss, WJ Murdoch, MJ Nijland, DC Skinner, PW Nathanielsz, SP Ford. 2003 Maternal undernutrition from early-to mid-gestation leads to growth retardation, cardiac ventricular hypertrophy, and increased liver weight in the fetal sheep. Biology of Reproduction. 69:133-140. 
Wallace, JM, M Matsuzaki, J Milne, R Aitken. 2006. Late but not early gestation maternal growth hormone treatment increases fetal adiposity in overnourished adolescent sheep. Biology of Reproduction. 75:231-239.

Wallace, JM, JS Milne, RP Aitken. 2004. Maternal growth hormone treatment from day 35 to 80 of gestation alters nutrient partitioning of uteroplacental growth in the overnourished adolescent sheep. Biology of Reproduction. 70:1277-1285.

Wallace, JM, TRH Regnault, SW Limesand, WW Hay Jr, RV Anthony. 2005. Investigating the cause of low birth weight contrasting ovine paradigms. Journal of Physiology. 565:19-26.

Wu, G, FW Baze,r TA Cudd, CJ Meininger, TE Spencer. 2004. Maternal nutrition and foetal development. Journal of Nutrition. 134 2169-2172.

Wu, G, FW Bazer, JM Wallace, TE Spencer. 2006. BOARD-INIVTED REVIEW: Intrauterine growth retardation: Implications for the animal sciences. Journal of Animal Science. 84 2316-2337. 


\section{Literature Cited}

Aguilar, J, M Reyley. 2005. The uterine tubal fluid: secretion, composition and biological effects. Animal Reproduction. 2:91-105.

Anderson, LL, S Jeftinija, CG Scanes. 2004. Growth hormone secretion: Molecular and cellular mechanisms and in vivo approaches. Experimental Biology and Medicine. 229:291-302.

Armitage, JA, YK Imran, PD Taylor, PW Nathanielsz, L Poston. 2004. Developmental programming of the metabolic syndrome by maternal nutritional imbalance: how strong is the evidence from experimental models in mammals. Journal of Physiology. 561:355-377.

Ashworth, CJ, FW Bazer. 1989. Changes in ovine conceptus and endometrial function following asynchronous embryo transfer or administration of progesterone. Biology of Reproduction. 40:425-433.

Bassett, NA, PD Gluckman. 1986. Pulsatile growth hormone secretion in the ovine fetus and neonatal lamb. Journal of Endocrinology. 109:307-312.

Bauer, MK, BB Breier, FH Bloomfield, EC Jensen, PD Gluckman, JE Harding. 2003. Chronic pulsatile infusion of growth hormone to growth-restricted foetal sheep increases circulating foetal insulin-like growth factor-I levels but not foetal growth. Journal of Endocrinology. 177:83-92.

Bauer, MK, JE Harding, BH Breier, PD Gluckman. 2000. Exogenous GH infusion to late-gestational foetal sheep does not alter foetal growth and metabolism. Journal of Endocrinology. 166:591-597.

Bauer, MK, JE Harding, NS Bassett, BH Breier, MH Oliver, BH Gallaher, PC Evans, SM Woodall, PD Gluckman. 1998. Fetal growth and placental function. Molecular and Cellular Endocrinology. 140:115-120.

Bazer, FW, RM Roberts, SM Mahalboob Basha, MT Zavy, D Caton, DH Barron. 1979. Method for obtaining ovine uterine secretions from unilaterally pregnant ewes. Journal of Animal Science. 49:1522-1527.

Bell, AW, BW McBride, R Slepetis, RJ Early, WB Currie. 1989. Chronic heat stress and prenatal development in sheep: I. Conceptus growth and maternal plasma hormones and metabolites. Journal of Animal Science. 67:3289-3299.

Bell, AW, WW Hay Jr., RA Ehrhardt. 1999. Placental transport of nutrients and its implications for fetal growth. Journal of Reproduction and Fertility Supplement. 54:401-410. 
Bjorkman, N. 1965. Fine structure of the ovine placentome. Journal of Anatomy. 99:283-297.

Bloomfield, FH, MK Bauer, PL Van Zijl, PD Gluckman, JE Harding. 2002. Amniotic IGF-I supplements improve gut growth but reduce circulating IGF-I in growth-restricted fetal sheep. American Journal of Physiology. 282:E259-E269.

Bloomfield, FH, PL van Zijl, MK Bauer, HH Phua, JE Harding. 2006. Effect of pulsatile growth hormone administration to the growth-restricted foetal sheep on somatotrophic axis gene expression in foetal and placental tissues. American Journal of Physiology. 291:E333-E339.

Borowicz, PP, DR Arnold, ML Johnson, AT Grazul-Bilska, DA Redmer, LP Reynolds. 2007. Placental growth throughout the last two thirds of pregnancy in sheep: vascular development and angiogenic factor expression. Biology of Reproduction. 76:259-267.

Brameld, JM, A Mostyn, J Dandrea, TJ Stephenson, JM Dawson, PJ Buttery, ME Symonds. 2000. Maternal nutrition alters the expression of insulin-like growth factors in fetal sheep liver and skeletal muscle. Journal of Endocrinology. 167:429-437.

Breier, BH, GR Ambler, H Sauerwein, A Surus, PD Gluckman. 1994. The induction of hepatic somatotrophic receptors after birth in sheep is dependent on parturition-associated mechanisms. Journal of Endocrinology. 141:101-108.

Bubb, KJ, ML Cock, MJ Black, M Dodic, WM Boon, HC Parkington, R Harding, M Tare. 2007. Intrauterine growth restriction delays cardiomyocyte maturation and alters coronary artery function in the foetal sheep. Journal of Physiology. 578:871-881.

Buhi, WC, IM Alvarex, AJ Kouba. 2000. Secreted proteins of the ovidcut. Cells Tissues Organs. 166:165-179.

Burrell, JH, AM Boyn, V Kumarsamy, A Hsieh, SI Head, ER Lumbers. 2003. Growth and maturation of cardiac myocytes in foetal sheep in the second half of gestation. Anatomical Research. 274A:952-961.

Cetin, I. 2001. Amino acid interconversions in the fetal-placental unit: The animal model and human studies in vivo. Pediatric Research 49:148-154.

Corstius, HB, MA Zimanyi, N Maka, T Herath, W Thomas, A Van Der, Laarse, NG Wreford, MJ Black. 2005. Effect of intrauterine growth restriction on the number of cardiomyocytes in rat hearts. Pediatric Research. 57:796800. 
Costine, BA, EK Inskeep, ME Wilson. 2005. Growth hormone at breeding modifies concetpus development and postnatal growth in sheep. Journal of Animal Science. 83:810-815.

Crisman, RO, LE McDonald, FN Thompson. 1980. Effects of progesterone or estradiol on uterine tubal transport of ova in the cow. Theriogenology. 13:141-147.

Currie, MJ, NS Bassett, PD Gluckman. 1997. Ovine glucose transporter-1 and-3: cDNA partical sequences and developmental gene expression in the placenta. Placenta. 18:393-401.

Dandrea, JV Wilson, G Gapalakrishnan, L Heasman, H Budge, T Stephenson, ME Symonds. 2001. Maternal nutritional manipulation of placental growth and glucose transpoter 1 (GLUT-1) abundance in sheep. Reproduction. 122:793-800.

Das, UG, J He, RA Ehrhardt, WW Hay Jr., SU Devaskar. 2000. Time-dependent physiological regulation of ovine placental GLUT-3 glucose transporter protein. American Journal of Physiology. 279:R2252-R2261.

De Zegher, F, J Daaboul, MM Grumbach, SL Kaplan. 1989. Hormone ontogeny in the ovine fetus and neonate. XXII. The effect of somatostatin on the growth hormone $(\mathrm{GH})$ response to $\mathrm{GH}$-Releasing Factor. Endocrinology. 124:1114-1117.

Douglas, RG, PD Gluckman, K Ball, B Breier, JHF Shaw. 1991. The effects of infusion of insulin like growth factor (IGF) I, IGF-II, and insulin on glucose and protein metabolism in fasted lambs. Journal of Clinical investigation. 88:614-622.

Ehrhardt, RA, AW Bell. 1995. Growth and metabolism of the ovine placenta during mid-gestation. Placenta. 16:727-741.

Ehrhardt, RA, AW Bell. 1997. Developmental increases in glucose transporter concentration in sheep placenta. American Journal of Physiology. 273:R1132-R1141.

Ford, SP, BW Hess, MM Schwope, MJ Nijland, JS Gilbert, KA Vonnahme, WJ Means, H Han, PW Nathanielsz. 2007. Maternal undernutrition during early to mid-gestation in the ewe results in altered growth, adiposity, and glucose tolerance in male offspring. Journal of Animal Science. 85:12851294.

Fowden, A.1995. Endocrine regulation of foetal growth. Reproduction Fertility and Development. 7:351-363. 
Fowden, AL, JW Ward, FPB Wooding, AJ Forhead, M Constancia. 2006. Programming placental nutrient transport capacity. Journal of Physiology. 572:5-15.

Galan, HL, MJ Hussey, A Barbera, E Ferrazzi, M Chung, JC Hobbins, FC Battaglia. 1999. Relationship of fetal growth to duration of heat stress in an ovine model of placental insufficiency. American Journal of Obstetrics and Gynecology. 180:1278-1282.

Gandolfi, F, RM Moor. 1987. Stimulation of early embryonic development in the by co-culture with oviduct epithelial cells. Journal of Reproduction and Fertility. 81:23-28.

Gandolfi, F, AL Tiziana, AL Brevini, L Richardson, CR Brown, MR Moor. 1989Characterization of proteins secreted by sheep oviduct epithelial cells and their function in embryonic development. Development. 106:303-312.

Gatfor, KL, TP Fletcher, A Rao, AR Egan, BJ Hosking, IJ Clark. 1997. GH, GHreleasing factor and somatostain in growing lambs: sex differences and mechanisms for sex differences. Journal of Endocrinology. 152:19-27.

Gluckman, PD, BH Breier, SR Davis. 1986.Phyiology of the somatotrophic axis with particular reference to the ruminant. Journal of Dairy Science. 70:442466.

Gluckman PD, GS Pinal. 2003 Regulation of foetal growth by the somatotrophic axis. Journal of Nutrition. 133 1741S-1746S.

Gluckman, PD, JH Buttler. 1983. Parturition-related changes in insulin-like growth factors-I and $-I I$ in the perinatal lamb. Journal of Endocrinology. 99:223-232.

Gluckman, PD, PL Mueller, SL Kaplan, AM Rudolph, MM Grumbach. 1979a. Hormone ontogeny in the ovine fetus. I. Circulating growth hormone in mid and late gestation. Endocrinology. 104:162-168.

Gluckman, PD, PL Mueller, SL Kaplan, AM Rudolph, MM Grumbach. 1979b. Hormone ontogeny in the ovine fetus. III. The effect of exogenous somatostatin. Endocrinology. 104:974-978.

Godfery, KM, DJP Barker. 2000. Foetal nutrition and adult disease. American Journal of Clinical Nutrition. 71:1344S-1352S.

Gootwine, E, TE Spencer, FW Bazer. 2007Litter-size-dependent intrauterine growth restriction in sheep. Animal. 1:547-564. 
Gray, CA, FF Bartol, KM Taylor, AA Wiley, WS Ramsey, TL Ott, FW Bazer, TE Spencer. 2000. Ovine uterine gland knock-out model: effects of gland ablation on the estrous cycle. Biology for Reproduction. 62:448-456.

Gray, CA, KM Taylor, WS Ramsey, JR Hill, FW Bazer, FF Bartol, TE Spencer. 2001. Endometrial glands are required for preimplantation conceptus elongation, and survival. Biology of Reproduction. 64.1608-1613.

Gray, CA, RC Burghardt, GA Johnson, FW Bazer, TE Spencer. 2002. Evidence that absence of endometrial gland secretions in uterine gland knockout ewes compromises conceptus survival and elongation. Reproduction. 124:289-300.

Harding, JE, PC Evans, PD Gluckman. 1997. Maternal growth hormone treatment increases placental diffusion capacity but not foetal or placental growth in sheep. Endocrinology. 138 5352-5358.

Harding, JE, L Liu, PC Evans, PD Gluckman. 1994. Insulin-like growth factor 1 alters feto-placental protein and carbohydrate metabolism in fetal sheep. Endocrinology. 134:1509-1514/

Hay, WW. 1995. Regulation of placental metabolism by glucose supply. Reproduction Fertility and Development. 7:365-375.

Heasman, L, L Clarke, K Firth, T Stephenson, ME Symonds. 1998. Influence of restricted maternal nutrition in early to mid gestation on placental and fetal development at term in sheep. Pediatric Rsearch. 44:546-551.

Holaskova, I. 2007. I. Distribution of Transforming Growth Factor Beta 1, TGF receptor II and Decorin in the Sheep Uterus Shortly After Breeding II. Effect of TGF Beta 1 on Gene Expression in the Sheep Uterus at the Time of Embryo Attachment III. Concentration of TGF Beta 1, 2, and 3 in Beef Bull and Ram Seminal Plasma, Dissertation, West Virginia University.

Igwebuike, UM. 2006. Trophoblast cells of ruminant placentas-A minireview. Animal Reproduction Science. 93:185-198.

Jansson, N, J Pettersson, A Haafiz, A Ericsson, I Palmberg, M Tranberg, V Ganapahty, TL Powell, T Jansson. 2006. Down-regulation of placental transport of amino acids precedes the development of intrauterine growth restriction in rates fed low protein diet. Journal of Physiology. 576:935946.

Jansson, T. 2001. Amino acid transporters in the human placenta. Pediatric Research. 49:141-147

Jansson, T, M Wennergren, NP Illsley. 1993. Glucose transportere protein expression in human placenta throughout gestation and in intrauterine 
growth retardation. Journal of Clinical Endocrinology and Metabolism. 77:1554-1562.

Jensen, EC, JE Harding, MK Bauer, PD Gluckman. 1999. Metabolic effects of IGF-I in the growth retarded fetal sheep. Journal of Endocrinology. 161:485-494.

Jozwik, M, C Teng, RB Wilkening, G Meschia, FC Battaglia. 2004. Reciprocal inhibition of umbilical uptake within groups of amino acids. American Journal of Physiology. 286:E376-E383.

Killian, GJ. 2004. Evidence for the role of oviduct secretions in sperm function, fertilization and embryo development. Aminal Reproduction Science. 8283:141-153.

Kleemann, DO, SK Walker, RF Seamark. Enhanced fetal growth in sheep administered progesterone during the first three days of pregnancy. Journal of Reproduction and Fertility. 102:411-417.

Koch, JM, JS Moritz, DC Lay Jr, ME Wilson. 2007. Effect of melengestrol acetate as an alternative to induce molting in hens on the expression of yolk proteins and turnover of oviductal epithelium. Animal Reproduction Science. 102:14-23.

Kwon, H, SP Ford, FW Bazer, TE Spencer, PW Nathanielsz, MJ Nijland, BW Hess, G Wu. Maternal nutrient restriction reduces concentrations of amino acids and polyamines in ovine maternal and fetal plasma and fetal fluids. Biology of Reproduction. 71:901-908.

Kudo, Y, CA Boyd. 2002. Human placental amino acid transporter genes: Expression and function. Reproduction. 124:593-600.

Lang, U, RS Baker, J Khoury, KE Clark. 2000. Effects of chronic reduction in uterine blood flow on fetal and placental growth in the sheep. American Journal of Physiology. 279:R53-R59.

Lemley, CO, Koch JM, Blemings KP, Krause KM, and Wilson ME. 2008a. Concomitant changes in progesterone catabolic enzymes, cytochrome P450 2C and 3A, with plasma insulin concentrations in ewes supplemented with sodium acetate or sodium propionate. Animal. (In Press).

Lemley CO, Butler ST, Butler WR, and Wilson ME. 2008b. Short communication: insulin alters hepatic progesterone catabolic enzymes, cytochrome P450 $2 \mathrm{C}$ and $3 \mathrm{~A}$, in dairy cows. Journal of Dairy Science. 91:641-645. 
Lemons, JA, EW Adcock III, D Jones Jr. MA Naughton, G Meschia, FC Battaglia. 1976. Umbilical uptake of amino acids in the unstressed fetal lamb. The Journal of Clinical Investigation. 58:1428-1434.

Li, J, JA Owens, PC Owens, JC Saunders, AL Fowden, RS Gilmour. 1996. The ontogeny of hepatic growth hormone receptor and insulin-like growth factor I gene expression in the sheep foetus during late gestation: Developmental regulation by cortisol. Endocrinology: 137:1650-1657.

Limesand, SW, TRH Regnault, WW Hay Jr. 2004. Characterization of glucose transporter $8\left(\mathrm{GLUT}^{*}\right)$ in the ovine placenta of normal and growth restricted fetuses. Placenta. 25:70-77.

Lok, F, JA Owends, L Mundy, JS Robinson, PC Owens. 1996. Insulin-like growth factor I promotes growth selectively in fetal sheep in late gestation. American Journal of Physiology. 270:R1148-1155.

Louey, S, ML Cock, R Harding. 2005. Long term concsequences of low birthweight on postnatal growth, adiposity and brain weight at maturity in sheep. Journal of Reproduction and Development. 51:59-68

Luther, J, J Miline, R Aitken, M Matsuzaki, L Reynolds, D Redmer, J Wallace. 2007. Placental growth, angiogenci gene expression, and vascular development in undernourished adolescent sheep. Biology of Reproduction. 77:351-357.

Maxfield, EK, KD Sinclair, LD Dunne, PJ Broadbent, $\mu$ Robison, E Steward, DG Kyle, CA Maltin. 1998. Temporary exposure of ovine embryos to an advanced uterine environment does not affect fetal weight but alters fetal muscle development. Biology of Reproduction. 59:321-325.

McGivan, JD, M Pastor-Anglada. 1994. Regulatory and molecular aspects of mammalian amino acid transport. Biochemistry Journal. 299:321-334.

Molina, RD, G Meschia, FC Battaglia, WW Hay. 1991. Gestational maturation of placental glucose transfer capacity in sheep. American Journal of Physiology. 261:R697-R704.

Moore, NW, JN Shelton. 1964. Egg transfer in sheep: Effect of degree of synchronization between donor and recipient, age of egg, and site of transfer on the survival of transferred eggs. Journal of Reproduction and Fertility. 7:145-152.

Murotsuki, J JRG Challis, VKM Han, LJ Fraher, R Gagnon. 1997. Chronic foetal placental embolization and hypoxemia cause hypertension and myocardial hypertrophy in fetal sheep. American Journal of Physiology. 272:R201R207. 
Murray, M. 1991. Microsomal cytochrome P450-dependent steroid metabolism in male sheep liver. Quantitative importance of 6ß-hydroxylation and evidence for the involvement of a P450 from the IIIA subfamily in the pathway. Journal of Steroid Biochemistry and Molecular Biology. 38:611619.

Murray, M. 1992. Participation of a cytochrome P450 enzyme from the 2C subfamily in progesterone 21-hydroxylation in sheep liver. Journal of Steroid Biochemistry and Molecular Biology. 43:591-593.

Murray, MK. 1993. An estrogen-dependent glycoprotein is synthesized and released from the oviduct in a temporal- and region-specific manner during early pregnancy in the ewe. Biology of Reproduction. 48:446-453.

Murotsuki, J, JRG Challis, VKM. Han, LJ Fraher, R Gagnon. 1997. Chronic fetal placental embolization and hypoxemia cause hypertension and myocardial hypertrophy in fetal sheep. American Journal of Physiology. 272:R201R207.

Nancarrow, CD, JL Hill. 1995. Oviduct proteins in fertilization and early embryo development. Journals of Reproduction and Fertility. Suppl. 49:3-13.

Nathanielsz, PW. 2000. Fetal programming: How the quality of fetal life alters biology for a lifetime. NeoReviews. 1:126-131

Noyan-Ashraf, MH, L Wu, R Wang, BHJ Jurlink. 2006. Dietary approaches to positively influence fetal determinants of adult health. FASEB Journal. 20:371-373.

Oliver, MH, JE Harding, BH Breier, PD Gluckman. 1996. Fetal insulin-like growth factor (IGF)-I and IGF-II are regulated differently by glucose or insulin in the sheep foetus. Reproduction Fertility and Development. 8:167-172.

Osgerby, JC, DC Wathers, DH Howard, TS Gass. 2002. The effect of maternal undernutrition on ovine fetal growth. Journal of Endocrinology. 173:131141.

Osgerby, JC, DC Wathers, DH Howard, TS Gass. 2004. The effect of maternal undernutrition on the placental growth trajectory and the uterine insulinlike growth factor axis in the pregnant ewe. Journal of Endocrinology. 182:89-103.

Ott, TL, AA Wiley, FF Bartol. 1997. Effects of stage of gestation and uterine ligation on ovine placentome development and glycosaminoglycans. Journal of Animal Science. 75:1053-1062.

Polkowska, J. 1995. Development of the gonadotrophic and somatotrophic axes of sheep. Journal of Reproduction and Fertility Supplement. 49:187-195. 
Ravelli, AC, JH. Meulen, C Osmond, DP. Barker, OP. Bleker. 1999. Obesity at the age of $50 \mathrm{y}$ in men and women exposed to famine prenatally. American Journal of Clinical Nutrition. 70:811-816

Ravelli, GP, ZA Stein, MW Susser. 1976. Obesity in young men after famine exposure in utero and early infancy. The New England Journal of Medicine. 295:349-353

Redmer, DA, RP Aitken, JS Milne, LP Reynolds, JM Wallace. 2005. INfulence of maternal nutrition on messenger RNA expression of placental angiogenic factors and their receptors at midgestation in adolescent sheep. Biology of Reproduction. 72:1004-1009.

Regnault, TRH, B De Vrijer, HL Galan, ML Davidsen, KA Trembler, FC Battaglia, RB Wilkensing, RV Anthony. 2003. The relationship between transplacental $\mathrm{O}_{2}$ diffusion and placental expression of PIGF, VEGF and their receptors in a placental insufficiency model of fetal growth restriction. Journal of Physiology. 550:641-656.

Regnault, TRH, JE Friedman, RB Wilkening, RV Anthony, WW Hay Jr. 2005. Fetoplacental transport and utilization of amino acids in IUGR-a review. Placenta. 26:S52-S62.

Reynolds, LP, DA Redmer. 1995. Utero-lacental vascular development and placental function. Journal of Animal Science. 73:1839-1851.

Reyonlds, LP, PP Borowicz, KA Vonnahme, ML Johnson, AT Gazul-Bilska, DA Redmer, JS Caton. 2005a. Placental angiogenesis in sheep models of compromised pregnancy. Journal of Physiology. 565:43-58.

Reyonlds, LP, PP Borowicz, KA Vonnahme, ML Johnson, AT Gazul-Bilska, JM Wallace, JS Caton, DA Redmer. 2005b. Animal models of placental angiogenesis. Placenta. 26:689-708.

Rivera, RM, CR Youngs, SP Ford. 1996. A comparison of the number of inner cell mass and trophectoderm cells of preimplantation meishan and Yorkshire pig embryos at similar developmental states. Journal of Reproduction and Fertility. 106:111-116.

Roberston, AF, WB. Karp. 1976. Placental transport of nutrients. Southern Medical Journal. 69:1358-1362.

Robinson, J, S Chidzanja, K Kind, F Lok, P Owens, J Owens. 1995. Placental control of fetal growth. Journal of Reproduction Fertility and Development. 7:333-344. 
Rosenfeld, CR, FH Morriss Jr., El Makowski, G Meschia, FC Battaglia. 1974. Circulatory changes in the reproductive tissues of ewes during pregnancy. Gynecological Investigation. 5: 252-568.

Rowson, LEA, RM Moor. 1966. Embryo transfer in the sheep: The significance of synchronizing oestrus in the donor and recipient animal. Journal of Reproduction and Fertility. 11:207-212.

Samson, F, F Bonnet, M Heimburger, C Rucker-Martin, DO Levitsky, GM Mazmanian, JJ Mercadier, A Serraf, 2000. Left ventricular alterations in a model of fetal left ventricular overload. Pediatric Research. 48:43-49.

Senger, PL. 1999. Pathways to Pregnancy and Parturition. $2^{\text {nd }}$ Edition. Current Conceptions, Inc.

Sheffel, CE, BR Pratt, WL Ferrell, EK Inskeep. 1982. Induced corpora lutea in the postpartum beef cow. II. Effects of treatment with progestogen and gonadotropins. Journal of Animal Science. 54:830-836.

Sinclair, KD, TG McEvoy, EK Maxfield, CA Maltin, LE Young, I Wilmut, PJ Broadbent, JJ Robinson. 1999. Aberrant fetal growth and development after in vitro culture of sheep zygotes. Journal of Reproduction and Fetility. 116:177-186.

Smith, DL, BM Stinefelt, KP Blemings, ME Wilson. 2006. Diet-induced alterations in progesterone clearance appear to be mediated by insulin signaling in hepatocytes. Journal of Animal Science. 84:1102-1109.

Spencer, TE, FW Bazer. 2004. Uterine and placental factors regulating conceptus growth in domestic animals. Journal of Animal Science Suppl. 82:E4-E13.

Spencer, TE, GA Johnson, FW Bazer, RC Burghardt. 2004. Implantation mechanisms: insights from the sheep. Reproduction. 128:657-668.

Stelwagen, K, DG Grieve, JS Walton, JL Ball, BW McBride. 1994. Effects of bovine somatotropin administration during the last trimester of gestation on maternal growth, and foetal and placental development in primigravid ewes. Animal Production. 58:87-94.

Stokes, H, JM Boda. 1968. Immunofluorescent localization of growth hormone and prolactin in the adenohypophysis of fetal sheep. Endocrinology. 83:1362-1366.

Suttie, JM, EA Lord, PD Gluckman, PF Fennessy, RP Littlejohn. Genetically lean and fat sheep differ in their growth hormone response to growth hormonereleasing factor. Domestic animal Endocrinology. 8:323-329. 
Sutton, R, CD Nancarrow, ALC Wallace. 1986. Oestrogen and seasonal effects on the production of an oestrus-associated glycoprotein in oviducal fluid of sheep. Journal of Reproduction and Fertility. 77:645-653.

Thomas, VM, RW Kott. A review of Montana winter range ewe nutrition research. 1995. 11:17-24.

Thureen, PJ, KA Trembler, G Meschia, EL Makowski, RB Wilkening. 1992. Placental glucose transport I heat-induced fetal growth retardation. American Journal of Physiology. 263:R578-R585.

Vonnahme KA, BW Hess, MJ Nijland, PW Nathanielsz, SP Ford. 2006. Placentomeal differentiation may compensate for maternal nutrient restriction in ewes adapted to harsh range conditions. Journal of Animal Science. 84:3451-3459.

Vonnahme KA, BW Hess, TR Hansen, RJ McCormick, DC Rule, GE Moss, WJ Murdoch, MJ Nijland, DC Skinner, PW Nathanielsz, SP Ford. 2003 Maternal undernutrition from early-to mid-gestation leads to growth retardation, cardiac ventricular hypertrophy, and increased liver weight in the foetal sheep. Biology of Reproduction. 69:133-140.

de Vrijer, B, TRH Regnault, RB Randall, B Wilkening, G Meschia, FG Battaglia. 2004. Pladntal uptake and transport of ACP, a neutral nonmetabolizable amino acid, in an ovine model of fetal growth restriction. American Journal of Physiology. 287:E1114-E1124.

Wallace, J, D Bourke, P Da Silva, R Aitken. 2001. Nutrient partitioning during adolescent pregnancy. Reproduction. 122:347-357.

Wallace, JM, DA Bourke, RP Aitken, JS Milne, WW Hay Jr. 2002a. Placental glucose transport in growth-restricted pregnancies induced by overnourishing adolescent sheep. Journal of Physiology. 547:85-94.

Wallace, JM, DA Bourke, RP Aitken, N Leitch, WW Hay Jr. 2002b. Blood flows and nutrient uptakes in growth=restricted pregnancies induced by overnourishing adolescent sheep. American Journal of Physiology. 282: R1027-R1036.

Wallace, JM, M Matsuzaki, J Milne, R Aitken. 2006. Late but not early gestation maternal growth hormone treatment increases fetal adiposity in overnourished adolescent sheep. Biology of Reproduction. 75 231-239.

Wallace, JM, JS Milne, DA Redmer, RP Aitken. 2006b. Effect of diet composition on pregnancy outcome in overnourished rapidly growing adolescent sheep. British Journal of Nutrition. 96:1060-1068. 
Wallace, JM, JS Milne, RP Aitken. 2004. Maternal growth hormone treatment from day 35 to 80 of gestation alters nutrient partitioning of uteroplacental growth in the overnourished adolescent sheep. Biology of Reproduction. 70:1277-1285.

Wallace, JM, RP Aitken, JS Milne, WW Hay Jr. 2004. Nutritionally mediated placental growth restriction in the growing adolescent: Consequences for the fetus. Biology of Reproduction. 71:1055-1062.

Wallace, JM, TRH Regnault, SW Limesand, WW Hay Jr, RV Anthony. 2005. Investigating the cause of low birth weight contrasting ovine paradigms. Journal of Physiology. 565 19-26.

Watson, AJ, PH Watson, M Arcellanal-Panlilio, D Warnes, SK Walker, GA Schultz, DT Armstrong, RF Seamark. 1994. A Growth phenotype map for ovine preimplantation and development. Biology of Reproduction. 50:725733.

Wilmut, I, DI Sales. 1981. Effect of an asynchronous environment on embryonic development in sheep. Journal of Reproduction and Fertility. 61:179-184.

Wooding, FBP, AL Fowden, AW Bell, RA Ehrhardt, SW Limesand, WW Hay. 2005. Localisation of glucose transport in the ruminant placenta: Implications for sequential use of transporter isoforms. Placenta. 26:626640.

Wu, G, FW Baze,r TA Cudd, CJ Meininger, TE Spencer. 2004. Maternal nutrition and foetal development. Journal of Nutrition. 134 2169-2172.

Wu, G, FW Bazer, JM Wallace, TE Spencer. 2006. BOARD-INIVTED REVIEW: Intrauterine growth retardation: Implications for the animal sciences. Journal of Animal Science. 84 2316-2337.

Young, LE, SC Butterwith, I Wilmut. 1996. Increased ovine foetal weight following transient asynchronous embryo transfer is not associated with increased placental weight at day 21 of gestation. Theriogenology. 45:231. 